\title{
2021 Taxonomic update of phylum Negarnaviricota (Riboviria: Orthornavirae), including the large orders Bunyavirales
} \section{and Mononegavirales}

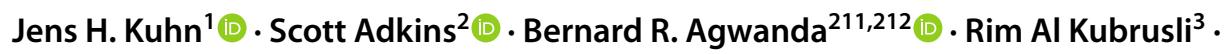
Sergey V. Alkhovsky (Альховский Сергей Владимирович) ${ }^{4}$ (D) Gaya K. Amarasinghe ${ }^{5}$ (D) Tatjana Avšič-Županc ${ }^{6}$ (D)

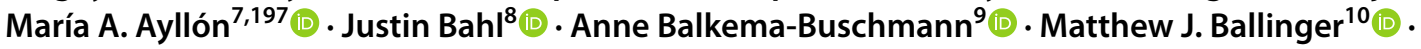

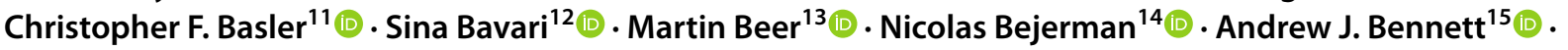

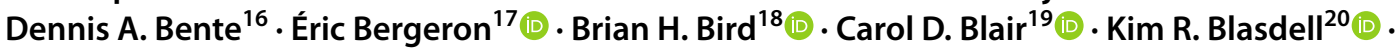

Dag-Ragnar Blystad ${ }^{21}$ (D) Jamie Bojko 22,198 (D) Wayne B. Borth ${ }^{23} \cdot$ Steven Bradfute ${ }^{24}$ (I) $\cdot$ Rachel Breyta $^{25,199}$ (1) .

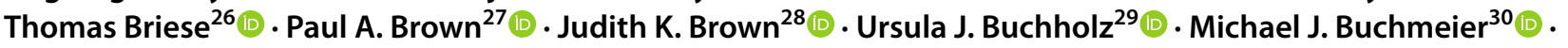
Alexander Bukreyev 31 - Felicity Burt ${ }^{32}$. Carmen Büttner ${ }^{3}$. C Charles H. Calisher ${ }^{33}$ - Mengji Cao (曹孟籍) ${ }^{34}$.

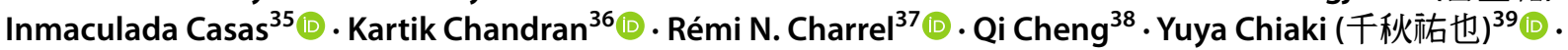
Marco Chiapello ${ }^{40}$ - Il-Ryong Choi ${ }^{41} \cdot$ Marina Ciuffo $^{40} \cdot$ J. Christopher S. Clegg $^{42} \cdot$ lan Crozier $^{43}$ (1) Elena Dal Bó ${ }^{44}$. Juan Carlos de la Torre ${ }^{45}$ (D) Xavier de Lamballerie ${ }^{37} \cdot$ Rik L. de Swart $^{46}$ (I) $\cdot$ Humberto Debat $^{47,200}$ (1) . Nolwenn M. Dheilly ${ }^{48}$ - Emiliano Di Cicco ${ }^{49} \cdot$ Nicholas Di Paola $^{50} \cdot$ Francesco Di Serio $^{51}$ • Ralf G. Dietzgen ${ }^{52}$. Michele Digiaro ${ }^{53} \cdot$ Olga Dolnik $^{54}$ (D) Michael A. Drebot ${ }^{55}$. J. Felix Drexler ${ }^{56}$ (D) William G. Dundon ${ }^{57}$ (D)

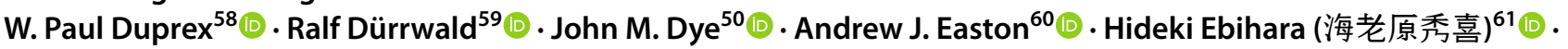
Toufic Elbeaino $^{62}$ (1) Koray Ergünay ${ }^{63}$ (1) - Hugh W. Ferguson ${ }^{213}$. Anthony R. Fooks ${ }^{64}(1) \cdot$ Marco Forgia ${ }^{65}$ (D)

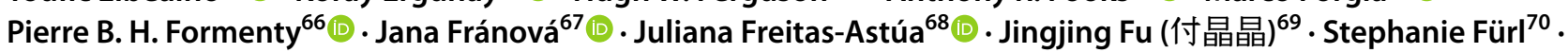
Selma Gago-Zachert ${ }^{71}$ (D) - George Fú Gāo (高福) ${ }^{214} \cdot$ María Laura García $^{72}$ (D) . Adolfo García-Sastre ${ }^{73}$ (D)

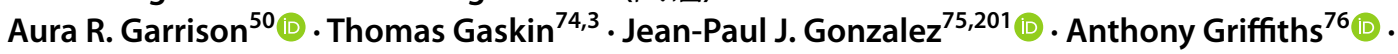

Tony L. Goldberg ${ }^{77}$ (1) Martin H. Groschup ${ }^{78}$ - Stephan Günther ${ }^{79}$ (D) Roy A. Hall ${ }^{80}$ - John Hammond ${ }^{81}$ (D)

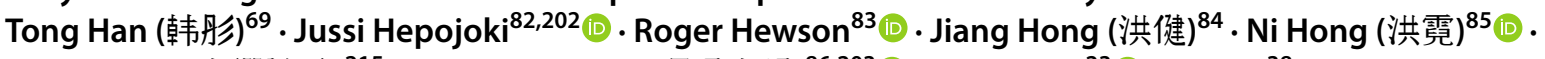

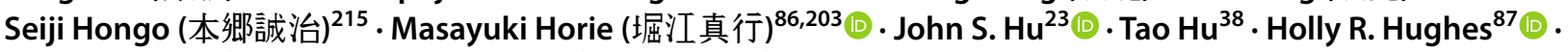
Florian Hüttner ${ }^{3} \cdot$ Timothy H. Hyndman $^{88}$ (D) M. Ilyas $^{89}$ (D) R Risto Jalkanen ${ }^{90}$ (D) Dàohóng Jiāng $(\text { 姜道宏 })^{91}$ (1) Gilda B. Jonson ${ }^{92}$ (1) S Sandra Junglen ${ }^{93,204}$. Fujio Kadono (上遠野冨士夫) $)^{94}$ - Karia H. Kaukinen ${ }^{95}$.

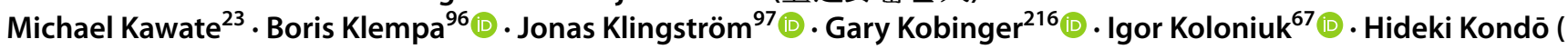
近藤秀樹 $)^{98}$ - Eugene V. Koonin ${ }^{99} \cdot$ Mart Krupovic $^{100}$ (1) Kenji Kubota (久保田健嗣) $)^{101}$ ( Gael Kurath ${ }^{102}$ (1) . Lies Laenen ${ }^{103,205}$ (1) Amy J. Lambert ${ }^{87}$ (D) Stanley L. Langevin ${ }^{104}$. Benhur Lee ${ }^{105}$ (I) Elliot J. Lefkowitz ${ }^{106}$ (D)

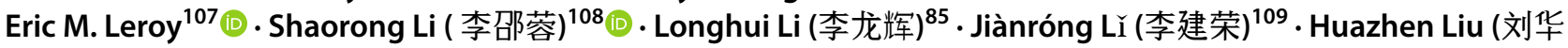
珍 $^{85} \cdot$ Igor S. Lukashevich ${ }^{110}$ (i) - Piet Maes ${ }^{103}$ (1) - William Marciel de Souza ${ }^{111}$ (D) Marco Marklewitz ${ }^{93,206}$ (i)

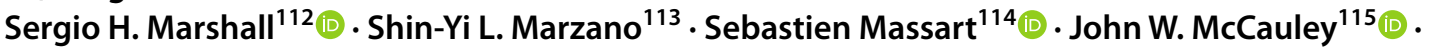
Michael Melzer ${ }^{116}$ @ Nicole Mielke-Ehret ${ }^{117} \cdot$ Kristina M. Miller $^{95} \cdot$ Tobi J. Ming $^{118}$ ๑l . Ali Mirazimi ${ }^{119}$. Gideon J. Mordecai ${ }^{120}\left(\right.$ Hans-Peter Mühlbach ${ }^{117}$. Elke Mühlberger ${ }^{76} \oplus$. Rayapati Naidu ${ }^{121} \oplus$ - Tomohide Natsuaki ( 夏秋知英) ${ }^{122}$. . José A. Navarro ${ }^{123}$. Sergey V. Netesov (Нетёсов Сергей Викторович) ${ }^{124}$ (1)

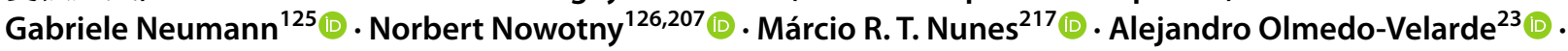
Gustavo Palacios ${ }^{50}$ (1) Vicente Pallás ${ }^{127}$ (1) Bernadett Pályi ${ }^{128}$ - Anna Papa ('Avva namá) ${ }^{129}$ (D)

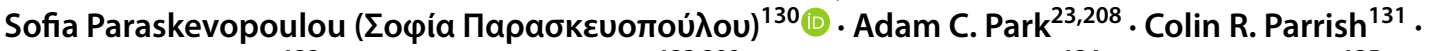
David A. Patterson ${ }^{132} \cdot$ Alex Pauvolid-Corrêa ${ }^{133,209}$ [D . Janusz T. Pawęska ${ }^{134}$ (D) . Susan Payne ${ }^{135}$ (1). Carlotta Peracchio ${ }^{40}$ (D) Daniel R. Pérez ${ }^{136}$ - Thomas S. Postler ${ }^{137}$ - Liying Qi (元立荣) $)^{138}$. Sheli R. Radoshitzky ${ }^{139}$ (D) Renato O. Resende ${ }^{140}$ (1) . Carina A. Reyes ${ }^{141} \cdot$ Bertus K. Rima $^{142}$ (1) . Gabriel Robles Luna ${ }^{141}$. Víctor Romanowski ${ }^{143}$ (D) Paul Rota ${ }^{218}$. Dennis Rubbenstroth ${ }^{144}$ (D) . Luisa Rubino ${ }^{145}$ (D) Jonathan A. Runstadler ${ }^{146}$ (i)

Communicated by Tim Skern.

Extended author information available on the last page of the article 


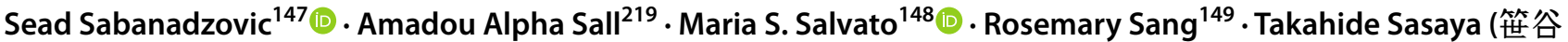
孝英 $)^{150}$ - Angela D. Schulze ${ }^{151} \cdot$ Martin Schwemmle ${ }^{152}$. Mang Shi (施莽) $)^{153}$ (1) Xiǎohóng Shí (石晓宏) ${ }^{154}$. Zhènglì Shí (石正丽) $)^{155}$. Yoshifumi Shimomoto (下元祥史) $)^{156}$. Yukio Shirako ${ }^{157}$. Stuart G. Siddell ${ }^{158}$ (1) Peter Simmonds $s^{159}$ (1) Manuela Sironi ${ }^{160}$. . Guy Smagghe ${ }^{161}$. Sophie Smither ${ }^{162}$ (1) Jin-Won Song (송 진 원) $)^{163}$. Kirsten Spann ${ }^{164}\left(\right.$ ) J Jessica R. Spengler ${ }^{165}$. Mark D. Stenglein ${ }^{166}$ (D) David M. Stone ${ }^{167}$ (D) Jari Sugano ${ }^{23}$. Curtis A. Suttle ${ }^{168}$. Amy Tabata ${ }^{95}$. Ayato Takada (高田礼人) ${ }^{169}$ (1) . Shigeharu Takeuchi (竹内繁治) . $^{170}$. David P. Tchouassi ${ }^{149}$. Amy Teffer ${ }^{171}$. Robert B. Tesh ${ }^{172} \cdot$ Natalie J. Thornburg ${ }^{173} \cdot$ Yasuhiro Tomitaka (富高保

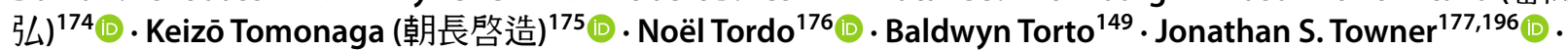

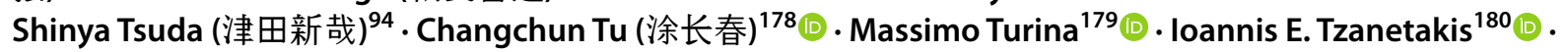
Janice Uchida ${ }^{23}$ (1) . Tomio Usugi (宇杉富雄) ${ }^{101}$. Anna Maria Vaira ${ }^{40}$ (1) Marta Vallino ${ }^{40}$ (1)

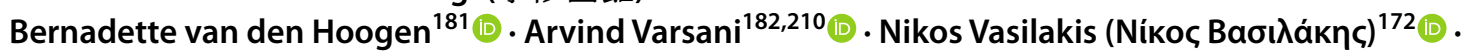

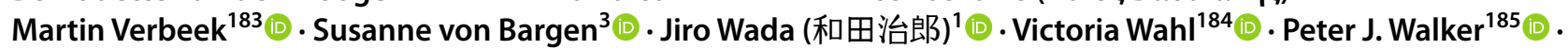
Lin-Fa Wang (王林发) ${ }^{186}$ (1) . Guoping Wang (王国平) $)^{85}$. Yanxiang Wang (王雁翔) ${ }^{85}$ ・ Yaqin Wang (王亚琴 $)^{38}$. Muhammad Waqas $^{187}$. Tàiyún Wèi (魏太云) $)^{188}$. Shaohua Wen (温少华 $)^{85} \cdot$ Anna E. Whitfield ${ }^{189}$ (1). John V. Williams ${ }^{190}$. Yuri I. Wolf ${ }^{99}$ - Jiangxiang Wu (吴建祥) ${ }^{38}$ - Lei Xu (徐雷) $)^{138}$. Hironobu Yanagisawa (栁澤広 宣) $)^{191}$. Caixia Yang (杨彩霞) ${ }^{69}$ (D) Z Zuokun Yang (杨作坤) ${ }^{85} \cdot$ F. Murilo Zerbini ${ }^{192}$ (D) L Lifeng Zhai (翟立峰) $)^{193}$. Yong-Zhen Zhang (张永振) $)^{220,221}$. Song Zhang (张松) ${ }^{34}$. Jinguo Zhang (张靖国) $)^{194}$. Zhe Zhang (张哲) ${ }^{85}$. Xueping Zhou (周雪平) ${ }^{195}$ (i)

Published online: 31 August 2021

This is a U.S. government work and not under copyright protection in the U.S.; foreign copyright protection may apply 2021, corrected publication 2021

\begin{abstract}
In March 2021, following the annual International Committee on Taxonomy of Viruses (ICTV) ratification vote on newly proposed taxa, the phylum Negarnaviricota was amended and emended. The phylum was expanded by four families (Aliusviridae, Crepuscuviridae, Myriaviridae, and Natareviridae), three subfamilies (Alpharhabdovirinae, Betarhabdovirinae, and Gammarhabdovirinae), 42 genera, and 200 species. Thirty-nine species were renamed and/ or moved and seven species were abolished. This article presents the updated taxonomy of Negarnaviricota as now accepted by the ICTV.
\end{abstract}

\section{Introduction}

Phylum Negarnaviricota was established in 2019 by the International Committee on Taxonomy of Viruses (ICTV) for negative-sense RNA viruses that can be connected evolutionarily through the possession of virally encoded RNA-directed RNA polymerases (RdRps). The phylum includes two subphyla, Haploviricotina and Polyploviricotina, for negative-sense RNA viruses that encode RdRps with or without mRNA capping activity, respectively. The two subphyla include four classes (Chunqiuviricetes, Milneviricetes, Monjiviricetes, and Yunchangviricetes) and two classes (Ellioviricetes and Insthoviricetes), respectively [56, 93, 109]. The phylum was last amended/emended in 2020 [57]. Here, we present the changes that were proposed to the phylum via official taxonomic proposals (TaxoProps) in 2020 and accepted by the ICTV in March 2021 (https://talk. ictvonline.org/files/ictv_official_taxonomy_updates_since_ the_8th_report/). These changes are now part of the official ICTV taxonomy.

\section{Taxonomic changes above the phylum rank}

The type species concept was abolished throughout virus taxonomy (TaxoProp 2020.001G.A.v1.Abolish_type_species).

\section{Taxonomic changes within order Jingchuvirales (Haploviricotina: Monjiviricetes)}

The order Jingchuvirales was thoroughly revised (TaxoProps 2020.026M.A.v1.Jingchuvirales and 2020.030M.R.Negarnaviricota_corrections). Four new families were created:

- Aliusviridae: genus Obscuruvirus, including a single species, Obscuruvirus quintum, was created for Atrato chu-like virus 5 (AClV-5), discovered in culicid mosquitoes (Psorophora albipes (Theobald, 1907)) sampled in Colombia [unpublished, GenBank \#MN661033]. Genus Ollusvirus was created for species Beetle mivirus, Shayang mivirus, and Taiyuan mivirus, which were moved from Chuviridae: Mivirus and renamed Ollusvirus coleopteri, Olluvirus shayangense, and Ollusvirus taiyuanense, respectively. Five new species were included in the genus: 
o Ollusvirus culvertonense for Culverton virus $(\mathrm{CvV})$, discovered by high-throughput sequencing (HTS) in a Hercules' flea (Macropsylla hercules Rothschild, 1905) sampled in Timbillica State Forest, New South Wales, Australia [41];

o Ollusvirus hanchengense for Hánchéng leafhopper mivirus (HLMV), discovered by HTS in a leafhopper (Psammotettix alienus (Dahlbom 1850)) sampled in Hánchéng (韩城市), Shaanxi/Shănxī Province (陕西省), China [39];

o Ollusvirus hymenopteri for hymenopteran churelated virus 123 (HCrV-123) discovered by HTS in a cleptoparasitic bee (Dioxys cincta (Jurine, 1807)) sampled in Lacs des Millefonts, Alpes-Maritimes, France [49];

o Ollusvirus insectii for hymenopteran chu-related virus 126 (HCrV-126), discovered by HTS in a crabronid wasp (Oxybelus bipunctatus Olivier, 1812) sampled in Battenberg, Rhineland-Palatinate (Rheinland-Pfalz), Germany [49]; and

o Ollusvirus scaldisense for Scaldis River bee virus (SRBV), discovered by HTS in a European orchard bee (Osmia cornuta (Latreille, 1805)) sampled in Ghent, Flemish Region (Vlaams Gewest), Belgium [88];

- Crepuscuviridae: a single genus, Aqualaruvirus, including a single species, Aqualaruvirus sialis, was created for megalopteran chu-related virus 119 (MCrV-119), discovered by HTS in a corydalid fly sampled in Bejuma, Carabobo State (Estado Carabobo), Venezuela [49];

- Myriaviridae: a single genus, Myriavirus, was created for species Myriapod mivirus, which was moved from Chuviridae: Mivirus and renamed Myriavirus myriapedis; and

- Natareviridae: a single genus, Charybdivirus, was created for species Charybdis mivirus, which was moved from Chuviridae: Mivirus and renamed Charybdivirus charybdis.

In family Chuviridae, 13 new genera were created:

- Genus Boscovirus was created for species Hippoboscid mivirus and Louse fly mivirus, which were moved from Chuviridae: Mivirus and renamed Boscovirus hippoboscidae and Boscovirus hypoboscidae, respectively;

- Genus Chuvivirus was created for species Brunnich mivirus and Crab mivirus, which were moved from Chuviridae: Mivirus and renamed Chuvivirus brunnichi and Chuvivirus canceris, respectively;

- Genus Culicidavirus was created for species Imjin mivirus and Mosquito mivirus, which were moved from Chuviridae: Mivirus and renamed Culicidavirus imjinense and Culicidavirus culicidae, respectively. Two new species were created:

o Culicidavirus culicis for Culex mosquito virus 5 (ClMV-5), discovered by HTS in a Culex mosquito sampled in the USA [86]; and

o Culicidavirus quitotaense for Culex mosquito virus 4 (ClMV-4), discovered by HTS in a culicid mosquito (Culex sp.) sampled in the USA [86];

- Genus Doliuvirus was created for a single new species, Doliuvirus culisetae, for Mos8Chu0 chuvirus (MoCV), discovered by HTS in culicid mosquitoes (Culiseta minnesotae Barr, 1957) sampled in the USA [unpublished; GenBank \#KX924630];

- Genus Demapteravirus was created for a single new species, Demapteravirus dermapteri, for dermapteran churelated virus 142 (DCrV-142), discovered by HTS in earwigs (Gonolabis marginalis (Dohrn, 1864)) sampled in Tsukuba (つくば市), Ibaraki Prefecture (茨城県), Japan [49];

- Genus Morsusvirus was created for species Argas mivirus, which was moved from Chuviridae: Mivirus and renamed Morsusvirus argatis;

- Genus Nigecruvirus was created for a single new species, Nigecruvirus ixodes, for blacklegged tick chuvirus-2 (BITC-2), discovered by HTS in a deer tick (Ixodes scapularis Say, 1821) sampled in the USA [100];

- Genus Odonatavirus was created for species Odonate mivirus, which was moved from Chuviridae: Mivirus and renamed Odonatavirus fabricii. Two new species were created:

o Odonatavirus draconis for odonatan chu-related virus 137 (OCrV-137), discovered by HTS in a common flatwing (Austroargiolestes icteromelas (Selys, 1862)) sampled in Uriarra State Forest, Australian Capital Territory, Australia [49]; and

o Odonatavirus odontis for odonatan chu-related virus 136 (OCrV-136), discovered by HTS in a whitewater rockmaster (Diphlebia lestoides (Selys, 1853)) sampled in Gibraltar Creek, Australian Capital Territory, Australia, [49];

- Genus Pediavirus was created for species Barnacle mivirus, which was moved from Chuviridae: Mivirus and renamed Pediavirus cirripedis;

- Genus Piscichuvirus was created for species Sanxia mivirus, which was moved from Chuviridae: Mivirus and renamed Piscichuvirus sanxiaense. Three new species were created: 
o Piscichuvirus franki for Herr Frank virus 1 (HFrV1), discovered by HTS in a Brazilian boa constrictor (Boa constrictor Linnaeus, 1758) [3];

o Piscichuvirus lycodontis for Guăngdōng red-banded snake chuvirus-like virus (GRSCV), discovered by HTS in a colubrid snake (Lycodon rufozonatus (Cantor, 1842) sampled in China [92]; and

o Piscichuvirus wenlingense for Wēnlǐng fish chu-like virus (WFClV), discovered by HTS in a longspine snipefish (Macroramphosus scolopax (Linnaeus, 1758)) sampled in China [92];

- Genus Pterovirus was created for a single new species, Pterovirus chulinense, for hymenopteran chu-related virus OKIAV147 (HCrV-147), discovered by HTS in an aphelinid wasp (Aphelinus abdominalis (Dalman, 1820)) in a laboratory culture of wasps of unknown geographical origin [49];

- Genus Scarabeuvirus was created for species Cockroach mivirus, Hubei odonate mivirus, Hubei mivirus, and Lishi mivirus, which were moved from Chuviridae: Mivirus and renamed Scarabeuvirus blattae, Scarabeuvirus dentati, Scarabeuvirus hubeiense, and Scarabeuvirus lishiense, respectively. A new species, Scarabeuvirus lampyris, was created for Lampyris noctiluca chuviruslike virus 1 (LNCIV-1), discovered by HTS in a common glow-worm (Lampyris noctiluca (Linnaeus, 1767)) sampled in Finland [102]; and

- Genus Taceavirus was created for species Wenling mivirus, which was moved from Chuviridae: Mivirus and renamed Taceavirus wenlingense.

In chuvirid genus Mivirus, three new species were created:

- Mivirus genovaense for Genoa virus $(\mathrm{GeV})$, discovered by HTS in an Australian paralysis tick (Ixodes holocyclus Neumann, 1899) sampled in New South Wales, Australia [42];

- Mivirus karukeraense for Karukera tick virus (KtV), discovered by HTS in ixodid ticks sampled in Guadeloupe/ Martinique, France [38]; and

- Mivirus rhipicephali for brown dog tick mivirus 1 (BDTMV-1), discovered by HTS in brown dog ticks (Rhipicephalus sanguineus (Latreille, 1806)) sampled in Trinidad and Tobago [87].

Six mivirus species were renamed:

- Lonestar mivirus $\rightarrow$ Mivirus amblyommae;

- Bole mivirus $\rightarrow$ Mivirus boleense;

- Changping mivirus $\rightarrow$ Mivirus changpingense;

- Dermacentor mivirus $\rightarrow$ Mivirus dermacentoris;
- Suffolk mivirus $\rightarrow$ Mivirus suffolkense; and

- Wuhan mivirus $\rightarrow$ Mivirus wuhanense.

Four mivirus species were deleted:

- Crustacean mivirus;

- Hermit mivirus;

- Lacewing mivirus; and

- Xinzhou mivirus.

\section{Taxonomic changes within order Mononegavirales (Haploviricotina: Monjiviricetes)}

\section{Family Mymonaviridae}

Family Mymonaviridae was thoroughly revised. Seven new genera were established:

- Genus Auricularimonavirus was established for one new species, Auricularimonavirus auriculariae, for Auricularia heimuer negative-stranded RNA virus 1 (AhNRSV-1), discovered in a jelly fungus (Auricularia heimuer F. Wu, B. K. Cui \& Y. C. Dai 2014) sampled in China [unpublished; GenBank \#MT259204];

- Genus Botrytimonavirus was established for one new species, Botrytimonavirus botrytidis, for Botrytis cinerea negative-stranded RNA virus 7 (BcNSRV-7), discovered in gray mold (Botrytis cinerea Pers. (1794)) sampled in Italy and Spain [84]. Species Dadou sclerotimonavirus and Drop sclerotimonavirus were moved from Mymonaviridae: Sclerotimonavirus and renamed Botrytimonavirus glycinis and Botrytimonavirus sclerotiniae, respectively. Sclerotinia sclerotiorum negative-stranded RNA virus 2-A (SsNSRV-2-A) and Sclerotinia sclerotiorum negative-stranded RNA virus 4-A (SsNSRV-4-A), both discovered by HTS in cottony rot fungi (Sclerotinia sclerotiorum (Lib.) de Bary (1884)) sampled in Australia [72], were moved into species Botrytimonavirus sclerotiniae;

- Genus Lentimonavirus was established for Lentinula hubramonavirus, which was moved from Mymonaviridae: Hubramonavirus and renamed Lentimonavirus lentinulae;

- Genus Penicillimonavirus was established for ten novel species:

o Penicillimonavirus alphapenicillii for Penicillium adametzioides negative-stranded RNA virus 1 (PaNsRV-1), discovered by HTS in a fungus (Penicillium 
adametzioides S. Abe ex G. Smith 1963) sampled in Spresiano, Veneto Region, Italy [73];

o Penicillimonavirus alphaplasmoparae for Plasmopara viticola lesion associated mononegaambi virus 1 (PvaMV-1), discovered by HTS in grapevines (Vitis sp.) infected by an oomycete (Plasmopara viticola (Berk. \& M.A. Curtis) Berl. \& De Toni, (1888)) sampled in Italy [17];

o Penicillimonavirus betapenicillii for Penicillium glabrum negative-stranded RNA virus 1 (PgRlV-1), discovered by HTS in a fungus (Penicillium glabrum (Wehmer) Westling, (1911)) sampled in Spresiano, Veneto Region, Italy [73];

o Penicillimonavirus betaplasmoparae for Plasmopara viticola lesion associated mononegaambi virus 2 (PvaMV-2) and Plasmopara viticola lesion associated mononegaambi virus 4 (PvaMV-4), both discovered by HTS in grapevines (Vitis sp.) infected by an oomycete (Plasmopara viticola (Berk. \& M.A. Curtis) Berl. \& De Toni, (1888)) sampled in Italy (PvaMV-2 and PvaMV-4) and Spain (PvaMV-2) [17];

o Penicillimonavirus deltaplasmoparae for Plasmopara viticola lesion associated mononegaambi virus 5 (PvaMV-5), discovered by HTS in grapevines (Vitis sp.) infected by an oomycete (Plasmopara viticola (Berk. \& M.A. Curtis) Berl. \& De Toni, (1888)) sampled in Italy [17];

o Penicillimonavirus epsilonplasmoparae for Plasmopara viticola lesion associated mononegaambi virus 6 (PvaMV-6), discovered by HTS in grapevines (Vitis sp.) infected by an oomycete (Plasmopara viticola (Berk. \& M.A. Curtis) Berl. \& De Toni, (1888)) sampled in Italy and Spain [17];

o Penicillimonavirus etaplasmoparae for Plasmopara viticola lesion associated mononegaambi virus 9 (PvaMV-9), discovered by HTS in grapevines (Vitis sp.) infected by an oomycete (Plasmopara viticola (Berk. \& M.A. Curtis) Berl. \& De Toni, (1888)) sampled in Italy [17];

o Penicillimonavirus gammaplasmopara for Plasmopara viticola lesion associated mononegaambi virus 3 (PvaMV-3), discovered by HTS in grapevines (Vitis sp.) infected by an oomycete (Plasmopara viticola (Berk. \& M.A. Curtis) Berl. \& De Toni, (1888)) sampled in Italy [17];

o Penicillimonavirus kilnbarnense for Kiln Barn virus (KBV), discovered by HTS in a spotted wing drosophila (Drosophila suzukii (Matsumura, 1931)) sampled in the UK [70]; and

o Penicillimonavirus zetaplasmoparae for Plasmopara viticola lesion associated mononegaambi virus 7 (PvaMV-7), discovered by HTS in grapevines (Vitis sp.) infected by an oomycete (Plasmopara viticola (Berk. \& M.A. Curtis) Berl. \& De Toni, (1888)) sampled in Italy [17];

- Genus Phyllomonavirus was established for one new species, Phyllomonavirus gysingense, for Gysinge virus (GYSV), discovered by HTS in culicid mosquitoes (Culex sp.) or associated fungi sampled in Sweden [80]. Species Phyllosphere sclerotimonavirus was moved from Mymonaviridae: Sclerotimonavirus and renamed Phyllomonavirus phyllospherae;

- Genus Plasmopamonavirus was established for one new species, Plasmopamonavirus plasmoparae, for Plasmopara viticola lesion associated mononegaambi virus 8 (PvaMV-8), discovered by HTS in grapevines (Vitis sp.) infected by an oomycete (Plasmopara viticola (Berk. \& M.A. Curtis) Berl. \& De Toni, (1888)) sampled in Spain [17]; and

- Genus Rhizomonavirus was established for one new species, Rhizomonavirus mali, for apple virus B (APPV-B), discovered by HTS in apple trees (Malus domestica Borkh., 1803) sampled in Washington, USA [110].

Genus Hubramonavirus was expanded by one new species, Hubramonavirus terrae, for H2BulkLitter1223 virus, discovered by HTS in grassland soil collected in Hopland, California, USA [98]. Species Hubei hubramonavirus was renamed as Hubramonavirus hubeiense (TaxoProp 2020.004F.A.v1.Mymona). Species Hubei sclerotimonavirus was deleted (TaxoProp 2020.006M.A.v1.Corrections).

Genus Sclerotimonavirus was expanded by eight novel species (TaxoProp 2020.004F.A.v1.Mymona):

- Sclerotimonavirus alphaclarireediae for Sclerotinia homoeocarpa TSA contig 1 (ShTSA-1) and Sclerotinia homoeocarpa TSA contig 2 (ShTSA-2), both discovered by data mining of transcriptome shotgun assemblies (TSAs) of a fungus (Sclerotinia homoeocarpa (Bennett, 1937)) [54];

- Sclerotimonavirus alphaplasmoparae for Plasmopara viticola lesion associated mymonavirus 1 (PvaMV-1), discovered by HTS in grapevines (Vitis sp.) infected by an oomycete (Plasmopara viticola (Berk. \& M.A. Curtis) Berl. \& De Toni, (1888)) sampled in Italy [17];

- Sclerotimonavirus alternariae for Alternaria tenuissima negative-stranded RNA virus 1 (AtNsRV-1), discovered by HTS in a fungus (Alternaria tenuissima Samuel Paul Wiltshire (1933)) sampled in Spresiano, Veneto Region, Italy [73];

- Sclerotimonavirus betaclarireediae for Sclerotinia homoeocarpa TSA contig 3 (ShTSA-3), discovered by data mining of transcriptome shotgun assemblies (TSAs) 
of a fungus (Sclerotinia homoeocarpa (Bennett, 1937)) [54];

- Sclerotimonavirus betaplasmoparae for Plasmopara viticola lesion associated mononega virus 2 (PvaMV-2), discovered by HTS in grapevines (Vitis sp.) infected by an oomycete (Plasmopara viticola (Berk. \& M.A. Curtis) Berl. \& De Toni, (1888)) sampled in Italy and Spain [17];

- Sclerotimonavirus botrytidis for Botrytis cinerea mymonavirus 1 (BcMyV-1), discovered by HTS in a gray mold (Botrytis cinerea Pers. (1794)) [40] and Sclerotinia sclerotiorum negative-stranded RNA virus 7 (SsNSRV-7), discovered by HTS in cottony rot fungi (Sclerotinia sclerotiorum (Lib.) de Bary (1884)) [72] sampled in Australia;

- Sclerotimonavirus penicillii for Penicillium cairnsense negative-stranded RNA virus 1 (PcNsRV-1), discovered by HTS in a fungus (Penicillium cairnsense Houbraken, J.; Frisvad, J.C.; Cole, T.; Samson, R.A. 2011) sampled in Spresiano, Veneto Region, Italy [73]; and

- Sclerotimonavirus terrae for H4BulkLitter234 virus, discovered by HTS in grassland soil collected in Hopland, California, USA [98].

Species Glycine sclerotimonavirus, Illinois sclerotimonavirus, and Sclerotinia sclerotimonavirus were renamed as Sclerotimonavirus fusarii, Sclerotimonavirus illinoisense, and Sclerotimonavirus sclerotiniae, respectively. Sclerotinia sclerotiorum negative-stranded RNA virus 1-A (SsNSRV1-A) and Sclerotinia sclerotiorum negative-stranded RNA virus 3-A (SsNSRV-3-A), both discovered by HTS in cottony rot (Sclerotinia sclerotiorum (Lib.) de Bary (1884)) sampled in Australia [72], were moved into the species Sclerotimonavirus sclerotiniae.

\section{Family Nyamiviridae}

One new genus, Formivirus, was established for four novel species (TaxoProp 2020.024M.A.v1. Nyamiviridae_1ngen_5nsp):

- Chalybion formivirus for hymenopteran orino-related virus OKIAV87 (HORV-87), discovered by HTS in a blue mud dauber (Chalybion californicum (Saussure, 1867)) sampled in Tennessee, USA [49];

- Exsecta formivirus for Formica exsecta virus 4 (FeV4), discovered by HTS in a narrow-headed ant (Formica exsecta Nylander, 1846) sampled on Hanko Peninsula (Hankoniemi), southwestern Finland [23];

- Fusca formivirus for Formica fusca virus 1 (FfusV-1), discovered by HTS in a formicid ant (Formica fusca Linnaeus, 1758) collected in Cambridge, East of England, UK [52]; and
- Gorytes formivirus for hymenopteran orino-related virus OKIAV85 (HORV-85), discovered by HTS in a sand wasp (Gorytes laticinctus (Lepeletier, 1832)) collected in Albersweiler, Rhineland-Palatinate (Rheinland-Pfalz), Germany in 2011 [49].

Genus Nyavirus was expanded by one species, Jacinto nyavirus, for San Jacinto virus (SJCV) isolated from a common starling (Sturnus vulgaris Linnaeus, 1758) sampled in Harris County, Texas [104] (TaxoProp 2020.024M.A.v1. Nyamiviridae_1ngen_5nsp).

\section{Family Paramyxoviridae}

Genus Metaavulavirus was expanded by one species, Avian metaavulavirus 22, for avian paramyxovirus 22 (APMV22 ) isolated from turtle doves (Streptopelia tranquebarica (Hermann, 1804)) sampled in Taiwan [64] (TaxoProp 2020.011M.A.v1.Metaavulavirus_1nsp).

Species Avian orthovulavirus 21 [sic] was deleted (TaxoProp 2020.006M.A.v1.Corrections).

\section{Family Rhabdoviridae}

Family Rhabdoviridae was split into three subfamilies:

- Alpharhabdovirinae for genera Almendravirus, Alphanemrhavirus, Arurhavirus, Barhavirus, Caligrhavirus, Curiovirus, Ephemerovirus, Hapavirus, Ledantevirus, Lostrhavirus, Lyssavirus, Mousrhavirus, Ohlsrhavirus, Perhabdovirus, Sawgrhavirus, Sigmavirus, Sprivivirus, Sripuvirus, Sunrhavirus, Tibrovirus, Tupavirus, Vesiculovirus, and Zarhavirus;

- Betarhabdovirinae for genera Alphanucleorhabdovirus, Betanucleorhabdovirus, Cytorhabdovirus, Dichorhavirus, Gammanucleorhabdovirus, and Varicosavirus; and

- Gammarhabdovirinae for genus Novirhabdovirus (TaxoProp 2020.016M.A.v1.Rhabdoviridae_3subfam).

Three new genera were included in subfamily Alpharhabdovirinae:

- Genus Alphapaprhavirus, including two novel species (TaxoProp 2020.014M.A.v1. Alphapaprhavirus_1gen2sp):

o Hubei alphapaprhavirus for Hubei lepidoptera virus 2 (HbLV-2), discovered by HTS in insects (Lepidoptera) sampled in Húběi Province (湖北省), China [91]; and

o Pararge alphapaprhavirus for Pararge aegeria rhabdovirus (PAeRV), discovered by HTS in speckled wood (Pararge aegeria (Linnaeus, 1758)) in 
Belgium [65]. Lepidopteran rhabdo-related virus OKIAV-12 [49] is a junior synonym of PAeRV;

- Genus Alpharicinrhavirus, including three novel species (TaxoProp 2020.001M.A.v1.Alpharicinrhavirus):

o Blanchseco alpharicinrhavirus for Blanchseco virus (BCOV), discovered by HTS in ixodid ticks (Amblyomma ovale Koch, 1844) sampled in Trinidad and Tobago [87];

o Bole alpharicinrhavirus for Bole tick virus 2 (BITV2), discovered by HTS in ixodid ticks (Hyalomma asiaticum Schulze et Schlottke, 1929) sampled in Bólè (博乐市), Xīnjiāng Uygur Autonomous Region (新疆维吾尔自治区), China [61];

o Wuhan alpharicinrhavirus for Wuhan tick virus 1 (WhTV-1), discovered by HTS in Asian blue ticks (Rhipicephalus microplus (Canestrini, 1888)) sampled in Wǔhàn (武汉市), Húběi Province (湖北省), China [61]. Rhipicephalus associated rhabdo-like virus (RaRLV/YN-rhabdoV1) [90] is a junior synonym of WhTV-1; and

- Genus Merhavirus, including two novel species (TaxoProp 2020.015M.A.v1.Merhavirus_1gen2nsp):

o Merida merhavirus for Merida virus (MERDV), discovered in southern house mosquitoes (Culex quinquefasciatus Say, 1823), black salt marsh mosquitoes (Aedes taeniorhynchus (Wiedemann, 1821)), and Aedes trivittatus (Coquillett, 1902) mosquitoes sampled on Yucatán Peninsula, Mexico [75]. Culex rhabdovirus (CXRV) [86] and Merida-like virus Turkey (MLVT) [28] are junior synonyms of MERDV; and

o Tritaeniorhynchus merhavirus for Culex tritaeniorhynchus rhabdovirus (CTRV) isolated from culicid mosquitoes (Aedes taeniorhynchus (Wiedemann, 1821)) sampled in Chiba (千葉市), Chiba Prefecture (千葉県), Japan [58].

Seven new genera, not assigned to a subfamily, were included in the family:

- Genus Alphacrustrhavirus, including two new species (TaxoProps 2020.023M.A.v1. $\mathrm{Rhabdoviridae}+7 \mathrm{ngen} \mathrm{n}_{-} 16 \mathrm{nsp} \quad$ and 2020.030M.R.Negarnaviricota_corrections):

o Wenling alphacrustrhavirus for Wenling crustacean virus 10 (WlCV-10), discovered by HTS in a pool of marine crustaceans of multiple families sampled in Zhèjiāng Province (浙江省), China [91]; and
Zhejiang alphacrustrhavirus for Wenling crustacean virus 11 (WlCV-11), discovered by HTS in a pool of marine crustaceans of multiple families sampled in Zhèjiāng Province (浙江省), China [91];

- Genus Alphadrosrhavirus, including two new species (TaxoProp 2020.023M.A.v1. Rhabdoviridae_7ngen_16nsp):

o Hubei alphadrosrhavirus for Wuhan house fly virus 2 (WhHFV-2), discovered by HTS in houseflies (Musca domestica Linnaeus, 1758) collected in Húběi Province (湖北省), China [61]; and

o Shayang alphadrosrhavirus for Shayang fly virus 3 (SyFV-3), discovered by HTS in oriental latrine flies (Chrysomya megacephala (Fabricius, 1794)) collected in Húběi Province (湖北省), China [61];

- Genus Alphahymrhavirus, including four new species (TaxoProp 2020.023M.A.v1. Rhabdoviridae_7ngen_16nsp):

o Cinereus alphahymrhavirus for hymenopteran rhabdo-related virus 38 (HyRRV-38), discovered in a TSA of a leaden spider wasp (Pompilus cinereus Fabricius, 1798) collected in Birkenheide, Rhineland-Palatinate (Rheinland-Pfalz), Germany [49];

o Hirtum alphahymrhavirus for hymenopteran rhabdo-related virus 109 (HyRRV-109), discovered in a TSA of a cricket hunter wasp (Chlorion hirtum (Kohl, 1885)) collected in Ein Bokek (צביץ בֹּּקָק), Israel [49];

o Neglectus alphahymrhavirus for Lasius neglectus virus 2 (LnegV-2), discovered in the transcriptome of an ant (Lasius neglectus Van Loon, Boomsma \& Andrásfalvy, 1990) sampled in the UK [52]; and

o Radians alphahymrhavirus for hymenopteran rhabdo-related virus 46 (HyRRV-46) discovered in a TSA of a cuckoo wasp (Chrysura radians (Harris, 1776)) collected in Turlin, Italy, in 2012 [49];

- Genus Betahymrhavirus, including two new species (TaxoProp 2020.023M.A.v1.Rhabdoviridae_7ngen_16nsp):

o Austriaca betahymrhavirus for hymenopteran rhabdo-related virus 23 (HyRRV-23), discovered in a TSA of a cuckoo wasp (Chrysura austriaca (Fabricius, 1804)) collected in Battenberg, RhinelandPalatinate (Rheinland-Pfalz), Germany [49]. Hymenopteran rhabdo-related virus 22 (HyRRV-22) [49] is a junior synonym of HyRVV-23; and

o Heterodontonyx betahymrhavirus for hymenopteran rhabdo-related virus 24 (HyRRV-24), discovered in 
a TSA of a spider wasp (Heterodontonyx sp.) collected in Western Australia [49];

- Genus Betanemrhavirus, including two new species (TaxoProp 2020.023M.A.v1. Rhabdoviridae_7ngen_16nsp):

o Hubei betanemrhavirus for Hubei rhabdo-like virus 9 (HbRLV-9) detected in large pig roundworms (Ascaris suum (Goeze, 1782)) sampled in Húběi Province (湖北省), China [91]; and

o Shayang betanemrhavirus for Shayang ascaridia galli virus 2 (SyAGV-2) detected in roundworms (Ascaridia galli Schrank, 1788 and Ascaris suum (Goeze, 1782)) sampled in Húběi Province (湖北 省), China, [91];

- Genus Betapaprhavirus, including two new species (TaxoProp 2020.023M.A.v1. Rhabdoviridae_7ngen_16nsp):

o Frugiperda betapaprhavirus for Spodoptera frugiperda rhabdovirus (SfruRV) isolated originally in the Sf9 cell line derived from a fall armyworm (Spodoptera frugiperda (J. E. Smith, 1797)) [67]; and

o Sylvina betapaprhavirus for lepidopteran rhabdorelated virus 34 (LeRRV-34), discovered in a TSA of an orange moth (Triodia sylvina (Linnaeus, 1761)) collected in Höhbeck, Lower Saxony (Niedersachsen), Germany [49]; and

- genus Betaricinrhavirus, including two new species (TaxoProp 2020.023M.A.v1.Rhabdoviridae_7ngen_16nsp):

o Chimay betaricinrhavirus for Chimay rhabdovirus (CRV), discovered by HTS in castor bean ticks (Ixodes ricinus (Linnaeus, 1758)) sampled in Belgium [unpublished; GenBank \#MF975531]; and

o Scapularis betaricinrhavirus for blacklegged tick rhabdovirus 1 (BLTRV-1), discovered by HTS in deer ticks (Ixodes scapularis Say, 1821) sampled in Connecticut and New York, USA [100].

Genus Alphanucleorhabdovirus was expanded by two species (TaxoProp 2020.013M.A.v1. Plant_rhabdoviruses_9nsp):

- Constricta yellow dwarf alphanucleorhabdovirus for constricta yellow dwarf virus (CYDV) first isolated from potato (Solanum tuberosum L.) in New Jersey, USA [11]. Potato yellow dwarf virus New Jersey (PYDV-New Jersey) is a junior synonym of CYDV [48]; and
- Peach alphanucleorhabdovirus for peach virus 1 (PeV1), discovered by HTS in peach (Prunus persica L.) trees sampled in China [115];

Genus Betanucleorhabdovirus was expanded by three species (TaxoProp 2020.013M.A.v1. Plant_rhabdoviruses_9nsp):

- Apple betanucleorhabdovirus for apple rootstock virus A (ApRVA), discovered by HTS in apple (Malus spp.) trees in North Gyeongsang Province (경 상 북 도), South Korea [4];

- Cardamom betanucleorhabdovirus for cardamom vein clearing virus (CdVCV), discovered by HTS in green cardamon (Elettaria cardamomum (L.) Maton) sampled in India [9]; and

- Pepper betanucleorhabdovirus for Zhuye pepper nucleorhabdovirus (ZPNRV), discovered by HTS in winged prickly ash (Zanthoxylum armatum DC. v. novemfolius) sampled in China [15].

Genus Cytorhabdovirus was expanded by five species (TaxoProps 2020.004M.A.v1.Cytorhabdovirus_3nsp and 2020.013M.A.v1.Plant_rhabdoviruses_9nsp):

- Strawberry cytorhabdovirus 1 for strawberry virus 1 (StrV-1) and strawberry-associated virus $1(\mathrm{SaV}-1)$, discovered by HTS in garden strawberries (Fragaria $\times$ ananassa Duchesne and Fragaria vesca var. semperflorens 'Rujana') and woodland strawberries (Fragaria vesca L.) sampled in China [25] and the Czech Republic [31];

- Trichosanthes cytorhabdovirus for Trichosanthes associated rhabdovirus 1 (TrARV1) identified in the transcriptome of cucurbit flowering plant (Trichosanthes krilowii Maxim.) sampled in China [37];

- Trifolium pratense cytorhabdovirus A for Trifolium pratense virus A (TpVA) isolated from red clovers (Trifolium pratense L.) sampled in Hladké Životice, MoravianSilesian Region (Moravskoslezský kraj), Czech Republic [32];

- Trifolium pratense cytorhabdovirus $B$ for Trifolium pratense virus B (TpVB) ), discovered by HTS in red clovers (Trifolium pratense L.) sampled in Boršov nad Vltavou, South Bohemia Region (Jihočeský kraj), Czech Republic [32]; and

- Yerba mate cytorhabdovirus for yerba mate virus A (YmVA), discovered by HTS in yerba mate (Ilex paraguariensis A.St.-Hil.) sampled in Gobernador Virasoro, Province of Corrientes (Provincia de Corrientes), Argentina [6].

Genus Ephemerovirus was expanded by three species (TaxoProp 2020.005M.A.v1.Ephemerovirus_3nsp): 
- Hayes ephemerovirus for Hayes Yard virus (HYV) isolated from a zebu (Bos taurus indicus Linnaeus, 1758) sampled in Northern Territory, Australia [12];

- Kent ephemerovirus for New Kent County virus (NKCV), discovered by HTS in a deer tick (Ixodes scapularis Say, 1821) sampled in New Kent County, Virginia, USA [100]; and

- Puchong ephemerovirus for Puchong virus (PUCV) first isolated in 1965 from culicid mosquitoes (Mansonia uniformis (Theobald, 1901)) collected in Selangor Darul Ehsan State (سلاغور دار الإحسان), Malaysia [51].

Genus Ledantevirus was expanded by one species, Bughendera ledantevirus, for Bughendera virus (BUGV), discovered by HTS in nycteribiid bat flies (Dipseliopoda) sampled in Bundibugyo District, Western Region, Uganda [7] (TaxoProp 2020.021M.A.v1.Ledantevirus_1nsp).

Genus Lostrhavirus was expanded by one species: Hyalomma lostrhavirus, for Xinjiang tick rhabdovirus (XjTRV), discovered by HTS in ixodid ticks (Hyalomma asiaticum Schulze et Schlottke, 1929) collected in Xīnjiāng Uygur Autonomous Region (新疆维吾尔自治区), China [unpublished; GenBank \#MH688524] (TaxoProp 2020.010M.A.v1. Lostrhavirus_1nsp). Species name Lonestar zarhavirus was corrected to Lonestar lostrhavirus (TaxoProp 2020.006M.A.v1.Corrections).

Genus Ohlsrhavirus was expanded by three species (TaxoProp 2020.007M.A.v1.Ohlsrhavirus_3nsp)

- Angeles ohlsrhavirus for Culex rhabdo-like virus Los Angeles (CRLVLA) detected by HTS in culicid mosquitoes (Culex sp.) collected in California, USA [86];

- Lobeira ohlsrhavirus for Lobeira virus (LOBV), discovered by HTS in culicid mosquitoes (Psorophora albigenu (Peryassú, 1908) and Aedes albopictus (Skuse, 1894)) collected in Mato Grosso State, Brazil [21, 94]; and

- Pseudovishnui ohlsrhavirus for Culex pseudovishnui rhabdo-like virus (CpRLV), discovered by HTS in culicid mosquitoes (Culex pseudovishnui Colless, 1957) collected in Isahaya (諫早市), Nagasaki Prefecture (長崎 県), Japan [30].

Genus Sigmavirus was expanded by ten species (TaxoProp 2020.003M.A.v1.Sigmavirus_10nsp):

- Capitata sigmavirus for Ceratitis capitata sigmavirus (CCapSV), discovered by HTS in Mediterranean fruit flies (Ceratitis capitata (Wiedemann, 1824)) sampled in Hawaii, USA [65];

- Domestica sigmavirus for Wuhan fly virus $2(\mathrm{WhFV}-2)$, discovered by HTS in houseflies (Musca domestica Linnaeus, 1758) sampled in Wǔhàn (武汉市), Húběi Province (湖北省), China [61];
- Hippoboscid sigmavirus for Wuhan louse fly virus 9 (WhLFV-9), discovered by HTS in louse flies (Hippoboscidae) sampled in Wǔhàn (武汉市), Húběi Province (湖北省), China [61];

- Hubei sigmavirus for Hubei diptera virus 9 (HbDV-9), discovered by HTS in unidentified flies (Diptera) sampled in Húběi Province (湖北省), China [91];

- Lousefly sigmavirus for Wuhan louse fly virus 10 (WhLFV-10), discovered by HTS in louse flies (Hippoboscidae) sampled in Wǔhàn (武汉市), Húběi Province (湖北省), China [61];

- Myga sigmavirusfor Hubei diptera virus 10 (HbDV-10), discovered by HTS in unidentified flies (Diptera) sampled in Húběi Province (湖北省), China [91];

- Shayang sigmavirus for Shayang fly virus 2 (SyFV-1), discovered by HTS in houseflies (Musca domestica Linnaeus, 1758) sampled in Shāyáng County (沙洋县), Húběi Province (湖北省), China [61];

- Sturtevanti sigmavirus for Drosophila sturtevanti sigmavirus (DStuSV), discovered by HTS in fruit flies (Drosophila sturtevanti Duda, 1927) sampled in Granada, Andalusia, Spain [65];

- Wuhan sigmavirus for Wuhan house fly virus 1 (WhHFV1), discovered by HTS in houseflies (Musca domestica Linnaeus, 1758) sampled in Wǔhàn (武汉市), Húběi Province (湖北省), China [61, 91]; and

- Ying sigmavirus for Hubei dimarhabdovirus 1 (HbDRV1), discovered by HTS in unidentified flies (Diptera) sampled in Húběi Province (湖北省), China [91].

Genus Sunrhavirus was expanded by one species, Dillard sunrhavirus, for Dillard's Draw virus (DDRV), discovered by HTS in culicid mosquitoes (Culex tarsalis Linnaeus, 1758) sampled in New Mexico, USA [82] (TaxoProp 2020.008M.A.v1.Sunrhavirus_1nsp).

Genus Varicosavirus was expanded by two species (TaxoProp 2020.013M.A.v1.Plant_rhabdoviruses_9nsp):

- Alopecurus varicosavirus for Alopecurus myosuroides varicosavirus 1 (AMVV-1) identified by transcriptome sequencing in black-grass (Alopecurus myosuroides Huds.) in the UK [85]; and

- Trifolium varicosavirus for red clover associated varicosavirus (RCaVV), discovered by HTS in red clover (Trifolium pratense L.) sampled in Hladké Životice, Moravian-Silesian Region (Moravskoslezský kraj), Czech Republic [53].

Genus Vesiculovirus was expanded by one species, Rhinolophus vesiculovirus, for Jinghong bat virus (JhBV), discovered in an intermediate horseshoe bat (Rhinolophus affinis Horsfield, 1823) sampled in Jǐnghóng (景洪市), Yúnnán Province (云南省), China 
[111] (TaxoProp 2020.009M.A.v1.Vesiculovirus_1nsp_ ren1sp). Species American bat vesiculovirus was renamed Eptesicus vesiculovirus (TaxoProp 2020.009M.A.v1. Vesiculovirus_1nsp_ren1sp).

\section{Taxonomic changes within order Bunyavirales (Polyploviricotina: Ellioviricetes)}

\section{Family Arenaviridae}

Genus Antennavirus was expanded by one species, Salmon antennavirus, for salmon pescarenavirus 1 (SPAV-1), discovered by HTS in Chinook salmon (Oncorhynchus tshawytscha (Walbaum, 1792)) and salmon pescarenavirus 2 (SPAV-2) in sockeye salmon (Oncorhynchus nerka (Walbaum, 1792)) [71] (TaxoProp 2020.018M.A.v1.Antennavirus).

Genus Hartmanivirus was expanded by two species: Heimat hartmanivirus for andere Heimat virus $1(\mathrm{aHeV}-1)$ and Setpatvet hartmanivirus for SetPatVet virus 1 (SPVV1), both discovered by HTS in Brazilian boa constrictors (Boa constrictor Linnaeus, 1758) [3, 43] (TaxoProp 2020.019M.A.v2.Hartmanivirus).

Genus Mammarenavirus was expanded by one species, Kitale mammarenavirus, for Kitale virus (KTLV) first discovered by HTS in a Macmillan's grammomys (Grammomys macmillani (Wroughton, 1907)), sampled in Kitale, TransNzoia County, Kenya [76] (TaxoProp 2020.017M.A.v2. Mammarenavirus).

\section{Family Cruliviridae}

In genus Lincruvirus, two new species were established (TaxoProp 2020.002M.A.v2.Lincruvirus_2nsp):

- Lincruvirus europense for European shore crab virus 1 (EscV-1; previously named "Carcinus maenas Portunibunyavirus 1"), discovered by HTS in European shore crabs (Carcinus maenas (Linnaeus, 1758)) [13]; and

- Lincruvirus sinense for Chinese mitten crab virus 1 $(\mathrm{CmcV}-1$; previously named "Eriocheir sinensis Bunya like virus"), discovered by HTS in Chinese mitten crabs (Eriocheir sinensis Milne-Edwards, 1853) [44].

Species Crustacean lincruvirus was renamed Lincruvirus wenlingense (TaxoProp 2020.002M.A.v2. Lincruvirus_2nsp).

\section{Family Fimoviridae}

Genus Emaravirus was expanded by ten species:
- Actinidia emaravirus 2 for Actinidia virus 2 (AcV-2), discovered by RT-PCR in kiwifruit (Actinidia sp.) collected in Zhèjiāng Province (浙江省), China [106] (TaxoProp 2020.012P.A.v1.Emaravirus_AcV-2);

- Aspen mosaic-associated emaravirus for aspen mosaicassociated virus (AsMaV), discovered by HTS in Eurasian aspen (Populus tremula L.) sampled in Sweden [103] (TaxoProp 2020.013P.A.v1.Emaravirus_AsMaV);

- Camellia japonica-associated emaravirus 1 for Camellia japonica-associated virus 1 (CjaV-1), discovered by HTS in common camellia (Camellia japonica L.) sampled at Lake Maggiore, Piedmont, Italy [78, 114] (TaxoProp 2020.018P.A.v1.Emaravirus_CjaV-1);

- Camellia japonica-associated emaravirus 2 for Camellia japonica-associated virus 2 (CjaV-2), discovered by HTS in common camellia (Camellia japonica L.) sampled at Lake Maggiore, Piedmont, Italy [78, 114] TaxoProp 2020.019P.A.v1.Emaravirus_CjaV-2);

- Jujube yellow mottle-associated emaravirus for jujube yellow mottle-associated virus (JYMaV), discovered by HTS in jujube (Ziziphus jujuba Mill.) sampled in Cháoyáng (朝阳市), Liáoníng Province (辽宁省), China [112] (TaxoProp 2020.020P.A.v1.Emaravirus_JYMaV);

- Lilac chlorotic ringspot-associated emaravirus for lilac chlorotic ringspot-associated virus (LiCRaV), discovered by HTS in lilac (Syringa vulgaris L.) sampled in Yán'ān (延安市), Shaanxi/Shănxī Province (陕西省), China [105] (TaxoProp 2020.014P.A.v1.Emaravirus_LiCRaV);

- Palo verde broom emaravirus for palo verde broom virus (PVBV), discovered by HTS in a blue palo verde tree (Parkinsonia florida (Benth. ex A.Gray) S. Wats.) sampled in Arizona, USA [47] (TaxoProp 2020.015P.A.v1. Emaravirus_PVBV);

- Pear chlorotic leaf spot-associated emaravirus for pear chlorotic leaf spot-associated virus (PCLSaV), discovered by HTS in Asian pear plants (Pyrus pyrifolia (Burm.) Nak.) sampled in southern China [63] (TaxoProp 2020.016P.A.v1.Emaravirus_PCLSaV);

- Perilla mosaic emaravirus for perilla mosaic virus (PerMV), discovered in perilla (Perilla frutescens (L.) Britton) sampled in Japan [55] (TaxoProp 2020.021P.A.v1.Emaravirus_PerMV); and

- Ti ringspot-associated emaravirus for ti ringspot-associated virus (TiRSaV), discovered in ti (Cordyline fruticosa L.) sampled on the islands of Oahu, Maui, and Hawaii, USA [74] (TaxoProp 2020.017P.A.v1.Emaravirus_TiRSaV).

\section{Family Hantaviridae}

Genus Actinovirus was expanded by one species, Perch actinovirus, for Bern perch virus (BRPV), discovered by HTS 
in European perch (Perca fluviatilis Linnaeus, 1758) sampled in Switzerland [unpublished; GenBank \# MN510769/ MN510770/MN510771] (TaxoProp 2020.025M.A.v2. Hantaviridae_5nsp).

Genus Mobatvirus was expanded by two species (TaxoProp 2020.025M.A.v2.Hantaviridae_5nsp):

- Lena mobatvirus for Lena virus (LENV), discovered by RT-PCR in a Laxmann's shrew (Sorex caecutiens Laxmann, 1785) sampled in Khabarovsk (Хабаровск), Khabarovsk Krai (Хабаровский край,) Russia [113]; and

- Xuan Son mobatvirus for Xuân Sơn virus (XSV), discovered by RT-PCR in a Pomona leaf-nosed bat (Hipposideros pomona K. Andersen, 1918) in Xuân Sơn National Park, Phú Tho Province, Vietnam [2].

Genus Orthohantavirus was expanded by two species (TaxoProp 2020.025M.A.v2.Hantaviridae_5nsp):

- Robina orthohantavirus for Robina virus (ROBV), discovered in a black flying fox (Pteropus alecto Temminck, 1837) sampled near Robina, Queensland, Australia [unpublished; GenBank \#MK165653/MK165654/ MK165655); and

- Tatenale orthohantavirus for Tatenale virus (TATV) first discovered by RT-PCR in a field vole (Microtus agrestis (Linnaeus, 1761)) trapped in North West England, UK $[16,81]$.

\section{Family Nairoviridae}

Family Nairoviridae was thoroughly revised (TaxoProps 2020.027M.A.v1.Nairoviridae_4ngen_30nsp and 2020.030M.R.Negarnaviricota_corrections). Four new genera were added:

- Genus Norwavirus was created for a single new species, Grotenhout norwavirus, for Grotenhout virus (GRHV), discovered by HTS in a castor bean tick (Ixodes ricinus (Linnaeus, 1758)) sampled in Grotenhout, Belgium [101]. Junior synonyms for Grotenhout virus are Norway nairovirus 1 [79] and Pustyn virus [unpublished; GenBank \#KT007142/KT007143];

- Genus Ocetevirus was created for a single new species, Blattodean ocetevirus, for blattodean nairo-related virus 321 (BNRV-321), now renamed red goblin roach virus 1 (RGRV-1), discovered by HTS in a red goblin roach (Paratemnopteryx couloniana (Saussure, 1863)) sampled in Germany [49];

- Genus Sabavirus was created for a single new species, South Bay sabavirus, for South Bay virus (SBV), discov- ered by HTS in a deer tick (Ixodes scapularis Say, 1821) in Great South Bay, New York, USA [99]; and

- Genus Xinspivirus was created for a single new species, Xinzhou xinspivirus, for Xīnzhōu spider virus (XSV), discovered by HTS in a brown sailor spider (Neoscona nautica (L. Koch, 1875)) in Xīnzhōu District (新洲 区), Wǔhàn (武汉市), Húběi Province (湖北省), China [61].

Genus Orthonairovirus was expanded by 26 species:

- Abu Hammad orthonairovirus for Abū Hammād virus (AHV) was moved from Dera Ghazi Khan orthonairovirus;

- Abu Mina orthonairovirus for Abū Mīnā virus (AMV) was moved from Dera Ghazi Khan orthonairovirus;

- Avalon orthonairovirus for Avalon virus (AVAV) was moved from Sakhalin orthonairovirus;

- Bandia orthonairovirus for Bandia virus (BDAV) was moved from Qalyub orthonairovirus;

- Burana orthonairovirus for Burana virus (BURV) was moved from Tamdy orthonairovirus;

- Congoid orthonairovirus for Crimean-Congo hemorrhagic fever virus (CCHFV) genogroup VI (Europe 2), now renamed Aigai virus (AIGV), isolated in 1975 from an ixodid tick (Rhipicephalus bursa Canestrini \&

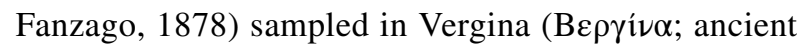

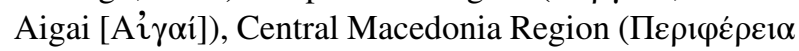

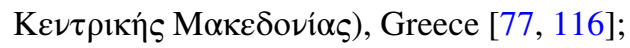

- Erve orthonairovirus for Erve virus (ERVEV) was moved from Thiafora orthonairovirus;

- Gossas orthonairovirus for Gossas virus (GOSV) was moved from Keterah orthonairovirus;

- Huangpi orthonairovirus for Huángpí tick virus 1 (HpTV-1) was moved from Tamdy orthonairovirus;

- Issyk-kul orthonairovirus for Issyk-kul virus (ISKV) was moved from Keterah orthonairovirus;

- Kupe orthonairovirus for kupe virus (KUPEV) was moved from Dugbe orthonairovirus;

- Leopards Hill orthonairovirus for Leopards Hill virus (LPHV) was moved from Keterah orthonairovirus;

- Meram orthonairovirus for Meram virus (MEMV), discovered by HTS in an ixodid tick (Hyalomma aegyptium Linnaeus, 1758) sampled in Konya, Central Anatolia Region (İç Anadolu Bölgesi), Turkey [29];

- Pacific Coast orthonairovirus for Pacific Coast tick nairovirus (PCTNV), discovered by HTS in a Pacific Coast tick (Dermacentor occidentalis Marx, 1892) sampled in Mendocino County, California, USA [14];

- Punta orthonairovirus for Punta Salinas virus (PSV) was moved from Hughes orthonairovirus;

- Sapphire orthonairovirus for Sapphire II virus (SAPV) was moved from Dera Ghazi Khan orthonairovirus; 
- Scot orthonairovirus for Clo Mor virus (CLMV) was moved from Sakhalin orthonairovirus;

- Soldado orthonairovirus for Soldado virus (SOLV) was moved from Hughes orthonairovirus;

- Tacheng orthonairovirus for Tăchéng tick virus 1 (TcTV1) was moved from Tamdy orthonairovirus;

- Taggert orthonairovirus for Taggert virus (TAGV) was moved from Sakhalin orthonairovirus;

- Tofla orthonairovirus for tofla virus (TFLV) was moved from Hazara orthonairovirus;

- Tunis orthonairovirus for Tunis virus (TUNV) was moved from Abu Hammad orthonairovirus;

- Vinegar Hill orthonairovirus for Vinegar Hill virus (VINHV) isolated in 1981 from ixodid ticks (Argas robertsi Hoogstraal, Kaiser \& Kohls, 1968) sampled in Gatton, Queensland, Australia [36, 97];

- Wenzhou orthonairovirus for Wēnzhōu tick virus (WzTV) was moved from Tamdy orthonairovirus;

- Yogue orthonairovirus for Yogue virus (YOGV) was moved from Keterah orthonairovirus; and

- Zirqa orthonairovirus for Zirqa virus (ZIRV) was moved from Hughes orthonairovirus.

\section{Family Peribunyaviridae}

Genus Orthobunyavirus was expanded by 16 species (TaxoProps 2020.012M.A.v1. Orthobunyavirus_16new_sp_abolish_1sp and 2020.030M.R.Negarnaviricota_corrections):

- Brazoran orthobunyavirus for brazoran virus (BRAZV) isolated from culicid mosquitoes (Culex sp.) in Brazoria and Montgomery Counties, Texas, USA [59];

- Buffalo Creek orthobunyavirus for Buffalo Creek virus (BUCV) first isolated in 1982 from culicid mosquitoes (Anopheles meraukensis Venhuis, 1932) in Darwin, Northern Territory, Australia [34, 107];

- Gan Gan orthobunyavirus for Gan Gan virus (GGV) first isolated in 1970 from culicid mosquitoes (Ochlerotatus vigilax (Skuse, 1889)) collected at Nelson Bay, New South Wales, Australia [33, 35, 69];

- Mapputta orthobunyavirus for Mapputta virus (MAPV) first isolated in 1960 from culicid mosquitoes (Anopheles meraukensis Venhuis, 1932) collected in Queensland, Australia [10, 26, 34];

- Maprik orthobunyavirus for Maprik virus (MPKV) first isolated in 1966 from culicid mosquitoes (Verrallina funerea (Theobald, 1903)) sampled in Maprik, East Sepik Province, Papua New Guinea [27, 34];

- Oyo orthobunyavirus for Oyo virus (OYOV) first isolated in 1964 in Nigeria [unpublished; GenBank \#HM63977/ HM63979/HM63980];
- Sedlec orthobunyavirus for Sedlec virus (SEDV) first isolated in 1984 from a Eurasian reed warbler (Acrocephalus scirpaceus (Hermann, 1804)) sampled in South Moravian Region (Jihomoravský kraj), Czech Republic [45, 46, 50];

- Triniti orthobunyavirus for Triniti virus (TNTV) isolated first in 1955 from a culicid mosquito (Trichoprosopon sp.) sampled in Port of Spain, Trinidad and Tobago $[62,96]$;

- Abras virus (ABRV) was moved from species Patois orthobunyavirus into new species Abras orthobunyavirus;

- Ananindeua virus (ANUV) was moved from species Guama orthobunyavirus into new species Ananindeua orthobunyavirus;

- Apeú virus (APEUV) was moved from species Caraparu orthobunyavirus into new species Apeu orthobunyavirus;

- Bruconha virus (BRUV) was moved from species Caraparu orthobunyavirus into new species Bruconha orthobunyavirus;

- Mahogany Hammock virus (MHV) was moved from species Guama orthobunyavirus into new species Mahogany Hammock orthobunyavirus;

- Matruh virus (MTRV) was moved from species Tete orthobunyavirus into new species Matruh orthobunyavirus;

- Moju virus (MOJUV) was moved from species Guama orthobunyavirus into new species Moju orthobunyavirus; and

- Shark River virus (SRV) was moved from species Patois orthobunyavirus into new species Shark River orthobunyavirus.

Species Zegla orthobunyavirus was abolished (TaxoProp 2020.012M.A.v1.Orthobunyavirus_16new_sp_abolish_1sp).

\section{Family Phasmaviridae}

The family was expanded by new genus Hymovirus for two new species (TaxoProp 2020.020M.A.v1.Phasmaviridae):

- Hymenopteran hymovirus 1 for hymenopteran phasmarelated virus OKIAV252 (HyHV-1), discovered by HTS in cuckoo wasps (Chrysura cuprea (Rossi, 1790)) in Pondel, Aosta Valley (Valle d'Aosta), Italy [49]; and

- Hymenopteran hymovirus 2 for hymenopteran phasmarelated virus OKIAV250 (HyHV-2) detected in cuckoo wasps (Chrysis gracillima Foerster, 1853) in Büchlberg/ Godramstein, Rhineland-Palatinate (Rheinland-Pfalz), Germany [49]. 
Genus Feravirus was expanded by two novel species (TaxoProp 2020.020M.A.v1.Phasmaviridae):

- Hemipteran feravirus for hemipteran phasma-related virus OKIAV247 (HeFV), discovered by HTS in a hawthorn shield bug (Acanthosoma haemorrhoidale (Linnaeus, 1758)) sampled in Donrath, North Rhine-Westphalia (Nordrhein-Westfalen), Germany [49]; and

- Neuropteran feravirus for neuropteran phasma-related virus OKIAV248 (NeFV), discovered by HTS in a green lacewing (Peyerimhoffina gracilis (Schneider, 1851)) sampled in Dürnstein, Lower Austria (Niederösterreich), Austria [49].

Genus Orthophasmavirus was expanded by four novel species (TaxoProp 2020.020M.A.v1.Phasmaviridae):

- Coleopteran orthophasmavirus for coleopteran phasmarelated virus OKIAV235 (CPRV), discovered by HTS in a harlequin ladybeetle (Harmonia axyridis (Pallas, 1773)) sampled in Jena, Thuringia (Thüringen), Germany [49];

- Hymenopteran orthophasmavirus 1 for hymenopteran phasma-related virus OKIAV228 (HyOV-1), discovered by HTS in a cuckoo wasp (Philoctetes bogdanovii (Radoszkovski, 1877)) in Pondel, Aosta Valley (Valle d'Aosta), Italy [49];

- Hymenopteran orthophasmavirus 2 for hymenopteran phasma-related virus OKIAV227 for (HyOV-2), discovered by HTS in a cuckoo wasp (Chrysis fasciata Olivier, 1790) in Bellheim, Rhineland-Palatinate (RheinlandPfalz), Germany [49]; and

- Niukluk phantom orthophasmavirus for Niukluk phantom virus (NUKV), discovered by HTS in a phantom midge (Chaoborus americanus (Johannsen, 1903)) sampled in the Niukluk River valley, Nome Census Area, Alaska, USA [5].

\section{Family Phenuiviridae}

The family was expanded by new genus Tanzavirus including a single new species, Human tanzavirus, for Dar es Salaam virus (DeSV), discovered by HTS in a human plasma sample collected in Dar es Salaam (دار السلام) Tanzania [60] (TaxoProp 2020.029M.A.v2.Phenuiviridae_1gen16sp).

Genus Bandavirus was expanded by one new species, Razdan bandavirus, for Razdan virus (RAZV) isolated from ixodid ticks (Dermacentor marginatus Sulzer, 1776) in Armenia in 1973 [66, 117] (TaxoProp 2020.029M.A.v2. Phenuiviridae_1gen16sp). Species name Lone Star bandavirus was corrected to Lone star bandavirus (TaxoProp 2020.006M.A.v1.Corrections).
Genus Coguvirus was expanded by one new species, Grapevine coguvirus, for grapevine associated cogu-like virus 1 (GaCLV-1), discovered by HTS in downy mildewinfected grapevines (Vitis sp.) sampled in Italy [18]. (TaxoProp 2020.029M.A.v2.Phenuiviridae_1gen16sp).

Genus Horwuvirus was expanded by one new species, Kimberley horwuvirus, for Fitzroy Crossing tenuilike virus 1 (FCTenV1) detected in culicid mosquitoes (Culex annulirostris Skuse, 1889) sampled in Kimberley Region, Australia [108] (TaxoProp 2020.029M.A.v2. Phenuiviridae_1gen16sp).

Genus Laulavirus was expanded by three new species: Grapevine laulavirus 2, 3, and 4 for grapevine associated cogu-like viruses 2, 3, and 4 (GaCLV-2, GaCLV-3, GaCLV4 ), respectively, discovered by HTS in downy mildewinfected grapevines (Vitis sp.) (GaCLV-2 and GaCLV-3) and esca-diseased grapevines (GaCLV-4) sampled in Italy [8, 18] (TaxoProp 2020.029M.A.v2.Phenuiviridae_1gen16sp).

Genus Mobuvirus was expanded by one new species, Narangue mobuvirus, for Narangue virus (NRGV), discovered by HTS in a culicid mosquito (Mansonia titillans (Walker, 1848)) sampled in Colombia [unpublished; GenBank \#MN661012/MN661013/MN661014] (TaxoProp 2020.029M.A.v2.Phenuiviridae_1gen16sp).

Genus Phasivirus was expanded by two new species:

- Guadeloupe phasivirus for Guadeloupe mosquito phasivirus (GMPV), discovered by HTS in mosquitoes (Aedes sp.) collected in Les Abymes, Guadeloupe, France [89]; and

- Kimberley phasivirus for Parry's Creek phasivirus 1 (PCPhasV1), discovered by HTS in culicid mosquitoes (Culex annulirostris Skuse, 1889) sampled in Kimberley Region, Australia [108] (TaxoProps 2020.029M.A.v2.Phenuiviridae_1gen16sp and 2020.030M.R.Negarnaviricota_corrections).

Genus Phlebovirus was expanded by six species:

- Bogoria phlebovirus for Bogoria virus (BGRV), discovered by HTS in phlebotomine sandflies sampled in Kapkuikui, Rift Valley Province, Kenya [68] (TaxoProp 2020.022M.A.v1.Phlebovirus_4sp);

- Corfou phlebovirus for Corfou virus (CFUV) isolated from psychodid sandflies (Phlebotomus major Annan-

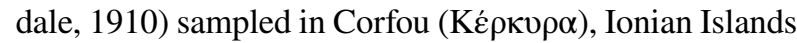

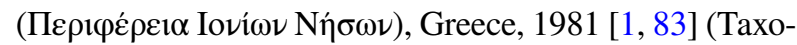
Prop 2020.029M.A.v2.Phenuiviridae_1gen16sp);

- Embossos phlebovirus for Embossos virus (EMBV), discovered by HTS in phlebotomine sandflies sampled in Kapkuikui, Rift Valley Province, Kenya [68] (TaxoProp 2020.022M.A.v1.Phlebovirus_4sp); 
- Kiborgoch phlebovirus for Kiborgoch virus (KBGV), discovered by HTS in phlebotomine sandflies sampled in Kapkuikui, Rift Valley Province, Kenya [68] (TaxoProp 2020.022M.A.v1.Phlebovirus_4sp);

- Penshurt phlebovirus for Penshurt virus (PEHV), discovered by RT-PCR in a Hoffmann's two-toed sloth (Choloepus hoffmanni Peters, 1858) sampled in Limón Province, Costa Rica [22] (TaxoProp 2020.029M.A.v2. Phenuiviridae_1gen16sp); and

- Perkerra phlebovirus for Perkerra virus (PKEV), discovered by HTS in phlebotomine sandflies sampled in Kapkuikui, Rift Valley Province, Kenya [68] (TaxoProp 2020.022M.A.v1.Phlebovirus_4sp).

Species names Salobo phlabovirus and Tico phebovirus were corrected to Salobo phlebovirus and Tico phlebovirus, respectively (TaxoProp 2020.006M.A.v1.Corrections).

Genus Pidchovirus was expanded by one new species, Coleopteran pidchovirus, for coleopteran phenui-related virus 308 (CoPrV-308), discovered by HTS in spider mite destroyers (Stethorus sp.) sampled on Mount Tamborine, Queensland, Australia [49]. (TaxoProp 2020.029M.A.v2. Phenuiviridae_1gen16sp).

Genus Rubodvirus was expanded by two new species: Grapevine rubodvirus 1 and 2 for grapevine Garan dmak virus (GGDV) and grapevine Muscat rose virus for (GMRV), discovered by HTS in grapevines (Vitis vinifera L.) samples from Armenia and Argentina, respectively [24] (TaxoProp 2020.029M.A.v2.Phenuiviridae_1gen16sp).

Genus Tenuivirus was expanded by one new species, European wheat striate mosaic tenuivirus, for European wheat striate mosaic virus (EWSMV) originally discovered in oats (Avena sativa L. cv. Pepino) in the 1960s [95] (TaxoProp 2020.029M.A.v2.Phenuiviridae_1gen16sp).

In genus Wenrivirus, Mourilyan virus (MoV), first discovered in 1996 in giant tiger prawns (Penaeus monodon Fabricius, 1798) sampled in Mourilyan, Queensland, Australia [19], was recognized as a senior synonym of Wēnzhōu shrimp virus 1 (WzSV-1) [20].

\section{Summary}

A summary of the current, ICTV-accepted taxonomy of the phylum Negarnaviricota is presented in an order-specific manner in Table 1 (Goujianvirales), Table 2 (Jingchuvirales), Table 3 (Mononegavirales), Table 4 (Muvirales), Table 5 (Serpentovirales), Table 6 (Articulavirales), and Table 7 (Bunyavirales) and in form of two posters (Supplementary Figure 1).

Supplementary Information The online version contains supplementary material available at https://doi.org/10.1007/s00705-021-05143-6.

Acknowledgements We thank Anya Crane (IRF-Frederick) for editing the manuscript.

The 2017-2020 International Committee on Taxonomy of Viruses (ICTV) Study Groups: Arenaviridae (Michael J. Buchmeier, Rémi N. Charrel, Jens H. Kuhn; J. Christopher S. Clegg; Juan Carlos de la Torre; Jean-Paul J. Gonzalez; Stephan Günther; Jussi Hepojoki; Igor S. Lukashevich; Sheli R. Radoshitzky; Víctor Romanowski; Maria S. Salvato; Manuela Sironi; Mark D. Stenglein), Artoviridae (Ralf G. Dietzgen; Dàohóng Jiāng (姜道宏); Jens H. Kuhn; Nikos Vasilakis

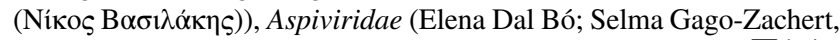
María Laura García; John Hammond; Tomohide Natsuaki (夏秋知 英); José A. Navarro; Vicente Pallás; Carina A. Reyes; Gabriel Robles Luna; Takahide Sasaya (笹谷孝英); Ioannis Tzanetakis; Anna Maria Vaira; Martin Verbeek), Bornaviridae (Thomas Briese; Ralf Dürrwald; Masayuki Horie (堀江真行); Timothy H. Hyndman; Jens H. Kuhn; Norbert Nowotny; Susan Payne; Dennis Rubbenstroth; Mark D. Stenglein; Keizō Tomonaga (朝長啓造)), Bunyavirales (Scott Adkins; Juan Carlos de la Torre; Sandra Junglen; Jens H. Kuhn; Amy J. Lambert; , Piet Maes; Marco Marklewitz; Gustavo Palacios; Takahide Sasaya (笹 谷孝英)), Filoviridae (Gaya K. Amarasinghe; Christopher F. Basler; Sina Bavari; Alexander Bukreyev; Kartik Chandran; Ian Crozier; Olga Dolnik; John M. Dye; Pierre B. H. Formenty; Anthony Griffiths; Roger Hewson; Jens H. Kuhn; Eric M. Leroy; Elke Mühlberger; Sergey V. Netesov (Нетёсов Сергей Викторович); Gustavo Palacios; Bernadett Pályi; Janusz T. Pawęska; Sophie Smither; Ayato Takada (高田礼人); Jonathan S. Towner; Victoria Wahl), Fimoviridae (Michele Digiaro; Toufic Elbeaino; Nicole Mielke-Ehret; Hans-Peter Mühlbach), Hantaviridae (Steven Bradfute; Charles H. Calisher; Boris Klempa; Jonas Klingström; Lies Laenen; Piet Maes; Jin-Won Song (송 진 원)), Monjiviricetes (Ralf G. Dietzgen; W. Paul Duprex; Dàohóng Jiāng (姜道宏); Jens H. Kuhn; Piet Maes; Janusz T. Pawęska; Bertus K. Rima; Dennis Rubbenstroth; Peter J. Walker), Mymonaviridae (María A. Ayllón; Dàohóng Jiāng (姜道宏); Shin-Yi L. Marzano), Nairoviridae (Dennis A. Bente; Éric Bergeron; Sergey V. Alkhovsky (Альховский Сергей Владимирович); Tatjana Avšič-Županc; Felicity Burt; Nicholas Di
Table 1 ICTV-accepted taxonomy of the order Goujianvirales (Negarnaviricota: Haploviricotina: Yunchangviricetes) as of March 2021

\begin{tabular}{lll}
\hline Genus & Species $^{\mathbb{I}}$ & Virus (abbreviation) $^{\&}$ \\
\hline $\begin{array}{l}\text { Family Yueviridae } \\
\text { Yuyuevirus }\end{array}$ & Beihai yuyuevirus & Běihǎi sesarmid crab virus 3 (BhSCV-3) \\
& Shahe yuyuevirus & Shāhé yuèvirus-like virus 1 (ShYLV-1) \\
\hline
\end{tabular}

Note that viruses are real objects that are assigned to concepts that are called taxa. Species, genera, families, and orders are taxa

"Taxon names are always italicized and always begin with a capital letter

${ }^{\&}$ Virus names are not italicized and are not capitalized, except if the name or a name component is a proper noun. This column lists the virus names with their correct (lack of) capitalization 
Table 2 ICTV-accepted taxonomy of the order Jingchuvirales (Negarnaviricota: Haploviricotina: Monjiviricetes) as of March 2021

\begin{tabular}{|c|c|c|}
\hline Genus & Species $^{\text {II }}$ & Virus (abbreviation) ${ }^{\&}$ \\
\hline \multicolumn{3}{|c|}{ Family Aliusviridae } \\
\hline Obscuruvirus & Obscuruvirus quintum & Atrato chu-like virus 5 (AClV-5) \\
\hline \multirow[t]{8}{*}{ Ollusvirus } & Ollusvirus coleopteri & Húběi coleoptera virus 3 (HbCV-3) \\
\hline & Ollusvirus culvertonense & Culverton virus $(\mathrm{CvV})$ \\
\hline & Ollusvirus hanchengense & Hánchéng leafhopper mivirus (HLMV) \\
\hline & Ollusvirus hymenopteri & hymenopteran chu-related virus 123 (HCrV-123) \\
\hline & Ollusvirus insectii & hymenopteran chu-related virus 126 (HCrV-126) \\
\hline & Ollusvirus scaldisense & Scaldis River bee virus (SRBV) \\
\hline & Ollusvirus shayangense & Shāyáng fly virus 1 (SyFV-1) \\
\hline & Ollusvirus taiyuanense & Tàiyuán leafhopper virus (TYLeV) \\
\hline \multicolumn{3}{|l|}{ Family Chuviridae } \\
\hline \multirow[t]{2}{*}{ Boscovirus } & Boscovirus hippoboscidae & Wǔhàn louse fly virus 7 (WhLFV-7) \\
\hline & Boscovirus hypoboscidae & Wǔhàn louse fly virus 6 (WhLFV-6) \\
\hline \multirow[t]{2}{*}{ Chuvivirus } & Chuvivirus brunnichi & Wēnlǐng crustacean virus 14 (WlCV-14) \\
\hline & Chuvivirus canceris & Wēnzhōu crab virus 2 (WzCV-2) \\
\hline \multirow[t]{4}{*}{ Culicidavirus } & Culicidavirus culicidae & Wǔhàn mosquito virus 8 (WhMV-8) \\
\hline & Culicidavirus culicis & Culex mosquito virus 5 (ClMV-5) \\
\hline & Culicidavirus imjinense & Imjin River virus 1 (IjRV-1) \\
\hline & Culicidavirus quitotaense & Culex mosquito virus 4 (ClMV-4) \\
\hline Demapteravirus & Demapteravirus dermapteri & dermapteran chu-related virus 142 (DCrV-142) \\
\hline Doliuvirus & Doliuvirus culisetae & Mos8Chu0 chuvirus (MoCV) \\
\hline \multirow[t]{10}{*}{ Mivirus } & Mivirus amblyommae & lone star tick chuvirus 1 (LSTCV-1) \\
\hline & Mivirus boleense & Bólè tick virus 3 (BTV-3) \\
\hline & Mivirus changpingense & Chāngpíng tick virus 2 (CpTV-2) \\
\hline & Mivirus dermacentoris & Chāngpíng tick virus 3 (CpTV-3) \\
\hline & & Tăchéng tick virus 5 (TcTV-5) \\
\hline & Mivirus genovaense & Genoa virus $(\mathrm{GeV})$ \\
\hline & Mivirus karukeraense & Karukera tick virus (KtV) \\
\hline & Mivirus rhipicephali & brown dog tick mivirus 1 (BDTMV-1) \\
\hline & Mivirus suffolkense & Suffolk virus (SFKV) \\
\hline & Mivirus wuhanense & Wǔhàn tick virus 2 (WhTV-2) \\
\hline Morsusvirus & Morsusvirus argatis & Tǎchéng tick virus 4 (TcTV-4) \\
\hline Nigecruvirus & Nigecruvirus ixodes & blacklegged tick chuvirus-2 (B1TC-2) \\
\hline \multirow[t]{3}{*}{ Odonatavirus } & Odonatavirus draconis & odonatan chu-related virus 137 (OCrV-137) \\
\hline & Odonatavirus fabricii & Húběi odonate virus 11 (HbOV-11) \\
\hline & Odonatavirus odontis & odonatan chu-related virus 136 (OCrV-136) \\
\hline Pediavirus & Pediavirus cirripedis & Běihǎi barnacle virus 9 (BhBV-9) \\
\hline \multirow[t]{4}{*}{ Piscichuvirus } & Piscichuvirus franki & Herr Frank virus 1 (HFrV-1) \\
\hline & Piscichuvirus lycodontis & Guăngdōng red-banded snake chuvirus-like virus (GRSCV) \\
\hline & Piscichuvirus sanxiaense & Sānxiá atyid shrimp virus 4 (SxASC-4) \\
\hline & Piscichuvirus wenlingense & Wēnlǐng fish chu-like virus (WFCIV) \\
\hline Pterovirus & Pterovirus chulinense & hymenopteran chu-related virus OKIAV147 (HCrV-147) \\
\hline \multirow[t]{5}{*}{ Scarabeuvirus } & Scarabeuvirus blattae & Wǔchāng cockroach virus 3 (WcLFV-3) \\
\hline & Scarabeuvirus dentati & Húběi chuvirus-like virus 3 (HbCLV-3) \\
\hline & Scarabeuvirus hubeiense & Húběi chuvirus-like virus 1 (HbCLV-1) \\
\hline & Scarabeuvirus lampyris & Lampyris noctiluca chuvirus-like virus 1 (LNClV-1) \\
\hline & Scarabeuvirus lishiense & Lǔshì spider virus 1 (LsSV-1) \\
\hline Taceavirus & Taceavirus wenlingense & Wēnlǐng crustacean virus 15 (WlCV-15) \\
\hline \multicolumn{3}{|c|}{ Family Crepuscuviridae } \\
\hline Aqualaruvirus & Aqualaruvirus sialis & megalopteran chu-related virus 119 (MCrV-119) \\
\hline
\end{tabular}


Table 2 (continued)

\begin{tabular}{lll}
\hline Genus & Species $^{\mathbb{I}}$ & Virus (abbreviation) $^{\&}$ \\
\hline $\begin{array}{l}\text { Family Myriaviridae } \\
\text { Myriavirus }\end{array}$ & Myriavirus myriapedis & Húběi myriapoda virus 8 (HbMV-8) \\
$\begin{array}{l}\text { Family Natareviridae } \\
\text { Charybdivirus }\end{array}$ & Charybdivirus charybdis & Wēnzhōu crab virus 3 (WzCV-3) \\
\hline
\end{tabular}

Note that viruses are real objects that are assigned to concepts that are called taxa. Species, genera, families, and orders are taxa

II Taxon names are always italicized and always begin with a capital letter

${ }^{\&}$ Virus names are not italicized and are not capitalized, except if the name or a name component is a proper noun. This column lists the virus names with their correct (lack of) capitalization. Lists of viruses within a given species are provisional at this point and will likely be amended in the near future

Table 3 ICTV-accepted taxonomy of the order Mononegavirales (Negarnaviricota: Haploviricotina: Monjiviricetes) as of March 2021

\begin{tabular}{|c|c|c|}
\hline Genus & Species ${ }^{I I}$ & Virus (abbreviation) ${ }^{\&}$ \\
\hline \multicolumn{3}{|l|}{ Family Artoviridae } \\
\hline \multirow[t]{2}{*}{ Hexartovirus } & Barnacle hexartovirus & Běihăi barnacle virus 8 (BhBV-8) \\
\hline & Caligid hexartovirus & Lepeophtheirus salmonis negative-stranded RNA virus 1 (LsNSRV-1) \\
\hline \multirow[t]{6}{*}{ Peropuvirus } & Beihai peropuvirus & Běihăi rhabdo-like virus 1 (BhRLV-1) \\
\hline & Hubei peropuvirus & Húběi rhabdo-like virus 6 (HbRLV-6) \\
\hline & Odonate peropuvirus & Húběi rhabdo-like virus 8 (HbRLV-8) \\
\hline & Pillworm peropuvirus & Húběi rhabdo-like virus 5 (HbRLV-5) \\
\hline & Pteromalus puparum peropuvirus & Pteromalus puparum negative-strand RNA virus 1 (PpNSRV-1) \\
\hline & Woodlouse peropuvirus & Běihăi rhabdo-like virus 2 (BhRLV-2) \\
\hline \multicolumn{3}{|l|}{ Family Bornaviridae } \\
\hline \multirow[t]{2}{*}{ Carbovirus } & Queensland carbovirus & jungle carpet python virus (JCPV) \\
\hline & Southwest carbovirus & southwest carpet python virus (SWCPV) \\
\hline Cultervirus & Sharpbelly cultervirus & Wǔhàn sharpbelly Bornavirus (WhSBV) \\
\hline \multirow[t]{16}{*}{ Orthobornavirus } & Elapid 1 orthobornavirus & Loveridge's garter snake virus 1 (LGSV-1) \\
\hline & Mammalian 1 orthobornavirus & Borna disease virus 1 (BoDV-1) \\
\hline & & Borna disease virus 2 (BoDV-2) \\
\hline & Mammalian 2 orthobornavirus & variegated squirrel bornavirus 1 (VSBV-1) \\
\hline & Passeriform 1 orthobornavirus & canary bornavirus $1(\mathrm{CnBV}-1)$ \\
\hline & & canary bornavirus $2(\mathrm{CnBV}-2)$ \\
\hline & & canary bornavirus $3(\mathrm{CnBV}-3)$ \\
\hline & Passeriform 2 orthobornavirus & estrildid finch bornavirus 1 (EsBV-1) \\
\hline & Psittaciform 1 orthobornavirus & parrot bornavirus 1 (PaBV-1) \\
\hline & & parrot bornavirus 2 (PaBV-2) \\
\hline & & parrot bornavirus 3 (PaBV-3) \\
\hline & & parrot bornavirus 4 (PaBV-4) \\
\hline & & parrot bornavirus 7 (PaBV-7) \\
\hline & Psittaciform 2 orthobornavirus & parrot bornavirus 5 (PaBV-5) \\
\hline & Waterbird 1 orthobornavirus & aquatic bird bornavirus $1(\mathrm{ABBV}-1)$ \\
\hline & & aquatic bird bornavirus $2(\mathrm{ABBV}-2)$ \\
\hline \multicolumn{3}{|l|}{ Family Filoviridae } \\
\hline Cuevavirus & Lloviu cuevavirus & Lloviu virus (LLOV) \\
\hline Dianlovirus & Mengla dianlovirus & Měnglà virus (MLAV) \\
\hline \multirow[t]{6}{*}{ Ebolavirus } & Bombali ebolavirus & Bombali virus (BOMV) \\
\hline & Bundibugyo ebolavirus & Bundibugyo virus (BDBV) \\
\hline & Reston ebolavirus & Reston virus (RESTV) \\
\hline & Sudan ebolavirus & Sudan virus (SUDV) \\
\hline & Tai Forest ebolavirus & Taï Forest virus (TAFV) \\
\hline & Zaire ebolavirus & Ebola virus (EBOV) \\
\hline
\end{tabular}


Table 3 (continued)

\begin{tabular}{|c|c|c|}
\hline Genus & Species ${ }^{\text {Il }}$ & Virus (abbreviation) ${ }^{\&}$ \\
\hline \multirow[t]{2}{*}{ Marburgvirus } & Marburg marburgvirus & Marburg virus (MARV) \\
\hline & & Ravn virus (RAVV) \\
\hline Striavirus & Xilang striavirus & Xīlăng virus (XILV) \\
\hline Thamnovirus & Huangjiao thamnovirus & Huángjiāo virus (HUJV) \\
\hline \multicolumn{3}{|l|}{ Family Lispiviridae } \\
\hline \multirow[t]{6}{*}{ Arlivirus } & Gerrid arlivirus & Sānxiá water strider virus 4 (SxWSV-4) \\
\hline & Hubei arlivirus & Húběi rhabdo-like virus 3 (HbRLV-3) \\
\hline & Lishi arlivirus & Lĭshì spider virus 2 (LsSV-2) \\
\hline & Odonate arlivirus & Húběi odonate virus 10 (HbOV-10) \\
\hline & Tacheng arlivirus & Tăchéng tick virus 6 (TcTV-6) \\
\hline & Wuchang arlivirus & Wǔchāng romanomermis nematode virus 2 (WcRNV-2) \\
\hline \multicolumn{3}{|l|}{ Family Mymonaviridae } \\
\hline Auricularimonavirus & Auricularimonavirus auriculariae & Auricularia heimuer negative-stranded RNA virus 1 (AhNRSV-1) \\
\hline \multirow[t]{6}{*}{ Botrytimonavirus } & Botrytimonavirus botrytidis & Botrytis cinerea negative-stranded RNA virus 7 (BcNSRV-7) \\
\hline & Botrytimonavirus glycinis & soybean leaf-associated negative-stranded RNA virus 3 (SLaNSRV-3) \\
\hline & Botrytimonavirus sclerotiniae & Sclerotinia sclerotiorum negative-stranded RNA virus 2 (SsNSRV-2) \\
\hline & & Sclerotinia sclerotiorum negative-stranded RNA virus 2-A (SsNSRV-2-A) \\
\hline & & Sclerotinia sclerotiorum negative-stranded RNA virus 4 (SsNSRV-4) \\
\hline & & Sclerotinia sclerotiorum negative-stranded RNA virus 4-A (SsNSRV-4-A) \\
\hline \multirow[t]{2}{*}{ Hubramonavirus } & Hubramonavirus hubeiense & Húběi rhabdo-like virus 4 (HbRLV-4) \\
\hline & Hubramonavirus terrae & H2BulkLitter1223 virus \\
\hline Lentimonavirus & Lentimonavirus lentinulae & Lentinula edodes negative-strand RNA virus 1 (LeNSRV-1) \\
\hline \multirow[t]{11}{*}{ Penicillimonavirus } & Penicillimonavirus alphapenicillii & Penicillium adametzioides negative-stranded RNA virus 1 (PaNsRV-1) \\
\hline & Penicillimonavirus alphaplasmoparae & Plasmopara viticola lesion associated mononegaambi virus 1 (PvaMV-1) \\
\hline & Penicillimonavirus betapenicillii & Penicillium glabrum negative-stranded RNA virus 1 (PgRlV-1) \\
\hline & Penicillimonavirus betaplasmoparae & Plasmopara viticola lesion associated mononegaambi virus 2 (PvaMV-2) \\
\hline & & Plasmopara viticola lesion associated mononegaambi virus 4 (PvaMV-4) \\
\hline & Penicillimonavirus deltaplasmoparae & Plasmopara viticola lesion associated mononegaambi virus 5 (PvaMV-5) \\
\hline & Penicillimonavirus epsilonplasmoparae & Plasmopara viticola lesion associated mononegaambi virus 6 (PvaMV-6) \\
\hline & Penicillimonavirus etaplasmoparae & Plasmopara viticola lesion associated mononegaambi virus 9 (PvaMV-9) \\
\hline & Penicillimonavirus gammaplasmopara & Plasmopara viticola lesion associated mononegaambi virus 3 (PvaMV-3) \\
\hline & Penicillimonavirus kilnbarnense & Kiln Barn virus (KBV) \\
\hline & Penicillimonavirus zetaplasmoparae & Plasmopara viticola lesion associated mononegaambi virus 7 (PvaMV-7) \\
\hline Plasmopamonavirus & Plasmopamonavirus plasmoparae & Plasmopara viticola lesion associated mononegaambi virus 8 (PvaMV-8) \\
\hline \multirow[t]{2}{*}{ Phyllomonavirus } & Phyllomonavirus gysingense & Gysinge virus (GYSV) \\
\hline & Phyllomonavirus phyllospherae & soybean leaf-associated negative-stranded RNA virus 4 (SLaNSRV-4) \\
\hline Rhizomonavirus & Rhizomonavirus mali & apple virus B (APPv-B) \\
\hline \multirow[t]{16}{*}{ Sclerotimonavirus } & Sclerotimonavirus alphaclarireediae & Sclerotinia homoeocarpa TSA contig 1 (ShTSA-1) \\
\hline & & Sclerotinia homoeocarpa TSA contig 2 (ShTSA-2) \\
\hline & Sclerotimonavirus alphaplasmoparae & Plasmopara viticola lesion associated mymonavirus 1 (PvaMV-1) \\
\hline & Sclerotimonavirus alternariae & Alternaria tenuissima negative-stranded RNA virus 1 (AtNsRV-1) \\
\hline & Sclerotimonavirus betaclarireediae & Sclerotinia homoeocarpa TSA contig 3 (ShTSA-3) \\
\hline & Sclerotimonavirus betaplasmoparae & Plasmopara viticola lesion associated mononega virus 2 (PvaMV-2) \\
\hline & Sclerotimonavirus botrytidis & Botrytis cinerea mymonavirus $1(\mathrm{BcMyV}-1)$ \\
\hline & & Sclerotinia sclerotiorum negative-stranded RNA virus 7 (SsNSRV-7) \\
\hline & Sclerotimonavirus fusarii & $\begin{array}{l}\text { Fusarium graminearum negative-stranded RNA virus } 1 \text { (FgNSRV-1) } \\
\text { soybean leaf-associated negative-stranded RNA virus } 1 \text { (SLaNSRV-1) }\end{array}$ \\
\hline & Sclerotimonavirus illinoisense & soybean leaf-associated negative-stranded RNA virus 2 (SLaNSRV-2) \\
\hline & Sclerotimonavirus penicillii & Penicillium cairnsense negative-stranded RNA virus 1 (PcNsRV-1) \\
\hline & Sclerotimonavirus sclerotiniae & Sclerotinia sclerotiorum negative-stranded RNA virus 1 (SsNSRV-1) \\
\hline & & Sclerotinia sclerotiorum negative-stranded RNA virus 1-A (SsNSRV-1-A) \\
\hline & & Sclerotinia sclerotiorum negative-stranded RNA virus 3 (SsNSRV-3) \\
\hline & & Sclerotinia sclerotiorum negative-stranded RNA virus 3-A (SsNSRV-3-A) \\
\hline & Sclerotimonavirus terrae & H4BulkLitter234 virus \\
\hline
\end{tabular}


Table 3 (continued)

\begin{tabular}{|c|c|c|}
\hline Genus & Species $^{\text {II }}$ & Virus (abbreviation) ${ }^{\&}$ \\
\hline \multicolumn{3}{|l|}{ Family Nyamiviridae } \\
\hline \multirow[t]{3}{*}{ Berhavirus } & Beihai berhavirus & Běihăi rhabdo-like virus 4 (BhRLV-4) \\
\hline & Echinoderm berhavirus & Běihăi rhabdo-like virus 5 (BhRLV-5) \\
\hline & Sipunculid berhavirus & Běihăi rhabdo-like virus 3 (BhRLV-3) \\
\hline \multirow[t]{3}{*}{ Crustavirus } & Beihai crustavirus & Běihǎi rhabdo-like virus 6 (BhRLV-6) \\
\hline & Wenling crustavirus & Wēnlíng crustacean virus 12 (WlCV-12) \\
\hline & Wenzhou crustavirus & Wēnzhōu crab virus 1 (WzCV-1) \\
\hline \multirow[t]{4}{*}{ Formivirus } & Chalybion formivirus & hymenopteran orino-related virus OKIAV87 (HORV-87) \\
\hline & Exsecta formivirus & Formica exsecta virus $4(\mathrm{FeV}-4)$ \\
\hline & Fusca formivirus & Formica fusca virus 1 (FfusV-1) \\
\hline & Gorytes formivirus & hymenopteran orino-related virus OKIAV85 (HORV-85) \\
\hline \multirow[t]{4}{*}{ Nyavirus } & Jacinto nyavirus & San Jacinto virus (SJCV) \\
\hline & Midway nyavirus & Midway virus (MIDWV) \\
\hline & Nyamanini nyavirus & Nyamanini virus (NYMV) \\
\hline & Sierra Nevada nyavirus & Sierra Nevada virus (SNVV) \\
\hline Orinovirus & Orinoco orinovirus & Orinoco virus $(\mathrm{ONCV})$ \\
\hline Socyvirus & Soybean cyst nematode socyvirus & soybean cyst nematode virus $1(\mathrm{SbCNV}-1)$ \\
\hline Tapwovirus & Tapeworm tapwovirus & Wēnzhōu tapeworm virus 1 (WzTWV-1) \\
\hline \multicolumn{3}{|l|}{ Family Paramyxoviridae } \\
\hline \multicolumn{3}{|l|}{ Subfamily Avulavirinae } \\
\hline \multirow[t]{11}{*}{ Metaavulavirus } & Avian metaavulavirus 2 & avian paramyxovirus $2(\mathrm{APMV}-2)$ \\
\hline & Avian metaavulavirus 5 & avian paramyxovirus 5 (APMV-5) \\
\hline & Avian metaavulavirus 6 & avian paramyxovirus 6 (APMV-6) \\
\hline & Avian metaavulavirus 7 & avian paramyxovirus 7 (APMV-7) \\
\hline & Avian metaavulavirus 8 & avian paramyxovirus 8 (APMV-8) \\
\hline & Avian metaavulavirus 10 & avian paramyxovirus 10 (APMV-10) \\
\hline & Avian metaavulavirus 11 & avian paramyxovirus 11 (APMV-11) \\
\hline & Avian metaavulavirus 14 & avian paramyxovirus 14 (APMV-14) \\
\hline & Avian metaavulavirus 15 & avian paramyxovirus 15 (APMV-15) \\
\hline & Avian metaavulavirus 20 & avian paramyxovirus 20 (APMV-20) \\
\hline & Avian metaavulavirus 22 & avian paramyxovirus 22 (APMV-22) \\
\hline \multirow[t]{9}{*}{ Orthoavulavirus } & Avian orthoavulavirus 1 & avian paramyxovirus $1(\mathrm{APMV}-1)^{1}$ \\
\hline & Avian orthoavulavirus 9 & avian paramyxovirus 9 (APMV-9) \\
\hline & Avian orthoavulavirus 12 & avian paramyxovirus 12 (APMV-12) \\
\hline & Avian orthoavulavirus 13 & avian paramyxovirus 13 (APMV-13) \\
\hline & Avian orthoavulavirus 16 & avian paramyxovirus 16 (APMV-16) \\
\hline & Avian orthoavulavirus 17 & Antarctic penguin virus A (APV-A) \\
\hline & Avian orthoavulavirus 18 & Antarctic penguin virus B (APV-B) \\
\hline & Avian orthoavulavirus 19 & Antarctic penguin virus $\mathrm{C}(\mathrm{APV}-\mathrm{C})$ \\
\hline & Avian orthoavulavirus 21 & avian paramyxovirus 21 (APMV-21) \\
\hline \multirow[t]{2}{*}{ Paraavulavirus } & Avian paraavulavirus 3 & avian paramyxovirus 3 (APMV-3) \\
\hline & Avian paraavulavirus 4 & avian paramyxovirus 4 (APMV-4) \\
\hline \multicolumn{3}{|c|}{ Subfamily Metaparamyxovirinae } \\
\hline Synodonvirus & Synodus synodonvirus & Wēnlǐng triplecross lizardfish paramyxovirus (WTLPV) \\
\hline \multicolumn{3}{|c|}{ Subfamily Orthoparamyxovirinae } \\
\hline \multirow[t]{2}{*}{ Aquaparamyxovirus } & Oncorhynchus aquaparamyxovirus & Pacific salmon paramyxovirus (PSPV) \\
\hline & Salmo aquaparamyxovirus & Atlantic salmon paramyxovirus (AsaPV) \\
\hline Ferlavirus & Reptilian ferlavirus & fer-de-lance virus (FDLV) \\
\hline \multirow[t]{5}{*}{ Henipavirus } & Cedar henipavirus & Cedar virus (CedV) \\
\hline & Ghanaian bat henipavirus & Ghana virus $(\mathrm{GhV})$ \\
\hline & Hendra henipavirus & Hendra virus $(\mathrm{HeV})$ \\
\hline & Mojiang henipavirus & Mòjiāng virus (MojV) \\
\hline & Nipah henipavirus & Nipah virus (NiV) \\
\hline
\end{tabular}


Table 3 (continued)

\begin{tabular}{|c|c|c|}
\hline Genus & Species ${ }^{\mathrm{I}}$ & Virus (abbreviation) ${ }^{\&}$ \\
\hline \multirow[t]{7}{*}{ Jeilongvirus } & Beilong jeilongvirus & Beilong virus (BeiV) \\
\hline & Jun jeilongvirus & $\mathrm{J}$ virus $(\mathrm{JV})$ \\
\hline & Lophuromys jeilongvirus 1 & Mount Mabu Lophuromys virus 1 (MMLV-1) \\
\hline & Lophuromys jeilongvirus 2 & Mount Mabu Lophuromys virus 2 (MMLV-2) \\
\hline & Miniopteran jeilongvirus & Shaan virus $(\mathrm{ShaV})$ \\
\hline & Myodes jeilongvirus & Pohorje Myodes paramyxovirus 1 (PMPV-1) \\
\hline & Tailam jeilongvirus & Tailam virus (TaiV) \\
\hline \multirow[t]{7}{*}{ Morbillivirus } & Canine morbillivirus & canine distemper virus (CDV) \\
\hline & Cetacean morbillivirus & cetacean morbillivirus (CeMV) \\
\hline & Feline morbillivirus & feline morbillivirus (FeMV) \\
\hline & Measles morbillivirus & measles virus $(\mathrm{MeV})$ \\
\hline & Phocine morbillivirus & phocine distemper virus (PDV) \\
\hline & Rinderpest morbillivirus & rinderpest virus (RPV) \\
\hline & Small ruminant morbillivirus & peste-des-petits-ruminants virus (PPRV) \\
\hline \multirow[t]{4}{*}{ Narmovirus } & Mossman narmovirus & Mossman virus (MossV) \\
\hline & Myodes narmovirus & bank vole virus $1(\mathrm{BaV}-1)$ \\
\hline & Nariva narmovirus & Nariva virus (NarV) \\
\hline & Tupaia narmovirus & Tupaia paramyxovirus (TupV) \\
\hline \multirow[t]{7}{*}{ Respirovirus } & Bovine respirovirus 3 & bovine parainfluenza virus 3 (BPIV-3) \\
\hline & Caprine respirovirus 3 & caprine parainfluenzavirus 3 (CPIV-3) \\
\hline & Human respirovirus 1 & human parainfluenza virus 1 (HPIV-1) \\
\hline & Human respirovirus 3 & human parainfluenza virus 3 (HPIV-3) \\
\hline & Murine respirovirus & Sendai virus $(\mathrm{SeV})$ \\
\hline & Porcine respirovirus 1 & porcine parainfluenza virus 1 (PPIV-1) \\
\hline & Squirrel respirovirus & giant squirrel virus $(\mathrm{GSqV})$ \\
\hline Salemvirus & Salem salemvirus & Salem virus (SalV) \\
\hline \multicolumn{3}{|c|}{ Subfamily Rubulavirinae } \\
\hline \multirow[t]{9}{*}{ Orthorubulavirus } & Human orthorubulavirus 2 & human parainfluenza virus 2 (HPIV-2) \\
\hline & Human orthorubulavirus 4 & human parainfluenza virus 4a (HPIV-4a) \\
\hline & & human parainfluenza virus 4b (HPIV-4b) \\
\hline & Mammalian orthorubulavirus 5 & parainfluenza virus 5 (PIV-5) \\
\hline & Mammalian orthorubulavirus 6 & Alston virus (AlsV) \\
\hline & Mapuera orthorubulavirus & Mapuera virus (MapV) \\
\hline & Mumps orthorubulavirus & mumps virus $(\mathrm{MuV})$ \\
\hline & Porcine orthorubulavirus & La Piedad Michoacán Mexico virus (LPMV) \\
\hline & Simian orthorubulavirus & simian virus $41(\mathrm{SV}-41)$ \\
\hline \multirow[t]{10}{*}{ Pararubulavirus } & Achimota pararubulavirus 1 & Achimota virus 1 (AchPV-1) \\
\hline & Achimota pararubulavirus 2 & Achimota virus 2 (AchPV-2) \\
\hline & Hervey pararubulavirus & Hervey virus (HerV) \\
\hline & Menangle pararubulavirus & Menangle virus (MenPV) \\
\hline & Sosuga pararubulavirus & Sosuga virus (SOSV) \\
\hline & Teviot pararubulavirus & Teviot virus (TevPV) \\
\hline & Tioman pararubulavirus & Tioman virus (TioPV) \\
\hline & Tuhoko pararubulavirus 1 & Tuhoko virus 1 (ThkPV-1) \\
\hline & Tuhoko pararubulavirus 2 & Tuhoko virus 2 (ThkPV-2) \\
\hline & Tuhoko pararubulavirus 3 & Tuhoko virus 3 (ThkPV-3) \\
\hline \multicolumn{3}{|c|}{ Unassigned (to subfamilies) } \\
\hline Cynoglossusvirus & Cynoglossus cynoglossusvirus & Wēnlǐng tonguesole paramyxovirus (WTSPV) \\
\hline Hoplichthysvirus & Hoplichthys hoplichthysvirus & Wēnlǐng hoplichthys paramyxovirus (WHPV) \\
\hline Scoliodonvirus & Scoliodon scoliodonvirus & Wēnzhōu pacific spadenose shark paramyxovirus (WPSSPV) \\
\hline \multicolumn{3}{|l|}{ Family Pneumoviridae } \\
\hline \multirow[t]{2}{*}{ Metapneumovirus } & Avian metapneumovirus & avian metapneumovirus (AMPV) \\
\hline & Human metapneumovirus & human metapneumovirus (HMPV) \\
\hline
\end{tabular}


Table 3 (continued)

\begin{tabular}{|c|c|c|}
\hline Genus & Species ${ }^{\pi}$ & Virus (abbreviation) ${ }^{\&}$ \\
\hline \multirow[t]{3}{*}{ Orthopneumovirus } & Bovine orthopneumovirus & bovine respiratory syncytial virus (BRSV) \\
\hline & Human orthopneumovirus & human respiratory syncytial virus (HRSV) \\
\hline & Murine orthopneumovirus & murine pneumonia virus (MPV) \\
\hline \multicolumn{3}{|c|}{ Family Rhabdoviridae } \\
\hline \multicolumn{3}{|c|}{ Subfamily Alpharhabdovirinae } \\
\hline \multirow[t]{6}{*}{ Almendravirus } & Arboretum almendravirus & Arboretum virus (ABTV) \\
\hline & Balsa almendravirus & Balsa virus (BALV) \\
\hline & Coot Bay almendravirus & Coot Bay virus (CBV) \\
\hline & Menghai almendravirus & Menghai virus (MRV) \\
\hline & Puerto Almendras almendravirus & Puerto Almendras virus (PTAMV) \\
\hline & Rio Chico almendravirus & Rio Chico virus (RCHV) \\
\hline \multirow[t]{2}{*}{ Alphanemrhavirus } & Xingshan alphanemrhavirus & Xingshan nematode virus 4 (XsNV-4) \\
\hline & Xinzhou alphanemrhavirus & Xinzhou nematode virus 4 (XzNV-4) \\
\hline \multirow[t]{2}{*}{ Alphapaprhavirus } & Hubei alphapaprhavirus & Hubei lepidoptera virus 2 (HbLV-2) \\
\hline & Pararge alphapaprhavirus & Pararge aegeria rhabdovirus (PAeRV) \\
\hline \multirow[t]{3}{*}{ Alpharicinrhavirus } & Blanchseco alpharicinrhavirus & Blanchseco virus (BCOV) \\
\hline & Bole alpharicinrhavirus & Bole tick virus 2 (BITV-2) \\
\hline & Wuhan alpharicinrhavirus & Wuhan tick virus 1 (WhTV-1) \\
\hline \multirow[t]{4}{*}{ Arurhavirus } & Aruac arurhavirus & Aruac virus (ARUV) \\
\hline & Inhangapi arurhavirus & Inhangapi virus (INHV) \\
\hline & Santabarbara arurhavirus & Santa Barbara virus (SBAV) \\
\hline & Xiburema arurhavirus & Xiburema virus (XIBV) \\
\hline \multirow[t]{3}{*}{ Barhavirus } & Bahia barhavirus & Bahia Grande virus (BGV) \\
\hline & & Harlingen virus (HARV) \\
\hline & Muir barhavirus & Muir Springs virus (MSV) \\
\hline \multirow[t]{3}{*}{ Caligrhavirus } & Caligus caligrhavirus & Caligus rogercresseyi rhabdovirus (CRogRV) \\
\hline & Lepeophtheirus caligrhavirus & Lepeophtheirus salmonis rhabdovirus 127 (LSalRV-127) \\
\hline & Salmonlouse caligrhavirus & Lepeophtheirus salmonis rhabdovirus 9 (LSalRV-9) \\
\hline \multirow[t]{4}{*}{ Curiovirus } & Curionopolis curiovirus & Curionopolis virus (CURV) \\
\hline & Iriri curiovirus & Iriri virus (IRIRV) \\
\hline & Itacaiunas curiovirus & Itacaiunas virus (ITAV) \\
\hline & Rochambeau curiovirus & Rochambeau virus (RBUV) \\
\hline \multirow[t]{12}{*}{ Ephemerovirus } & Adelaide River ephemerovirus & Adelaide River virus (ARV) \\
\hline & Berrimah ephemerovirus & Berrimah virus (BRMV) \\
\hline & Bovine fever ephemerovirus & bovine ephemeral fever virus (BEFV) \\
\hline & Hayes ephemerovirus & Hayes Yard virus (HYV) \\
\hline & Kent ephemerovirus & New Kent County virus (NKCV) \\
\hline & Kimberley ephemerovirus & Kimberley virus (KIMV) \\
\hline & & Malakal virus (MALV) \\
\hline & Koolpinyah ephemerovirus & Koolpinyah virus (KOOLV) \\
\hline & Kotonkan ephemerovirus & kotonkan virus (KOTV) \\
\hline & Obodhiang ephemerovirus & Obodhiang virus (OBOV) \\
\hline & Puchong ephemerovirus & Puchong virus (PUCV) \\
\hline & Yata ephemerovirus & Yata virus (YATV) \\
\hline \multirow[t]{11}{*}{ Hapavirus } & Flanders hapavirus & Flanders virus (FLAV) \\
\hline & Gray Lodge hapavirus & Gray Lodge virus (GLOV) \\
\hline & Hart Park hapavirus & Hart Park virus (HPV) \\
\hline & Holmes hapavirus & Holmes Jungle virus (HOJV) \\
\hline & Joinjakaka hapavirus & Joinjakaka virus (JOIV) \\
\hline & Kamese hapavirus & Kamese virus (KAMV) \\
\hline & La Joya hapavirus & La Joya virus (LJV) \\
\hline & Landjia hapavirus & Landjia virus (LANV = LJAV) \\
\hline & Manitoba hapavirus & Manitoba virus $(\mathrm{MANV}=\mathrm{MNTBV})$ \\
\hline & Marco hapavirus & Marco virus (MCOV) \\
\hline & Mosqueiro hapavirus & Mosqueiro virus (MQOV) \\
\hline
\end{tabular}


Table 3 (continued)

\begin{tabular}{|c|c|c|}
\hline Genus & Species ${ }^{\text {II }}$ & Virus (abbreviation) ${ }^{\&}$ \\
\hline & Mossuril hapavirus & Mossuril virus (MOSV) \\
\hline & Ngaingan hapavirus & Ngaingan virus (NGAV) \\
\hline & Ord River hapavirus & Ord River virus (ORV) \\
\hline & Parry Creek hapavirus & Parry Creek virus (PCV) \\
\hline & Wongabel hapavirus & Wongabel virus (WONV) \\
\hline \multirow[t]{17}{*}{ Ledantevirus } & Barur ledantevirus & Barur virus (BARV) \\
\hline & Bughendera ledantevirus & Bughendera virus (BUGV) \\
\hline & Fikirini ledantevirus & Fikirini virus (FKRV) \\
\hline & Fukuoka ledantevirus & Fukuoka virus (FUKV) \\
\hline & Kanyawara ledantevirus & Kanyawara virus (KYAV) \\
\hline & Kern Canyon ledantevirus & Kern Canyon virus (KCV) \\
\hline & Keuraliba ledantevirus & Keuraliba virus (KEUV) \\
\hline & Kolente ledantevirus & Kolente virus (KOLEV) \\
\hline & Kumasi ledantevirus & Kumasi rhabdovirus (KRV) \\
\hline & Le Dantec ledantevirus & Le Dantec virus (LDV) \\
\hline & Mount Elgon bat ledantevirus & Mount Elgon bat virus (MEBV) \\
\hline & Nishimuro ledantevirus & Nishimuro virus (NISV) \\
\hline & Nkolbisson ledantevirus & Nkolbisson virus (NKOV) \\
\hline & Oita ledantevirus & Oita virus (OITAV) \\
\hline & Vaprio ledantevirus & Vaprio virus (VAPV) \\
\hline & Wuhan ledantevirus & Wuhan louse fly virus 5 (WLFV-5) \\
\hline & Yongjia ledantevirus & Yongjia tick virus 2 (YTV-2) \\
\hline \multirow[t]{2}{*}{ Lostrhavirus } & Hyalomma lostrhavirus & Xinjiang tick rhabdovirus (XjTRV) \\
\hline & Lonestar lostrhavirus & lone star tick rhabdovirus (LITRV) \\
\hline \multirow[t]{17}{*}{ Lyssavirus } & Aravan lyssavirus & Aravan virus (ARAV) \\
\hline & Australian bat lyssavirus & Australian bat lyssavirus (ABLV) \\
\hline & Bokeloh bat lyssavirus & Bokeloh bat lyssavirus (BBLV) \\
\hline & Duvenhage lyssavirus & Duvenhage virus (DUVV) \\
\hline & European bat 1 lyssavirus & European bat lyssavirus 1 (EBLV-1) \\
\hline & European bat 2 lyssavirus & European bat lyssavirus 2 (EBLV-2) \\
\hline & Gannoruwa bat lyssavirus & Gannoruwa bat lyssavirus (GBLV) \\
\hline & Ikoma lyssavirus & Ikoma lyssavirus (IKOV) \\
\hline & Irkut lyssavirus & Irkut virus (IRKV) \\
\hline & Khujand lyssavirus & Khujand virus (KHUV) \\
\hline & Lagos bat lyssavirus & Lagos bat virus (LBV) \\
\hline & Lleida bat lyssavirus & Lleida bat lyssavirus (LLEBV) \\
\hline & Mokola lyssavirus & Mokola virus (MOKV) \\
\hline & Rabies lyssavirus & rabies virus (RABV) \\
\hline & Shimoni bat lyssavirus & Shimoni bat virus (SHIBV) \\
\hline & Taiwan bat lyssavirus & Taiwan bat lyssavirus (TWBLV) \\
\hline & West Caucasian bat lyssavirus & West Caucasian bat virus (WCBV) \\
\hline \multirow[t]{2}{*}{ Merhavirus } & Merida merhavirus & Merida virus (MERDV) \\
\hline & Tritaeniorhynchus merhavirus & Culex tritaeniorhynchus rhabdovirus (CTRV) \\
\hline Mousrhavirus & Moussa mousrhavirus & Moussa virus (MOUV) \\
\hline \multirow[t]{8}{*}{ Ohlsrhavirus } & Angeles ohlsrhavirus & Culex rhabdo-like virus Los Angeles (CRLVLA) \\
\hline & Culex ohlsrharhavirus & Culex rhabdo-like virus (CRLV) \\
\hline & Lobeira ohlsrhavirus & Lobeira virus (LOBV) \\
\hline & Northcreek ohlsrhavirus & North Creek virus (NORCV) \\
\hline & Ohlsdorf ohlsrhavirus & Ohlsdorf virus (OHLDV) \\
\hline & Pseudovishnui ohlsrhavirus & Culex pseudovishnui rhabdo-like virus (CpRLV) \\
\hline & Riverside ohlsrhavirus & Riverside virus (RISV) \\
\hline & Tongilchon ohlsrhavirus & Tongilchon virus 1 (TCHV-1) \\
\hline \multirow[t]{3}{*}{ Perhabdovirus } & Anguillid perhabdovirus & eel virus European X (EVEX) \\
\hline & Perch perhabdovirus & perch rhabdovirus (PRV) \\
\hline & Sea trout perhabdovirus & lake trout rhabdovirus (LTRV) \\
\hline
\end{tabular}


Table 3 (continued)

\begin{tabular}{|c|c|c|}
\hline Genus & Species ${ }^{\mathbb{I}}$ & Virus (abbreviation) ${ }^{\&}$ \\
\hline \multirow[t]{4}{*}{ Sawgrhavirus } & Connecticut sawgrhavirus & Connecticut virus (CNTV) \\
\hline & Island sawgrhavirus & Long Island tick rhabdovirus (LITRV) \\
\hline & Minto sawgrhavirus & New Minto virus (NMV) \\
\hline & Sawgrass sawgrhavirus & Sawgrass virus (SAWV) \\
\hline \multirow[t]{17}{*}{ Sigmavirus } & Capitata sigmavirus & Ceratitis capitata sigmavirus (CCapSV) \\
\hline & Domestica sigmavirus & Wuhan fly virus 2 (WhFV-2) \\
\hline & Drosophila affinis sigmavirus & Drosophila affinis sigmavirus (DAffSV) \\
\hline & Drosophila ananassae sigmavirus & Drosophila ananassae sigmavirus (DAnaSV) \\
\hline & Drosophila immigrans sigmavirus & Drosophila immigrans sigmavirus (DImmSV) \\
\hline & Drosophila melanogaster sigmavirus & Drosophila melanogaster sigmavirus (DMelSV) \\
\hline & Drosophila obscura sigmavirus & Drosophila obscura sigmavirus (DObsSV) \\
\hline & Drosophila tristis sigmavirus & Drosophila tristis sigmavirus (DTriSV) \\
\hline & Hippoboscid sigmavirus & Wuhan louse fly virus 9 (WhLFV-9) \\
\hline & Hubei sigmavirus & Hubei diptera virus 9 (HbDV-9) \\
\hline & Lousefly sigmavirus & Wuhan louse fly virus 10 (WhLFV-10) \\
\hline & Muscina stabulans sigmavirus & Muscina stabulans sigmavirus (MStaSV) \\
\hline & Myga sigmavirus & Hubei diptera virus 10 (HbDV-10) \\
\hline & Shayang sigmavirus & Shayang fly virus 2 (SyFV-1) \\
\hline & Sturtevanti sigmavirus & Drosophila sturtevanti sigmavirus (DStuSV) \\
\hline & Wuhan sigmavirus & Wuhan house fly virus 1 (WhHFV-1) \\
\hline & Ying sigmavirus & Hubei dimarhabdovirus 1 (HbDRV-1) \\
\hline \multirow[t]{4}{*}{ Sprivivirus } & Carp sprivivirus & spring viremia of carp virus (SVCV) \\
\hline & Pike fry sprivivirus & grass carp rhabdovirus (GrCRV) \\
\hline & & pike fry rhabdovirus (PFRV) \\
\hline & & tench rhabdovirus (TenRV) \\
\hline \multirow[t]{8}{*}{ Sripuvirus } & Almpiwar sripuvirus & Almpiwar virus (ALMV) \\
\hline & Chaco sripuvirus & Chaco virus (CHOV) \\
\hline & Charleville sripuvirus & Charleville virus (CHVV) \\
\hline & Cuiaba sripuvirus & Cuiaba virus (CUIV) \\
\hline & Hainan sripuvirus & Hainan black-spectacled toad rhabdovirus (HnBSTRV) \\
\hline & Niakha sripuvirus & Niakha virus (NIAV) \\
\hline & Sena Madureira sripuvirus & Sena Madureira virus (SMV) \\
\hline & Sripur sripuvirus & Sripur virus (SRIV) \\
\hline \multirow[t]{7}{*}{ Sunrhavirus } & Dillard sunrhavirus & Dillard's Draw virus (DDRV) \\
\hline & Garba sunrhavirus & Garba virus (GARV) \\
\hline & Harrison sunrhavirus & Harrison Dam virus (HARDV) \\
\hline & Kwatta sunrhavirus & Kwatta virus (KWAV) \\
\hline & Oakvale sunrhavirus & Oak Vale virus (OVV) \\
\hline & Sunguru sunrhavirus & Sunguru virus (SUNV) \\
\hline & Walkabout sunrhavirus & Walkabout Creek virus (WACV) \\
\hline \multirow[t]{8}{*}{ Tibrovirus } & Bas Congo tibrovirus & Bas-Congo virus (BASV) \\
\hline & Beatrice Hill tibrovirus & Beatrice Hill virus (BHV) \\
\hline & Coastal Plains tibrovirus & Coastal Plains virus (CPV) \\
\hline & Ekpoma 1 tibrovirus & Ekpoma virus 1 (EKV-1) \\
\hline & Ekpoma 2 tibrovirus & Ekpoma virus $2(\mathrm{EKV}-2)$ \\
\hline & Sweetwater Branch tibrovirus & Sweetwater Branch virus (SWBV) \\
\hline & Tibrogargan tibrovirus & Bivens Arm virus (BAV) \\
\hline & & Tibrogargan virus (TIBV) \\
\hline \multirow[t]{3}{*}{ Tupavirus } & Durham tupavirus & Durham virus (DURV) \\
\hline & Klamath tupavirus & Klamath virus (KLAV) \\
\hline & Tupaia tupavirus & tupaia rhabdovirus (TUPV) \\
\hline \multirow[t]{2}{*}{ Vesiculovirus } & Alagoas vesiculovirus & vesicular stomatitis Alagoas virus (VSAV) \\
\hline & Carajas vesiculovirus & Carajás virus (CJSV) \\
\hline
\end{tabular}


Table 3 (continued)

\begin{tabular}{|c|c|c|}
\hline \multirow[t]{2}{*}{ Genus } & \multirow{2}{*}{$\frac{\text { Species }^{\mathrm{II}}}{\text { Chandipura vesiculovirus }}$} & \multirow{2}{*}{$\begin{array}{l}\text { Virus (abbreviation) }^{\&} \\
\text { Chandipura virus (CHPV) }\end{array}$} \\
\hline & & \\
\hline & Cocal vesiculovirus & Cocal virus $(\mathrm{COCV})$ \\
\hline & Eptesicus vesiculovirus & American bat vesiculovirus (ABVV) \\
\hline & Indiana vesiculovirus & vesicular stomatitis Indiana virus (VSIV) \\
\hline & Isfahan vesiculovirus & Isfahan virus (ISFV) \\
\hline & Jurona vesiculovirus & Jurona virus (JURV) \\
\hline & Malpais Spring vesiculovirus & Malpais Spring virus (MSPV) \\
\hline & Maraba vesiculovirus & Maraba virus (MARAV) \\
\hline & Morreton vesiculovirus & Morreton virus (MORV) \\
\hline & New Jersey vesiculovirus & vesicular stomatitis New Jersey virus (VSNJV) \\
\hline & Perinet vesiculovirus & Perinet virus (PERV) \\
\hline & Piry vesiculovirus & Piry virus (PIRYV) \\
\hline & Radi vesiculovirus & Radi virus (RADV) \\
\hline & Rhinolophus vesiculovirus & Jinghong bat virus (JhBV) \\
\hline & Yug Bogdanovac vesiculovirus & Yug Bogdanovac virus (YBV) \\
\hline Zarhavirus & Zahedan zarhavirus & Zahedan rhabdovirus (ZARV) \\
\hline \multicolumn{3}{|l|}{ Subfamily Betarhabdovirinae } \\
\hline \multirow[t]{12}{*}{ Alphanucleorhabdovirus } & Constricta yellow dwarf alphanucleorhabdovirus & constricta yellow dwarf virus (CYDV) \\
\hline & Eggplant mottled dwarf alphanucleorhabdovirus & eggplant mottled dwarf virus (EMDV) \\
\hline & Maize Iranian mosaic alphanucleorhabdovirus & maize Iranian mosaic virus (MIMV) \\
\hline & Maize mosaic alphanucleorhabdovirus & maize mosaic virus (MMV) \\
\hline & Morogoro maize-associated alphanucleorhabdovirus & Morogoro maize-associated virus (MMaV) \\
\hline & Peach alphanucleorhabdovirus & peach virus $1(\mathrm{PeV} 1)$ \\
\hline & Physostegia chlorotic mottle alphanucleorhabdovirus & Physostegia chlorotic mottle virus (PhCMoV) \\
\hline & Potato yellow dwarf alphanucleorhabdovirus & potato yellow dwarf virus (PYDV) \\
\hline & Rice yellow stunt alphanucleorhabdovirus & rice yellow stunt virus (RYSV) \\
\hline & & rice transitory yellowing virus (RTYV) \\
\hline & Taro vein chlorosis alphanucleorhabdovirus & taro vein chlorosis virus (TaVCV) \\
\hline & Wheat yellow striate alphanucleorhabdovirus & wheat yellow striate virus (WYSV) \\
\hline \multirow[t]{9}{*}{ Betanucleorhabdovirus } & Alfalfa betanucleorhabdovirus & alfalfa-associated nucleorhabdovirus (AaNV) \\
\hline & Apple betanucleorhabdovirus & apple rootstock virus A (ApRVA) \\
\hline & Blackcurrant betanucleorhabdovirus & blackcurrant-associated rhabdovirus (BCaRV) \\
\hline & Cardamom betanucleorhabdovirus & cardamom vein clearing virus (CdVCV) \\
\hline & Datura yellow vein betanucleorhabdovirus & datura yellow vein virus (DYVV) \\
\hline & Pepper betanucleorhabdovirus & Zhuye pepper nucleorhabdovirus (ZPNRV) \\
\hline & Sonchus yellow net betanucleorhabdovirus & Sonchus yellow net virus (SYNV) \\
\hline & Sowthistle yellow vein betanucleorhabdovirus & sowthistle yellow vein virus (SYVV) \\
\hline & Trefoil betanucleorhabdovirus & birds-foot trefoil-associated virus (BFTV) \\
\hline \multirow[t]{14}{*}{ Cytorhabdovirus } & Alfalfa dwarf cytorhabdovirus & alfalfa dwarf virus (ADV) \\
\hline & Barley yellow striate mosaic cytorhabdovirus & barley yellow striate mosaic virus (BYSMV) \\
\hline & Broccoli necrotic yellows cytorhabdovirus & broccoli necrotic yellows virus (BNYV) \\
\hline & Cabbage cytorhabdovirus & cabbage cytorhabdovirus 1 (CCyV-1) \\
\hline & $\begin{array}{l}\text { Colocasia bobone disease-associated cytorhabdovi- } \\
\text { rus }\end{array}$ & Colocasia bobone disease-associated virus $(\mathrm{CBDaV})$ \\
\hline & Festuca leaf streak cytorhabdovirus & Festuca leaf streak virus (FLSV) \\
\hline & Lettuce necrotic yellows cytorhabdovirus & lettuce necrotic yellows virus (LNYV) \\
\hline & Lettuce yellow mottle cytorhabdovirus & lettuce yellow mottle virus (LYMoV) \\
\hline & Maize-associated cytorhabdovirus & maize-associated cytorhabdovirus (MaCV) \\
\hline & Maize yellow striate cytorhabdovirus & maize yellow striate virus (MYSV) \\
\hline & Northern cereal mosaic cytorhabdovirus & northern cereal mosaic virus (NCMV) \\
\hline & Papaya cytorhabdovirus & papaya virus $\mathrm{E}(\mathrm{PpVE})$ \\
\hline & Persimmon cytorhabdovirus & persimmon virus A (PeVA) \\
\hline & Raspberry vein chlorosis cytorhabdovirus & raspberry vein chlorosis virus (RVCV) \\
\hline
\end{tabular}


Table 3 (continued)

\begin{tabular}{|c|c|c|}
\hline \multirow[t]{2}{*}{ Genus } & \multirow{2}{*}{$\begin{array}{l}\text { Species }^{\text {II }} \\
\text { Rice stripe mosaic cytorhabdovirus }\end{array}$} & \multirow{2}{*}{$\begin{array}{l}\text { Virus (abbreviation) }^{\&} \\
\text { rice stripe mosaic virus (RSMV) }\end{array}$} \\
\hline & & \\
\hline & Sonchus cytorhabdovirus 1 & Sonchus virus (SonV) \\
\hline & Strawberry crinkle cytorhabdovirus & strawberry crinkle virus (SCV) \\
\hline & Strawberry cytorhabdovirus 1 & strawberry-associated virus $1(\mathrm{SaV}-1)$ \\
\hline & & strawberry virus $1(\mathrm{StrV}-1)$ \\
\hline & Trichosanthes cytorhabdovirus & Trichosanthes associated rhabdovirus 1 (TrARV1) \\
\hline & Trifolium pratense cytorhabdovirus $A$ & Trifolium pratense virus A (TpVA) \\
\hline & Trifolium pratense cytorhabdovirus $B$ & Trifolium pratense virus B (TpVB) \\
\hline & Tomato yellow mottle-associated cytorhabdovirus & tomato yellow mottle-associated virus (TYMaV) \\
\hline & Wheat American striate mosaic cytorhabdovirus & wheat American striate mosaic virus (WASMV) \\
\hline & Wuhan 4 insect cytorhabdovirus & Wuhan insect virus 4 (WuIV-4) \\
\hline & Wuhan 5 insect cytorhabdovirus & Wuhan insect virus 5 (WuIV-5) \\
\hline & Wuhan 6 insect cytorhabdovirus & Wuhan insect virus 6 (WuIV-6) \\
\hline & Yerba mate chlorosis-associated cytorhabdovirus & yerba mate chlorosis-associated virus ( $\mathrm{YmCaV})$ \\
\hline & Yerba mate cytorhabdovirus & yerba mate virus A (YmVA) \\
\hline \multirow[t]{5}{*}{ Dichorhavirus } & Citrus chlorotic spot dichorhavirus & citrus chlorotic spot virus (CiCSV) \\
\hline & Citrus leprosis $N$ dichorhavirus & citrus leprosis virus $\mathrm{N}$ (CiLV-N) \\
\hline & Clerodendrum chlorotic spot dichorhavirus & Clerodendrum chlorotic spot virus (ClCSV) \\
\hline & Coffee ringspot dichorhavirus & coffee ringspot virus (CoRSV) \\
\hline & Orchid fleck dichorhavirus & orchid fleck virus (OFV) \\
\hline Gammanucleorhabdovirus & Maize fine streak gammanucleorhabdovirus & maize fine streak virus (MFSV) \\
\hline \multirow[t]{3}{*}{ Varicosavirus } & Alopecurus varicosavirus & Alopecurus myosuroides varicosavirus 1 (AMVV-1) \\
\hline & Lettuce big-vein associated varicosavirus & lettuce big-vein associated virus (LBVaV) \\
\hline & Trifolium varicosavirus & red clover associated varicosavirus ( $\mathrm{RCaVV})$ \\
\hline \multicolumn{3}{|c|}{ Subfamily Gammarhabdovirinae } \\
\hline \multirow[t]{4}{*}{ Novirhabdovirus } & Hirame novirhabdovirus & hirame rhabdovirus (HIRRV = HIRV) \\
\hline & Piscine novirhabdovirus & viral hemorrhagic septicemia virus (VHSV) \\
\hline & Salmonid novirhabdovirus & infectious hematopoietic necrosis virus (IHNV) \\
\hline & Snakehead novirhabdovirus & snakehead rhabdovirus (SHRV) \\
\hline \multicolumn{3}{|l|}{ Unassigned (to subfamilies) } \\
\hline \multirow[t]{2}{*}{ Alphacrustrhavirus } & Wenling alphacrustrhavirus & Wenling crustacean virus $10(\mathrm{WlCV}-10)$ \\
\hline & Zhejiang alphacrustrhavirus & Wenling crustacean virus $10(\mathrm{WlCV}-11)$ \\
\hline \multirow[t]{2}{*}{ Alphadrosrhavirus } & Hubei alphadrosrhavirus & Wuhan house fly virus 2 (WhHFV-2) \\
\hline & Shayang alphadrosrhavirus & Shayang fly virus 3 (SyFV-3) \\
\hline \multirow[t]{4}{*}{ Alphahymrhavirus } & Cinereus alphahymrhavirus & hymenopteran rhabdo-related virus 38 (HyRRV-38) \\
\hline & Hirtum alphahymrhavirus & hymenopteran rhabdo-related virus 109 (HyRRV-109) \\
\hline & Neglectus alphahymrhavirus & Lasius neglectus virus 2 (LnegV-2) \\
\hline & Radians alphahymrhavirus & hymenopteran rhabdo-related virus 46 (HyRRV-46) \\
\hline \multirow[t]{2}{*}{ Betahymrhavirus } & Austriaca betahymrhavirus & hymenopteran rhabdo-related virus 23 (HyRRV-23) \\
\hline & Heterodontonyx betahymrhavirus & hymenopteran rhabdo-related virus 24 (HyRRV-24) \\
\hline \multirow[t]{2}{*}{ Betanemrhavirus } & Hubei betanemrhavirus & Hubei rhabdo-like virus 9 (HbRLV-9) \\
\hline & Shayang betanemrhavirus & Shayang ascaridia galli virus 2 (SyAGV-2) \\
\hline \multirow[t]{2}{*}{ Betapaprhavirus } & Frugiperda betapaprhavirus & Spodoptera frugiperda rhabdovirus (SfruRV) \\
\hline & Sylvina betapaprhavirus & lepidopteran rhabdo-related virus 34 (LeRRV-34) \\
\hline \multirow[t]{2}{*}{ Betaricinrhavirus } & Chimay betaricinrhavirus & Chimay rhabdovirus (CRV) \\
\hline & Scapularis betaricinrhavirus & blacklegged tick rhabdovirus 1 (BLTRV-1) \\
\hline \multicolumn{3}{|l|}{ Family Sunviridae } \\
\hline Sunshinevirus & Reptile sunshinevirus 1 & Sunshine Coast virus (SunCV) \\
\hline Family Xinmoviridae & & \\
\hline
\end{tabular}


Table 3 (continued)

\begin{tabular}{lll}
\hline Genus & Species $^{\mathbb{l}}$ & Virus (abbreviation) $^{\&}$ \\
\hline Anphevirus & Bolahun anphevirus & Bolahun virus (BLHV) \\
& Gambie virus (GAMV) \\
& Dipteran anphevirus & Húběi diptera virus 11 (HbDV-11) \\
Drosophilid anphevirus & Drosophila unispina virus 1 (DuniV-1) \\
Odonate anphevirus & Húběi rhabdo-like virus 7 (HbRLV-7) \\
Orthopteran anphevirus & Húběi orthoptera virus 5 (HbOV-5) \\
& Shuangao anphevirus & Shuāngào fly virus 2 (SgFV-2) \\
& Xincheng anphevirus & Xīnchéng mosquito virus (XcMV) \\
\hline
\end{tabular}

Note that viruses are real objects that are assigned to concepts that are called taxa. Species, genera, subfamilies, families, and orders are taxa.

${ }^{1}$ Includes: Newcastle disease virus (NDV)

"ITaxon names are always italicized and always begin with a capital letter

${ }^{\&}$ Virus names are not italicized and are not capitalized, except if the name or a name component is a proper noun. This column lists the virus names with their correct (lack of) capitalization. Lists of viruses within a given species are provisional at this point and will likely be amended in the near future

Table $4 I C T V$-accepted taxonomy of the order Muvirales (Negarnaviricota: Haploviricotina: Chunqiuviricetes) as of March 2021

Table 5 ICTV-accepted taxonomy of the order Serpentovirales (Negarnaviricota: Haploviricotina: Milneviricetes) as of March 2021

\begin{tabular}{lll}
\hline Genus & Species $^{\mathbb{I I}}$ & ${\text { Virus (abbreviation) })^{\&}}^{\text {Family Qinviridae }}$ \\
Yingvirus & Beihai yingvirus & \\
& Charybdis yingvirus & Běihǎi sesarmid crab virus 4 (BhSCV-4) \\
& Wubei yingvirus & Húběi qínvirus-like virus 1 (HbQLV-1) \\
& Sanxia yingvirus & Sānxiá qínvirus-like virus 1 (SxQLV-1) \\
& Shahe yingvirus & Shāhé qínvirus-like virus 1 (ShQLV-1) \\
& Wenzhou yingvirus & Wēnzhōu qínvirus-like virus 1 (WzQLV-1) \\
& Wuhan yingvirus & Wǔhàn insect virus 15 (WhIV-15) \\
& Xinzhou yingvirus & Xīnzhōu nematode virus 3 (XzNV-3) \\
\hline
\end{tabular}

Note that viruses are real objects that are assigned to concepts that are called taxa. Species, genera, families, and orders are taxa

II Taxon names are always italicized and always begin with a capital letter

${ }^{\&}$ Virus names are not italicized and are not capitalized, except if the name or a name component is a proper noun. This column lists the virus names with their correct (lack of) capitalization

\begin{tabular}{|c|c|c|}
\hline Genus & Species ${ }^{\text {II }}$ & Virus (abbreviation) ${ }^{\&}$ \\
\hline \multicolumn{3}{|c|}{ Family Aspiviridae } \\
\hline Ophiovirus & $\begin{array}{l}\text { Blueberry mosaic associated ophiovirus } \\
\text { Citrus psorosis ophiovirus } \\
\text { Freesia sneak ophiovirus } \\
\text { Lettuce ring necrosis ophiovirus } \\
\text { Mirafiori lettuce big-vein ophiovirus } \\
\text { Ranunculus white mottle ophiovirus } \\
\text { Tulip mild mottle mosaic ophiovirus }\end{array}$ & $\begin{array}{l}\text { blueberry mosaic associated virus (BlMaV) } \\
\text { citrus psorosis virus (CPsV) } \\
\text { freesia sneak virus (FreSV) } \\
\text { lettuce ring necrosis virus (LRNV) } \\
\text { Mirafiori lettuce big-vein virus (MLBVV) } \\
\text { ranunculus white mottle virus (RWMV) } \\
\text { tulip mild mottle mosaic virus (TMMMV) }\end{array}$ \\
\hline
\end{tabular}

Note that viruses are real objects that are assigned to concepts that are called taxa. Species, genera, families, and orders are taxa

II Taxon names are always italicized and always begin with a capital letter

${ }^{\&}$ Virus names are not italicized and are not capitalized, except if the name or a name component is a proper noun. This column lists the virus names with their correct (lack of) capitalization 
Table 6 ICTV-accepted taxonomy of the order Articulavirales

(Negarnaviricota:

Polyploviricotina:

Insthoviricetes) as of March 2021

\begin{tabular}{lll}
\hline Genus & Species $^{\text {II }}$ & Virus (abbreviation) $^{\&}$ \\
\hline $\begin{array}{l}\text { Family Amnoonviridae } \\
\text { Tilapinevirus }\end{array}$ & Tilapia tilapinevirus & \\
Family Orthomyxoviridae & & tilapia lake virus (TiLV) \\
Alphainfluenzavirus & Influenza A virus & \\
Betainfluenzavirus & Influenza B virus & influenza A virus (FLUAV) \\
Deltainfluenzavirus & Influenza D virus & influenza B virus (FLUBV) \\
Gammainfluenzavirus & Influenza C virus & influenza C virus (FLUCV) \\
Isavirus & Salmon isavirus & infectious salmon anemia virus (ISAV) \\
Quaranjavirus & Johnston Atoll quaranjavirus & Johnston Atoll virus (JAV) \\
& Quaranfil quaranjavirus & Quaranfil virus (QRFV) \\
Thogotovirus & Dhori thogotovirus & Dhori virus (DHOV) \\
& Thogoto thogotovirus & Thogoto virus (THOV)
\end{tabular}

Note that viruses are real objects that are assigned to concepts that are called taxa. Species, genera, families, and orders are taxa

II Taxon names are always italicized and always begin with a capital letter

${ }^{\&}$ Virus names are not italicized and are not capitalized, except if the name or a name component is a proper noun. This column lists the virus names with their correct (lack of) capitalization

Table 7 ICTV-accepted taxonomy of the order Bunyavirales (Negarnaviricota: Polyploviricotina: Ellioviricetes) as of March 2020

\begin{tabular}{|c|c|c|}
\hline Genus & Species ${ }^{\mathbb{I}}$ & Virus (abbreviation) ${ }^{\&}$ \\
\hline \multicolumn{3}{|l|}{ Family Arenaviridae } \\
\hline \multirow[t]{4}{*}{ Antennavirus } & Hairy antennavirus & Wēnlǐng frogfish arenavirus 2 (WlFAV-2) \\
\hline & Salmon antennavirus & salmon pescarenavirus 1 (SPAV-1) \\
\hline & & salmon pescarenavirus $2(\mathrm{SPAV}-2)$ \\
\hline & Striated antennavirus & Wēnlǐng frogfish arenavirus 1 (WlFAV-1) \\
\hline \multirow[t]{9}{*}{ Hartmanivirus } & Haartman hartmanivirus & Haartman Institute snake virus 1 (HISV-1) \\
\hline & & Haartman Institute snake virus 2 (HISV-2) \\
\hline & Heimat hartmanivirus & andere Heimat virus $1(\mathrm{aHeV}-1)$ \\
\hline & Muikkunen hartmanivirus & Dante Muikkunen virus 1 (DaMV-1) \\
\hline & Schoolhouse hartmanivirus & old schoolhouse virus $1(\mathrm{OScV}-1)$ \\
\hline & & old schoolhouse virus 2 (OScV-2) \\
\hline & Setpatvet hartmanivirus & SetPatVet virus 1 (SPVV-1) \\
\hline & Zurich hartmanivirus & veterinary pathology Zurich virus 1 (VPZV-1) \\
\hline & & veterinary pathology Zurich virus 2 (VPZV-2) \\
\hline \multirow[t]{16}{*}{ Mammarenavirus } & Allpahuayo mammarenavirus & Allpahuayo virus (ALLV) \\
\hline & Alxa mammarenavirus & Alxa virus (ALXV) \\
\hline & Argentinian mammarenavirus & Junín virus (JUNV) \\
\hline & Bear Canyon mammarenavirus & Bear Canyon virus (BCNV) \\
\hline & Brazilian mammarenavirus & Sabiá virus (SBAV) \\
\hline & Cali mammarenavirus & Pichindé virus (PICHV) \\
\hline & Chapare mammarenavirus & Chapare virus (CHAPV) \\
\hline & Chevrier mammarenavirus & Lìjiāng virus (LIJV) \\
\hline & Cupixi mammarenavirus & Cupixi virus (CUPXV) \\
\hline & Flexal mammarenavirus & Flexal virus (FLEV) \\
\hline & Gairo mammarenavirus & Gairo virus (GAIV) \\
\hline & Guanarito mammarenavirus & Guanarito virus (GTOV) \\
\hline & Ippy mammarenavirus & Ippy virus (IPPYV) \\
\hline & Kitale mammarenavirus & Kitale virus (KTLV) \\
\hline & Lassa mammarenavirus & Lassa virus (LASV) \\
\hline & Latino mammarenavirus & Latino virus (LATV) \\
\hline
\end{tabular}


Table 7 (continued)

\begin{tabular}{|c|c|c|}
\hline Genus & Species ${ }^{I I}$ & Virus (abbreviation) ${ }^{\&}$ \\
\hline & Loei River mammarenavirus & Loei River virus (LORV) \\
\hline & Lujo mammarenavirus & Lujo virus (LUJV) \\
\hline & Luna mammarenavirus & Luli virus (LULV) \\
\hline & & Luna virus (LUAV) \\
\hline & Lunk mammarenavirus & Lunk virus (LNKV) \\
\hline & Lymphocytic choriomeningitis mammarenavirus & Dandenong virus (DANV) \\
\hline & & lymphocytic choriomeningitis virus (LCMV) \\
\hline & Machupo mammarenavirus & Machupo virus (MACV) \\
\hline & Mariental mammarenavirus & Mariental virus (MRLV) \\
\hline & Merino Walk mammarenavirus & Merino Walk virus (MRWV) \\
\hline & Mobala mammarenavirus & mobala virus (MOBV) \\
\hline & Mopeia mammarenavirus & Mopeia virus (MPOV) \\
\hline & & Morogoro virus (MORV) \\
\hline & Okahandja mammarenavirus & Okahandja virus (OKAV) \\
\hline & Oliveros mammarenavirus & Oliveros virus (OLVV) \\
\hline & Paraguayan mammarenavirus & Paraná virus (PRAV) \\
\hline & Planalto mammarenavirus & Aporé virus (APOV) \\
\hline & Pirital mammarenavirus & Pirital virus (PIRV) \\
\hline & Ryukyu mammarenavirus & Ryukyu virus (RYKV) \\
\hline & Serra do Navio mammarenavirus & Amaparí virus (AMAV) \\
\hline & Solwezi mammarenavirus & Solwezi virus (SOLV) \\
\hline & Souris mammarenavirus & souris virus (SOUV) \\
\hline & Tacaribe mammarenavirus & Tacaribe virus (TCRV) \\
\hline & Tamiami mammarenavirus & Tamiami virus (TMMV) \\
\hline & Wenzhou mammarenavirus & Wēnzhōu virus (WENV) \\
\hline & Whitewater Arroyo mammarenavirus & Big Brushy Tank virus (BBRTV) \\
\hline & & Catarina virus (CTNV) \\
\hline & & Skinner Tank virus (SKTV) \\
\hline & & Tonto Creek virus (TTCV) \\
\hline & & Whitewater Arroyo virus (WWAV) \\
\hline & Xapuri mammarenavirus & Xapuri virus (XAPV) \\
\hline \multirow[t]{8}{*}{ Reptarenavirus } & California reptarenavirus & CAS virus (CASV) \\
\hline & Giessen reptarenavirus & University of Giessen virus 1 (UGV-1) \\
\hline & & University of Giessen virus 2 (UGV-2) \\
\hline & & University of Giessen virus 3 (UGV-3) \\
\hline & Golden reptarenavirus & Golden Gate virus (GOGV) \\
\hline & Ordinary reptarenavirus & tavallinen suomalainen mies virus 2 (TSMV-2) \\
\hline & Rotterdam reptarenavirus & ROUT virus (ROUTV) \\
\hline & & University of Helsinki virus 1 (UHV-1) \\
\hline \multicolumn{3}{|c|}{ Family Cruliviridae } \\
\hline \multirow[t]{3}{*}{ Lincruvirus } & Lincruvirus europense & European shore crab virus 1 (EscV-1) \\
\hline & Lincruvirus sinense & Chinese mitten crab virus $1(\mathrm{CmcV}-1)$ \\
\hline & Lincruvirus wenlingense & Wēnlǐng crustacean virus 9 (W1CV-9) \\
\hline \multicolumn{3}{|c|}{ Family Fimoviridae } \\
\hline \multirow[t]{11}{*}{ Emaravirus } & Actinidia chlorotic ringspot-associated emaravirus & Actinidia chlorotic ringspot-associated virus (AcCRaV) \\
\hline & Actinidia emaravirus 2 & Actinidia virus 2 (AcV-2) \\
\hline & Aspen mosaic-associated emaravirus & aspen mosaic-associated virus (AsMaV) \\
\hline & Blackberry leaf mottle associated emaravirus & blackberry leaf mottle-associated virus (BLMaV) \\
\hline & Camellia japonica-associated emaravirus 1 & Camellia japonica-associated virus $1(\mathrm{CjaV}-1)$ \\
\hline & Camellia japonica-associated emaravirus 2 & Camellia japonica-associated virus $2(\mathrm{CjaV}-2)$ \\
\hline & European mountain ash ringspot-associated emaravirus & European mountain ash ringspot-associated virus (EMARaV) \\
\hline & Fig mosaic emaravirus & fig mosaic virus (FMV) \\
\hline & High Plains wheat mosaic emaravirus & High Plains wheat mosaic virus (HPWMoV) \\
\hline & Jujube yellow mottle-associated emaravirus & jujube yellow mottle-associated virus (JYMaV) \\
\hline & Lilac chlorotic ringspot-associated virus & lilac chlorotic ringspot-associated virus ( $\mathrm{LiCRaV})$ \\
\hline
\end{tabular}


Table 7 (continued)

\begin{tabular}{|c|c|c|}
\hline Genus & Species ${ }^{\pi}$ & Virus (abbreviation) ${ }^{\&}$ \\
\hline & Palo verde broom emaravirus & palo verde broom virus (PVBV) \\
\hline & Pear chlorotic leaf spot-associated emaravirus & pear chlorotic leaf spot-associated virus (PCLSaV) \\
\hline & Perilla mosaic emaravirus & perilla mosaic virus (PerMV) \\
\hline & Pigeonpea sterility mosaic emaravirus 1 & pigeonpea sterility mosaic virus 1 (PPSMV-1) \\
\hline & Pigeonpea sterility mosaic emaravirus 2 & pigeonpea sterility mosaic virus 2 (PPSMV-2) \\
\hline & Pistacia emaravirus $B$ & pistacia virus $\mathrm{B}$ (PiVB) \\
\hline & Raspberry leaf blotch emaravirus & raspberry leaf blotch virus (RLBV) \\
\hline & Redbud yellow ringspot-associated emaravirus & redbud yellow ringspot-associated virus (RYRaV) \\
\hline & Rose rosette emaravirus & rose rosette virus (RRV) \\
\hline & Ti ringspot-associated emaravirus & ti ringspot-associated virus ( $\mathrm{TiRSaV})$ \\
\hline \multicolumn{3}{|l|}{ Family Hantaviridae } \\
\hline \multicolumn{3}{|c|}{ Subfamily Actantavirinae } \\
\hline \multirow[t]{4}{*}{ Actinovirus } & Batfish actinovirus & Wēnlǐng minipizza batfish virus (WEMBV) \\
\hline & Goosefish actinovirus & Wēnlǐng yellow goosefish virus (WEYGV) \\
\hline & Perch actinovirus & Bern perch virus (BRPV) \\
\hline & Spikefish actinovirus & Wēnlǐng red spikefish virus (WERSV) \\
\hline \multicolumn{3}{|c|}{ Subfamily Agantavirinae } \\
\hline Agnathovirus & Hagfish agnathovirus & Wēnlĩng hagfish virus (WEHV) \\
\hline \multicolumn{3}{|c|}{ Subfamily Mammantavirinae } \\
\hline \multirow[t]{2}{*}{ Loanvirus } & Brno loanvirus & Brno virus (BRNV) \\
\hline & Longquan loanvirus & Lóngquán virus (LQUV) \\
\hline \multirow[t]{5}{*}{ Mobatvirus } & Laibin mobatvirus & Láibīn virus (LAIV) \\
\hline & Lena mobatvirus & Lena virus (LENV) \\
\hline & Nova mobatvirus & Nova virus (NVAV) \\
\hline & Quezon mobatvirus & Quezon virus (QZNV) \\
\hline & Xuan Son mobatvirus & Xuân Sơn virus (XSV) \\
\hline \multirow[t]{29}{*}{ Orthohantavirus } & Andes orthohantavirus & Andes virus (ANDV) \\
\hline & & Castelo dos Sonhos virus (CASV) \\
\hline & & Lechiguanas virus $(\mathrm{LECV}=\mathrm{LECHV})$ \\
\hline & & Orán virus (ORNV) \\
\hline & Asama orthohantavirus & Asama virus (ASAV) \\
\hline & Asikkala orthohantavirus & Asikkala virus (ASIV) \\
\hline & Bayou orthohantavirus & bayou virus (BAYV) \\
\hline & & Catacamas virus (CATV) \\
\hline & Black Creek Canal orthohantavirus & Black Creek Canal virus (BCCV) \\
\hline & Bowe orthohantavirus & Bowé virus (BOWV) \\
\hline & Bruges orthohantavirus & Bruges virus (BRGV) \\
\hline & Cano Delgadito orthohantavirus & Caño Delgadito virus (CADV) \\
\hline & Cao Bang orthohantavirus & Cao Bằng virus (CBNV) \\
\hline & & Liánghé virus (LHEV) \\
\hline & Choclo orthohantavirus & Choclo virus (CHOV) \\
\hline & Dabieshan orthohantavirus & Dàbiéshān virus (DBSV) \\
\hline & Dobrava-Belgrade orthohantavirus & Dobrava virus (DOBV) \\
\hline & & Kurkino virus (KURV) \\
\hline & & Saaremaa virus (SAAV) \\
\hline & & Sochi virus (SOCV) \\
\hline & El Moro Canyon orthohantavirus & Carrizal virus (CARV) \\
\hline & & El Moro Canyon virus (ELMCV) \\
\hline & & Huitzilac virus (HUIV) \\
\hline & Fugong orthohantavirus & Fúgòng virus (FUGV) \\
\hline & Fusong orthohantavirus & Fǔsōng virus (FUSV) \\
\hline & Hantaan orthohantavirus & Amur virus (AMRV) \\
\hline & & Hantaan virus (HTNV) \\
\hline & & Soochong virus (SOOV) \\
\hline & Jeju orthohantavirus & Jeju virus (JJUV) \\
\hline
\end{tabular}


Table 7 (continued)

\begin{tabular}{|c|c|c|}
\hline Genus & Species ${ }^{\pi}$ & Virus (abbreviation) ${ }^{\&}$ \\
\hline & Kenkeme orthohantavirus & Kenkeme virus (KKMV) \\
\hline & Khabarovsk orthohantavirus & Khabarovsk virus (KHAV) \\
\hline & & Topografov virus (TOPV) \\
\hline & Laguna Negra orthohantavirus & Laguna Negra virus (LANV) \\
\hline & & Maripa virus (MARV) \\
\hline & & Rio Mamoré virus (RIOMV) \\
\hline & Luxi orthohantavirus & Lúxī virus (LUXV) \\
\hline & Maporal orthohantavirus & Maporal virus (MAPV) \\
\hline & Montano orthohantavirus & Montaño virus (MTNV) \\
\hline & Necocli orthohantavirus & Necoclí virus (NECV) \\
\hline & Oxbow orthohantavirus & Oxbow virus (OXBV) \\
\hline & Prospect Hill orthohantavirus & Prospect Hill virus (PHV) \\
\hline & Puumala orthohantavirus & Hokkaido virus (HOKV) \\
\hline & & Muju virus (MUJV) \\
\hline & & Puumala virus (PUUV) \\
\hline & Robina orthohantavirus & Robina virus (ROBV) \\
\hline & Rockport orthohantavirus & Rockport virus (RKPV) \\
\hline & Sangassou orthohantavirus & Sangassou virus (SANGV) \\
\hline & Seewis orthohantavirus & Seewis virus (SWSV) \\
\hline & Seoul orthohantavirus & gōu virus (GOUV) \\
\hline & & Seoul virus (SEOV) \\
\hline & Sin Nombre orthohantavirus & New York virus (NYV) \\
\hline & & Sin Nombre virus (SNV) \\
\hline & Tatenale orthohantavirus & Tatenale virus (TATV) \\
\hline & Thailand orthohantavirus & Anjozorobe virus (ANJZV) \\
\hline & & Serang virus (SERV) \\
\hline & & Thailand virus (THAIV) \\
\hline & Tigray orthohantavirus & Tigray virus (TIGV) \\
\hline & Tula orthohantavirus & Adler virus (ADLV) \\
\hline & & Tula virus (TULV) \\
\hline & Yakeshi orthohantavirus & Yákèshí virus (YKSV) \\
\hline Thottimvirus & Imjin thottimvirus & Imjin virus (MJNV) \\
\hline & Thottapalayam thottimvirus & Thottapalayam virus (TPMV) \\
\hline Subfamily Repant & & \\
\hline Reptillovirus & Gecko reptillovirus & Hăinán oriental leaf-toed gecko virus (HOLGV) \\
\hline Family Leishbuviric & & \\
\hline Shilevirus & Leptomonas shilevirus & Leptomonas moramango virus (LEPMV) \\
\hline Family Mypovirida & & \\
\hline Hubavirus & Myriapod hubavirus & Húběi myriapoda virus 5 (HbMV-5) \\
\hline Family Nairovirida & & \\
\hline Norwavirus & Grotenhout norwavirus & Grotenhout virus (GRHV) \\
\hline Ocetevirus & Blattodean ocetevirus & red goblin roach virus 1 (RGRV-1) \\
\hline Orthonairovirus & Abu Hammad orthonairovirus & Abū Ḥammād virus (AHV) \\
\hline & Abu Mina orthonairovirus & Abū Mīnā virus (AMV) \\
\hline & Artashat orthonairovirus & Artashat virus (ARTSV) \\
\hline & Avalon orthonairovirus & Avalon virus (AVAV) \\
\hline & Chim orthonairovirus & Chim virus (CHIMV) \\
\hline & Bandia orthonairovirus & Bandia virus (BDAV) \\
\hline & Burana orthonairovirus & Burana virus (BURV) \\
\hline & Congoid orthonairovirus & Aigai virus (AIGV) \\
\hline & Crimean-Congo hemorrhagic fever orthonairovirus & Crimean-Congo hemorrhagic fever virus (CCHFV) \\
\hline & Dera Ghazi Khan orthonairovirus & Dera Ghazi Khan virus (DGKV) \\
\hline & Dugbe orthonairovirus & Dugbe virus (DUGV) \\
\hline & Erve orthonairovirus & Erve virus (ERVEV) \\
\hline & Estero Real orthonairovirus & Estero Real virus (ERV) \\
\hline
\end{tabular}


Table 7 (continued)

\begin{tabular}{|c|c|c|}
\hline Genus & Species ${ }^{I I}$ & Virus (abbreviation) $)^{\&}$ \\
\hline & Gossas orthonairovirus & Gossas virus (GOSV) \\
\hline & Hazara orthonairovirus & Hazara virus (HAZV) \\
\hline & Huangpi orthonairovirus & Huángpí tick virus 1 (HpTV-1) \\
\hline & Hughes orthonairovirus & Caspiy virus (CASV) \\
\hline & & Farallon virus (FARV) \\
\hline & & Great Saltee virus (GRSV) \\
\hline & & Hughes virus (HUGV) \\
\hline & & Raza virus (RAZAV) \\
\hline & Issyk-kul orthonairovirus & Issyk-kul virus (ISKV) \\
\hline & Kasokero orthonairovirus & Kasokero virus (KASV = KASOV) \\
\hline & Keterah orthonairovirus & Keterah virus (KTRV) \\
\hline & & Uzun-Agach virus (UZAV) \\
\hline & Kupe orthonairovirus & kupe virus (KUPEV) \\
\hline & Leopards Hill orthonairovirus & Leopards Hill virus (LPHV) \\
\hline & Meram orthonairovirus & Meram virus (MEMV) \\
\hline & Nairobi sheep disease orthonairovirus & Nairobi sheep disease virus (NSDV) \\
\hline & Pacific Coast orthonairovirus & Pacific Coast tick nairovirus (PCTNV) \\
\hline & Punta orthonairovirus & Punta Salinas virus (PSV) \\
\hline & Qalyub orthonairovirus & Geran virus (GERV) \\
\hline & & Qalyub virus (QYBV) \\
\hline & Sakhalin orthonairovirus & Sakhalin virus (SAKV) \\
\hline & & Tillamook virus (TILLV) \\
\hline & Sapphire orthonairovirus & Sapphire II virus (SAPV) \\
\hline & Scot orthonairovirus & Clo Mor virus $(\mathrm{CMV}=\mathrm{CLMV})$ \\
\hline & Soldado orthonairovirus & Soldado virus (SOLV) \\
\hline & Tacheng orthonairovirus & Tăchéng tick virus 1 (TcTV-1) \\
\hline & Taggert orthonairovirus & Taggert virus (TAGV) \\
\hline & Tamdy orthonairovirus & Tamdy virus (TAMV) \\
\hline & Thiafora orthonairovirus & Thiafora virus (TFAV) \\
\hline & Tofla orthonairovirus & tofla virus (TFLV) \\
\hline & Tunis orthonairovirus & Tunis virus (TUNV) \\
\hline & Vinegar Hill orthonairovirus & Vinegar Hill virus (VINHV) \\
\hline & Wenzhou orthonairovirus & Wēnzhōu tick virus (WzTV) \\
\hline & Yogue orthonairovirus & Yogue virus (YOGV) \\
\hline & Zirqa orthonairovirus & Zirqa virus (ZIRV) \\
\hline Sabavirus & South Bay sabavirus & South Bay virus (SBV) \\
\hline Shaspivirus & Spider shaspivirus & Shāyáng spider virus 1 (SySV-1) \\
\hline Striwavirus & Strider striwavirus & Sānxiá water strider virus 1 (SxWSV-1) \\
\hline Xinspivirus & Xinzhou xinspivirus & Xīnzhōu spider virus (XSV) \\
\hline \multicolumn{3}{|c|}{ Family Peribunyaviridae } \\
\hline \multirow[t]{3}{*}{ Herbevirus } & Herbert herbevirus & Herbert virus (HEBV) \\
\hline & Kibale herbevirus & Kibale virus (KIBV) \\
\hline & Tai herbevirus & Taï virus (TAIV) \\
\hline \multirow[t]{12}{*}{ Orthobunyavirus } & Abras orthobunyavirus & Abras virus (ABRV) \\
\hline & Acara orthobunyavirus & Acará virus (ACAV) \\
\hline & & Moriche virus (MORV) \\
\hline & Aino orthobunyavirus & Aino virus (AINOV) \\
\hline & Akabane orthobunyavirus & Akabane virus (AKAV) \\
\hline & & Tinaroo virus (TINV) \\
\hline & & Yaba-7 virus $(\mathrm{Y} 7 \mathrm{~V})$ \\
\hline & Alajuela orthobunyavirus & Alajuela virus (ALJV) \\
\hline & & San Juan virus (SJV) \\
\hline & Anadyr orthobunyavirus & Anadyr virus (ANADV) \\
\hline & Ananindeua orthobunyavirus & Ananindeua virus (ANUV) \\
\hline & Anhembi orthobunyavirus & Anhembi virus (AMBV) \\
\hline
\end{tabular}


Table 7 (continued)

\begin{tabular}{|c|c|c|}
\hline Genus & Species ${ }^{\pi}$ & Virus (abbreviation) ${ }^{\&}$ \\
\hline & \multirow[t]{7}{*}{ Anopheles A orthobunyavirus } & Anopheles A virus (ANAV) \\
\hline & & Arumateua virus $(\mathrm{ARTV}=\mathrm{ARMTV})$ \\
\hline & & Caraipé virus $(\mathrm{CPEV}=\mathrm{CRPV})$ \\
\hline & & Las Maloyas virus (LMV) \\
\hline & & Lukuni virus (LUKV) \\
\hline & & Trombetas virus (TRMV) \\
\hline & & Tucuruí virus (TUCV = TUCRV) \\
\hline & \multirow[t]{2}{*}{ Anopheles B orthobunyavirus } & Anopheles B virus (ANBV) \\
\hline & & Boracéia virus (BORV) \\
\hline & Apeu orthobunyavirus & Apeú virus (APEUV) \\
\hline & \multirow[t]{5}{*}{ Bakau orthobunyavirus } & Bakau virus (BAKV) \\
\hline & & Ketapang virus (KETV) \\
\hline & & Nola virus (NOLAV) \\
\hline & & Tanjong Rabok virus (TRV) \\
\hline & & Telok Forest virus (TFV) \\
\hline & Batai orthobunyavirus & Batai virus (BATV) \\
\hline & Batama orthobunyavirus & Batama virus (BMAV) \\
\hline & Bellavista orthobunyavirus & Bellavista virus (BELLV) \\
\hline & Benevides orthobunyavirus & Benevides virus $(\mathrm{BVSV}=\mathrm{BENV})$ \\
\hline & \multirow[t]{5}{*}{ Bertioga orthobunyavirus } & Bertioga virus (BERV) \\
\hline & & Cananéia virus (CNAV) \\
\hline & & Guaratuba virus (GTBV) \\
\hline & & Itimirim virus (ITIV) \\
\hline & & Mirim virus (MIRV) \\
\hline & Bimiti orthobunyavirus & bimiti virus (BIMV) \\
\hline & Birao orthobunyavirus & Birao virus (BIRV) \\
\hline & Botambi orthobunyavirus & Botambi virus (BOTV) \\
\hline & Bozo orthobunyavirus & Bozo virus (BOZOV) \\
\hline & Brazoran orthobunyavirus & brazoran virus (BRAZV) \\
\hline & Bruconha orthobunyavirus & Bruconha virus (BRUV) \\
\hline & Buffalo Creek orthobunyavirus & Buffalo Creek virus (BUCV) \\
\hline & \multirow[t]{10}{*}{ Bunyamwera orthobunyavirus } & Bunyamwera virus (BUNV) \\
\hline & & Germiston virus (GERV) \\
\hline & & Lokern virus (LOKV) \\
\hline & & Mboké virus (MBOV) \\
\hline & & Ngari virus (NRIV) \\
\hline & & Northway virus (NORV) \\
\hline & & Santa Rosa virus (SARV) \\
\hline & & Shokwe virus (SHOV) \\
\hline & & Stanfield virus (STAV) \\
\hline & & Xingu virus (XINV) \\
\hline & \multirow[t]{3}{*}{ Bushbush orthobunyavirus } & Benfica virus $(\mathrm{BENV}=\mathrm{BNFV})$ \\
\hline & & Bushbush virus (BSBV) \\
\hline & & Juan Díaz virus (JDV) \\
\hline & Buttonwillow orthobunyavirus & Buttonwillow virus (BUTV) \\
\hline & \multirow[t]{2}{*}{ Bwamba orthobunyavirus } & Bwamba virus (BWAV) \\
\hline & & Pongola virus (PGAV) \\
\hline & \multirow[t]{3}{*}{ Cache Valley orthobunyavirus } & Cache Valley virus (CVV) \\
\hline & & Cholul virus (CHLV) \\
\hline & & Tlacotalpan virus (TLAV) \\
\hline & Cachoeira Porteira orthobunyavirus & Cachoeira Porteira virus (CPOV) \\
\hline & \multirow[t]{2}{*}{ California encephalitis orthobunyavirus } & California encephalitis virus (CEV) \\
\hline & & Morro Bay virus (MBV) \\
\hline & Capim orthobunyavirus & Capim virus (CAPV) \\
\hline & Caraparu orthobunyavirus & Caraparú virus (CARV) \\
\hline
\end{tabular}


Table 7 (continued)

\begin{tabular}{|c|c|c|}
\hline Genus & Species ${ }^{I I}$ & Virus (abbreviation) $)^{\&}$ \\
\hline & \multirow{6}{*}{ Cat Que orthobunyavirus } & El Huayo virus (EHUV) \\
\hline & & Itaya virus (ITYV) \\
\hline & & Ossa virus (OSSAV) \\
\hline & & Vinces virus (VINV) \\
\hline & & Cát Quế virus (CQV) \\
\hline & & Oya virus (OYAV) \\
\hline & Catu orthobunyavirus & Catú virus (CATUV) \\
\hline & Enseada orthobunyavirus & Enseada virus (ENSV) \\
\hline & Faceys paddock orthobunyavirus & Facey's paddock virus (FPV) \\
\hline & Fort Sherman orthobunyavirus & Fort Sherman virus (FSV) \\
\hline & \multirow[t]{5}{*}{ Gamboa orthobunyavirus } & Brus Laguna virus (BLAV) \\
\hline & & Calchaquí virus (CQIV) \\
\hline & & Gamboa virus (GAMV) \\
\hline & & Pueblo Viejo virus (PVV) \\
\hline & & Soberanía virus (SOBV) \\
\hline & Gan Gan orthobunyavirus & Gan Gan virus (GGV) \\
\hline & Guajara orthobunyavirus & Guajará virus (GJAV) \\
\hline & Guama orthobunyavirus & Guamá virus (GMAV) \\
\hline & Guaroa orthobunyavirus & Guaroa virus (GROV) \\
\hline & Iaco orthobunyavirus & Iaco virus (IACOV) \\
\hline & Ilesha orthobunyavirus & Ilesha virus (ILEV) \\
\hline & Ingwavuma orthobunyavirus & Ingwavuma virus (INGV) \\
\hline & \multirow[t]{4}{*}{ Jamestown Canyon orthobunyavirus } & Inkoo virus (INKV) \\
\hline & & Jamestown Canyon virus (JCV) \\
\hline & & Jerry Slough virus (JSV) \\
\hline & & South River virus (SORV) \\
\hline & Jatobal orthobunyavirus & Jatobal virus (JATV) \\
\hline & Kaeng Khoi orthobunyavirus & Kaeng Khoi virus (KKV) \\
\hline & Kairi orthobunyavirus & kairi virus (KRIV) \\
\hline & Keystone orthobunyavirus & Keystone virus (KEYV) \\
\hline & \multirow[t]{2}{*}{ Koongol orthobunyavirus } & koongol virus (KOOV) \\
\hline & & wongal virus (WONV) \\
\hline & La Crosse orthobunyavirus & La Crosse virus (LACV) \\
\hline & Leanyer orthobunyavirus & Leanyer virus (LEAV) \\
\hline & Lumbo orthobunyavirus & Lumbo virus (LUMV) \\
\hline & Macaua orthobunyavirus & Macauã virus (MCAV) \\
\hline & Madrid orthobunyavirus & Madrid virus (MADV) \\
\hline & \multirow[t]{2}{*}{ Maguari orthobunyavirus } & Maguari virus (MAGV) \\
\hline & & Playas virus (PLAV) \\
\hline & Mahogany Hammock orthobunyavirus & Mahogany Hammock virus (MHV) \\
\hline & Main Drain orthobunyavirus & Main Drain virus (MDV) \\
\hline & \multirow[t]{2}{*}{ Manzanilla orthobunyavirus } & Manzanilla virus (MANV) \\
\hline & & Inini virus (INIV) \\
\hline & Mapputta orthobunyavirus & Mapputta virus (MAPV) \\
\hline & Maprik orthobunyavirus & Maprik virus (MPKV) \\
\hline & \multirow[t]{6}{*}{ Marituba orthobunyavirus } & Gumbo Limbo virus (GLV) \\
\hline & & Marituba virus (MTBV) \\
\hline & & Murutucú virus (MURV) \\
\hline & & Nepuyo virus (NEPV) \\
\hline & & Restan virus (RESV) \\
\hline & & Zungarococha virus (ZUNV) \\
\hline & Matruh orthobunyavirus & Matruh virus (MTRV) \\
\hline & Melao orthobunyavirus & Melao virus (MELV) \\
\hline & Moju orthobunyavirus & Moju virus (MOJUV) \\
\hline & Mermet orthobunyavirus & Mermet virus (MERV) \\
\hline
\end{tabular}


Table 7 (continued)

\begin{tabular}{|c|c|c|}
\hline Genus & Species ${ }^{\pi}$ & Virus (abbreviation) ${ }^{\&}$ \\
\hline & \multirow[t]{2}{*}{ Minatitlan orthobunyavirus } & Minatitlán virus (MNTV) \\
\hline & & Palestina virus (PLSV) \\
\hline & \multirow[t]{2}{*}{ MPoko orthobunyavirus } & M’Poko virus (MPOV) \\
\hline & & Yaba-1 virus (Y1V) \\
\hline & \multirow[t]{3}{*}{ Nyando orthobunyavirus } & Eretmapodites virus (ERETV) \\
\hline & & Mojuí dos Campos virus (MDCV) \\
\hline & & Nyando virus (NDV) \\
\hline & \multirow[t]{4}{*}{ Olifantsvlei orthobunyavirus } & Bobia virus (BIAV) \\
\hline & & Dabakala virus (DABV) \\
\hline & & Olifantsvlei virus (OLIV) \\
\hline & & Oubi virus (OUBIV) \\
\hline & \multirow[t]{2}{*}{ Oriboca orthobunyavirus } & Itaquí virus (ITQV) \\
\hline & & Oriboca virus (ORIV) \\
\hline & \multirow[t]{5}{*}{ Oropouche orthobunyavirus } & Iquitos virus (IQTV) \\
\hline & & Madre de Dios virus (MDDV) \\
\hline & & Oropouche virus (OROV) \\
\hline & & Perdões virus (PDEV) \\
\hline & & Pintupo virus (PINTV) \\
\hline & Oyo orthobunyavirus & Oyo virus (OYOV) \\
\hline & \multirow[t]{3}{*}{ Patois orthobunyavirus } & Babahoya virus (BABV) \\
\hline & & Pahayokee virus (PAHV) \\
\hline & & Patois virus (PATV) \\
\hline & Peaton orthobunyavirus & peaton virus (PEAV) \\
\hline & Potosi orthobunyavirus & Potosi virus (POTV) \\
\hline & Sabo orthobunyavirus & Sabo virus (SABOV) \\
\hline & San Angelo orthobunyavirus & San Angelo virus (SAV) \\
\hline & Sango orthobunyavirus & Sango virus (SANV) \\
\hline & \multirow[t]{4}{*}{ Schmallenberg orthobunyavirus } & Douglas virus (DOUV) \\
\hline & & Sathuperi virus (SATV) \\
\hline & & Schmallenberg virus (SBV) \\
\hline & & Shamonda virus (SHAV) \\
\hline & Sedlec orthobunyavirus & Sedlec virus (SEDV) \\
\hline & Serra do Navio orthobunyavirus & Serra do Navio virus (SDNV) \\
\hline & Shark River orthobunyavirus & Shark River virus (SRV) \\
\hline & \multirow[t]{2}{*}{ Shuni orthobunyavirus } & Kaikalur virus (KAIV) \\
\hline & & Shuni virus (SHUV) \\
\hline & \multirow[t]{2}{*}{ Simbu orthobunyavirus } & Para virus (PARAV) \\
\hline & & Simbu virus (SIMV) \\
\hline & \multirow[t]{2}{*}{ Snowshoe hare orthobunyavirus } & Khatanga virus (KHATV) \\
\hline & & snowshoe hare virus (SSHV) \\
\hline & Sororoca orthobunyavirus & Sororoca virus (SORV) \\
\hline & \multirow[t]{4}{*}{ Tacaiuma orthobunyavirus } & CoAr 1071 virus (CA1071V) \\
\hline & & CoAr 3627 virus (CA3626V) \\
\hline & & Tacaiuma virus (TCMV) \\
\hline & & Virgin River virus (VRV) \\
\hline & Tahyna orthobunyavirus & Ťahyňa virus (TAHV) \\
\hline & Tataguine orthobunyavirus & Tataguine virus (TATV) \\
\hline & Tensaw orthobunyavirus & Tensaw virus (TENV) \\
\hline & \multirow[t]{4}{*}{ Tete orthobunyavirus } & Bahig virus (BAHV) \\
\hline & & Tete virus (TETEV) \\
\hline & & Tsuruse virus (TSUV) \\
\hline & & Weldona virus (WELV) \\
\hline & Thimiri orthobunyavirus & Thimiri virus (THIV) \\
\hline & Timboteua orthobunyavirus & Timboteua virus (TBTV) \\
\hline & Triniti orthobunyavirus & Triniti virus (TNTV) \\
\hline
\end{tabular}


Table 7 (continued)

\begin{tabular}{|c|c|c|}
\hline Genus & Species ${ }^{I I}$ & Virus (abbreviation) ${ }^{\&}$ \\
\hline & Trivittatus orthobunyavirus & Achiote virus (ACHOV) \\
\hline & & Trivittatus virus (TVTV) \\
\hline & Turlock orthobunyavirus & Lednice virus (LEDV) \\
\hline & & Turlock virus (TURV) \\
\hline & & Umbre virus (UMBV) \\
\hline & Utinga orthobunyavirus & Utinga virus (UTIV) \\
\hline & Witwatersrand orthobunyavirus & Witwatersrand virus (WITV) \\
\hline & Wolkberg orthobunyavirus & Wolkberg virus (WBV) \\
\hline & Wyeomyia orthobunyavirus & Rio Pracupi virus \\
\hline & & Taiassui virus (TAIAV) \\
\hline & & Tucunduba virus (TUCV) \\
\hline & & Wyeomyia virus (WYOV) \\
\hline \multirow[t]{5}{*}{ Pacuvirus } & Caimito pacuvirus & Caimito virus (CAIV) \\
\hline & Chilibre pacuvirus & Chilibre virus (CHIV) \\
\hline & Pacui pacuvirus & Pacui virus (PACV) \\
\hline & Rio Preto da Eva pacuvirus & Rio Preto da Eva virus (RPEV) \\
\hline & Tapirape pacuvirus & Tapirapé virus (TAPV) \\
\hline Shangavirus & Insect shangavirus & Shuāngào insect virus 1 (SgIV-1) \\
\hline \multicolumn{3}{|l|}{ Family Phasmaviridae } \\
\hline \multirow[t]{3}{*}{ Feravirus } & Ferakferavirus & Ferak virus (FRKV) \\
\hline & Hemipteran feravirus & hemipteran phasma-related virus OKIAV247 (HeFV) \\
\hline & Neuropteran feravirus & neuropteran phasma-related virus OKIAV248 (NeFV) \\
\hline \multirow[t]{2}{*}{ Hymovirus } & Hymenopteran hymovirus 1 & hymenopteran phasma-related virus OKIAV252 (HyHV-1) \\
\hline & Hymenopteran hymovirus 2 & hymenopteran phasma-related virus OKIAV250 (HyHV-2) \\
\hline Jonvirus & Jonchet jonvirus & jonchet virus (JONV) \\
\hline \multirow[t]{13}{*}{ Orthophasmavirus } & Anopheles orthophasmavirus & Anopheles triannulatus orthophasmavirus (AtOPV) \\
\hline & Coleopteran orthophasmavirus & coleopteran phasma-related virus OKIAV235 (CPRV) \\
\hline & Culex orthophasmavirus & Culex phasma-like virus (CPLV) \\
\hline & Ganda orthophasmavirus & Ganda bee virus (GBEEV) \\
\hline & Hymenopteran orthophasmavirus 1 & hymenopteran phasma-related virus OKIAV228 (HyOV-1) \\
\hline & Hymenopteran orthophasmavirus 2 & hymenopteran phasma-related virus OKIAV227 (HyOV-2) \\
\hline & Kigluaik phantom orthophasmavirus & Kigluaik phantom virus (KIGV) \\
\hline & Niukluk phantom orthophasmavirus & Niukluk phantom virus (NUKV) \\
\hline & Odonate orthophasmavirus & Húběi odonate virus 8 (HbOV-8) \\
\hline & Qingling orthophasmavirus & Húběi odonate virus 9 (HbOV-9) \\
\hline & Wuchang cockroach orthophasmavirus 1 & Wǔchāng cockroach virus 1 (WcCV-1) \\
\hline & Wuhan mosquito orthophasmavirus 1 & Wǔhàn mosquito virus 1 (WhMV-1) \\
\hline & Wuhan mosquito orthophasmavirus 2 & Wǔhàn mosquito virus 2 (WhMV-2) \\
\hline Sawastrivirus & Sanxia sawastrivirus & Sānxiá water strider virus 2 (SxWSV-2) \\
\hline Wuhivirus & Insect whivirus & Wǔhàn insect virus 2 (WhIV-2) \\
\hline \multicolumn{3}{|l|}{ Family Phenuiviridae } \\
\hline \multirow[t]{8}{*}{ Bandavirus } & Bhanja bandavirus & Bhanja virus (BHAV) \\
\hline & Dabie bandavirus & severe fever with thrombocytopenia syndrome virus (SFTSV) \\
\hline & Guertu bandavirus & Gùěrtú virus (GTV) \\
\hline & Heartland bandavirus & Heartland virus (HRTV) \\
\hline & Hunter Island bandavirus & Albatross Island virus (ABIV) \\
\hline & Kismaayo bandavirus & Kismaayo virus (KISV) \\
\hline & Lone star bandavirus & lone star virus (LSV) \\
\hline & Razdan bandavirus & Razdan virus (RAZV) \\
\hline Beidivirus & Dipteran beidivirus & Húběi diptera virus 3 (HbDV-3) \\
\hline \multirow[t]{3}{*}{ Coguvirus } & Citrus coguvirus & citrus concave gum-associated virus (CCGaV) \\
\hline & Coguvirus eburi & citrus virus $\mathrm{A}(\mathrm{CiV}-\mathrm{A})$ \\
\hline & Grapevine coguvirus & grapevine associated cogu-like virus 1 (GaCLV-1) \\
\hline Entovirus & Entoleuca entovirus & Entoleuca phenui-like virus 1 (EnPLV-1) \\
\hline
\end{tabular}


Table 7 (continued)

\begin{tabular}{|c|c|c|}
\hline Genus & Species ${ }^{\pi}$ & Virus (abbreviation) ${ }^{\&}$ \\
\hline \multirow[t]{3}{*}{ Goukovirus } & Cumuto goukovirus & Cumuto virus (CUMV) \\
\hline & Gouleako goukovirus & Gouléako virus (GOLV) \\
\hline & Yichang insect goukovirus & Yíchāng insect virus (YcIV) \\
\hline \multirow[t]{2}{*}{ Horwuvirus } & Horsefly horwuvirus & Wǔhàn horsefly virus (WhHV) \\
\hline & Kimberley horwuvirus & Fitzroy Crossing tenui-like virus 1 (FCTenV1) \\
\hline Hudivirus & Dipteran hudivirus & Húběi diptera virus 4 (HbDV-4) \\
\hline Hudovirus & Lepidopteran hudovirus & Húběi lepidoptera virus 1 (HbLV-1) \\
\hline \multirow[t]{3}{*}{ Ixovirus } & Blackleg ixovirus & blacklegged tick virus 1 (BLTV-1) \\
\hline & Norway ixovirus & Fairhair virus (FHAV) \\
\hline & Scapularis ixovirus & blacklegged tick virus 3 (BLTV-3) \\
\hline \multirow[t]{4}{*}{ Laulavirus } & Grapevine laulavirus 2 & grapevine associated cogu-like virus 2 (GaCLV-2) \\
\hline & Grapevine laulavirus 3 & grapevine associated cogu-like virus 3 (GaCLV-3) \\
\hline & Grapevine laulavirus 4 & grapevine associated cogu-like virus 4 (GaCLV-4) \\
\hline & Laurel Lake laulavirus & Laurel Lake virus (LLV) \\
\hline Lentinuvirus & Lentinula lentinuvirus & Lentinula edodes negative-strand RNA virus 2 (LeNSRV-2) \\
\hline \multirow[t]{2}{*}{ Mobuvirus } & Mothra mobuvirus & Mothra virus (MTHV) \\
\hline & Narangue mobuvirus & Ñarangue virus (NRGV) \\
\hline \multirow[t]{7}{*}{ Phasivirus } & Badu phasivirus & Badu virus (BADUV) \\
\hline & Dipteran phasivirus & Húběi diptera virus 5 (HbDV-5) \\
\hline & Fly phasivirus & Wǔhàn fly virus 1 (WhFV-1) \\
\hline & Guadeloupe phasivirus & Guadeloupe mosquito phasivirus (GMPV) \\
\hline & Kimberley phasivirus & Parry's Creek phasivirus 1 (PCPhasV1) \\
\hline & Phasi Charoen-like phasivirus & Phasi Charoen-like virus (PCLV) \\
\hline & Wutai mosquito phasivirus & Wǔtái mosquito virus (WtMV) \\
\hline \multirow[t]{31}{*}{ Phlebovirus } & Adana phlebovirus & Adana virus (ADAV) \\
\hline & Aguacate phlebovirus & Aguacate virus (AGUV) \\
\hline & Alcube phlebovirus & Alcube virus (ACBV) \\
\hline & Alenquer phlebovirus & Alenquer virus (ALEV) \\
\hline & Ambe phlebovirus & Ambé virus (ABEV) \\
\hline & Anhanga phlebovirus & Anhangá virus (ANHV) \\
\hline & Arumowot phlebovirus & Arumowot virus (AMTV) \\
\hline & Buenaventura phlebovirus & Buenaventura virus (BUEV) \\
\hline & Bogoria phlebovirus & Bogoria virus (BGRV) \\
\hline & Bujaru phlebovirus & Bujaru virus (BUJV) \\
\hline & Cacao phlebovirus & Cacao virus (CACV) \\
\hline & Campana phlebovirus & Campana virus (CMAV) \\
\hline & Candiru phlebovirus & Ariquemes virus (ARQV) \\
\hline & & Candirú virus (CDUV) \\
\hline & & Jacundá virus (JCNV) \\
\hline & & Morumbi virus (MR(M)BV) \\
\hline & & Mucura virus (MCRV/MRAV) \\
\hline & & Serra Norte virus (SRNV) \\
\hline & Chagres phlebovirus & Chagres virus (CHGV) \\
\hline & Cocle phlebovirus & Coclé virus (CCLV) \\
\hline & Corfou phlebovirus & Corfou virus (CFUV) \\
\hline & Dashli phlebovirus & Dāshlī virus (DASV) \\
\hline & Durania phlebovirus & Durania virus (DRNV) \\
\hline & Echarate phlebovirus & Echarate virus (ECHV) \\
\hline & Embossos phlebovirus & Embossos virus (EMBV) \\
\hline & Gabek phlebovirus & Gabek forest virus (GFV) \\
\hline & Gordil phlebovirus & Gordil virus (GORV) \\
\hline & Icoaraci phlebovirus & Icoaraci virus (ICOV) \\
\hline & Itaituba phlebovirus & Itaituba virus (ITAV) \\
\hline & Itaporanga phlebovirus & Itaporanga virus (ITPV) \\
\hline & Ixcanal phlebovirus & Ixcanal virus (IXCV) \\
\hline
\end{tabular}


Table 7 (continued)

\begin{tabular}{|c|c|c|}
\hline Genus & Species ${ }^{\pi}$ & Virus (abbreviation) ${ }^{\&}$ \\
\hline & Karimabad phlebovirus & Karimabad virus (KARV) \\
\hline & Kiborgoch phlebovirus & Kiborgoch virus (KBGV) \\
\hline & La Gloria phlebovirus & La Gloria virus (LAGV) \\
\hline & Lara phlebovirus & Rio Claro virus (RICV) \\
\hline & Leticia phlebovirus & Leticia virus (LTCV) \\
\hline & Maldonado phlebovirus & Maldonado virus (MLOV) \\
\hline & Mariquita phlebovirus & Mariquita virus (MRQV) \\
\hline & Massilia phlebovirus & Massilia virus (MASV) \\
\hline & Medjerda phlebovirus & Medjerda Valley virus (MVV) \\
\hline & Mona Grita phlebovirus & Mona Grita virus (MOGV) \\
\hline & Mukawa phlebovirus & Mukawa virus (MKWV) \\
\hline & Munguba phlebovirus & Munguba virus (MUNV) \\
\hline & Naples phlebovirus & Arrábida virus (ARRV) \\
\hline & & Balkan virus (BALKV) \\
\hline & & Fermo virus (FERV) \\
\hline & & Granada virus (GRV = GRAV) \\
\hline & & Saddaguia virus (SADV) \\
\hline & & sandfly fever Naples virus (SFNV) \\
\hline & Nique phlebovirus & Nique virus (NIQV) \\
\hline & Ntepes phlebovirus & Ntepes virus (NTPV) \\
\hline & Odrenisrou phlebovirus & Odrénisrou virus (ODRV) \\
\hline & Oriximina phlebovirus & Oriximiná virus (ORXV) \\
\hline & Pena Blanca phlebovirus & Peña Blanca virus (PEBV) \\
\hline & Penshurt phlebovirus & Penshurt virus (PEHV) \\
\hline & Perkerra phlebovirus & Perkerra virus (PKEV) \\
\hline & Punique phlebovirus & Punique virus (PUNV) \\
\hline & Punta Toro phlebovirus & Capira virus (CAPIV) \\
\hline & & Punta Toro virus (PTV) \\
\hline & Rift Valley fever phlebovirus & Rift Valley fever virus (RVFV) \\
\hline & Rio Grande phlebovirus & Rio Grande virus (RGV) \\
\hline & Saint Floris phlebovirus & Saint-Floris virus (SAFV) \\
\hline & Salanga phlebovirus & Salanga virus (SLGV) \\
\hline & Salehabad phlebovirus & Adria virus (ADRV) \\
\hline & & Arbia virus (ARBV) \\
\hline & & Bregalaka virus (BREV) \\
\hline & & Olbia virus (OLBV) \\
\hline & & Salehabad virus (SALV) \\
\hline & & Zaba virus (ZABAV) \\
\hline & Salobo phlebovirus & Salobo virus (SLBOV) \\
\hline & Sicilian phlebovirus & sandfly fever Sicilian virus (SFSV) \\
\hline & Tapara phlebovirus & Tapará virus (TPRV) \\
\hline & Tehran phlebovirus & Tehran virus (THEV) \\
\hline & Tico phlebovirus & Tico virus (TICV) \\
\hline & Toros phlebovirus & Toros virus (TORV) \\
\hline & Toscana phlebovirus & Toscana virus (TOSV) \\
\hline & Tres Almendras phlebovirus & Tres Almendras virus (TRAV) \\
\hline & Turuna phlebovirus & Turuna virus (TUAV) \\
\hline & Uriurana phlebovirus & Uriurana virus (URIV) \\
\hline & Urucuri phlebovirus & Urucuri virus (URUV) \\
\hline & Viola phlebovirus & viola virus (VIOV) \\
\hline & Zerdali phlebovirus & Zerdali virus (ZERV) \\
\hline \multirow[t]{2}{*}{ Pidchovirus } & Coleopteran pidchovirus & coleopteran phenui-related virus 308 (CoPrV-308) \\
\hline & Pidgey pidchovirus & Pidgey virus (PGYV) \\
\hline
\end{tabular}


Table 7 (continued)

\begin{tabular}{|c|c|c|}
\hline Genus & Species ${ }^{\pi}$ & Virus (abbreviation) ${ }^{\&}$ \\
\hline \multirow[t]{4}{*}{ Rubodvirus } & Apple rubodvirus 1 & apple rubbery wood virus 1 (ARWV-1) \\
\hline & Apple rubodvirus 2 & apple rubbery wood virus 2 (ARWV-2) \\
\hline & Grapevine rubodvirus 1 & grapevine Garan dmak virus (GGDV) \\
\hline & Grapevine rubodvirus 2 & grapevine Muscat rose virus (GMRV) \\
\hline Tanzavirus & Human tanzavirus & Dar es Salaam virus (DeSV) \\
\hline \multirow[t]{9}{*}{ Tenuivirus } & Echinochloa hoja blanca tenuivirus & Echinochloa hoja blanca virus (EHBV) \\
\hline & European wheat striate mosaic tenuivirus & European wheat striate mosaic virus (EWSMV) \\
\hline & Iranian wheat stripe tenuivirus & Iranian wheat stripe virus (IWSV) \\
\hline & Maize stripe tenuivirus & maize stripe virus $(\mathrm{MStV}=\mathrm{MSpV})$ \\
\hline & Melon tenuivirus & melon chlorotic spot virus (MeCSV) \\
\hline & Rice grassy stunt tenuivirus & rice grassy stunt virus (RGSV) \\
\hline & Rice hoja blanca tenuivirus & rice hoja blanca virus (RHBV) \\
\hline & Rice stripe tenuivirus & rice stripe virus $(\mathrm{RSV}=\mathrm{RStV})$ \\
\hline & Urochloa hoja blanca tenuivirus & Urochloa hoja blanca virus (UHBV) \\
\hline \multirow[t]{23}{*}{ Uukuvirus } & American dog uukuvirus & American dog tick virus (ADAV) \\
\hline & Dabieshan uukuvirus & Dàbiéshān tick virus (DBSH) \\
\hline & Grand Arbaud uukuvirus & Grand Arbaud virus (GAV) \\
\hline & Huangpi uukuvirus & Huángpí tick virus 2 (HpTV-2) \\
\hline & Kabuto mountain uukuvirus & Kabuto mountain virus (KAMV) \\
\hline & Kaisodi unkuvirus & Kaisodi virus (KASDV) \\
\hline & Lihan uukuvirus & Lǐhán tick virus (LITV) \\
\hline & Manawa unkuvirus & Manawa virus (MWAV) \\
\hline & Murre unkuvirus & murre virus (MURV) \\
\hline & Pacific coast unkuvirus & Pacific coast tick virus (PACV) \\
\hline & Precarious Point unkuvirus & Precarious Point virus (PPV) \\
\hline & Rukutama uukuvirus & Rukutama virus (RUKV) \\
\hline & Schmid uukuvirus & Nile Warbler virus (NIWV) \\
\hline & Silverwater uukuvirus & Silverwater virus (SILV) \\
\hline & Tacheng uukuvirus & Tăchéng tick virus 2 (TCGV) \\
\hline & Uukuniemi unkuvirus & Chizé virus (CHZV) \\
\hline & & Fin V 707 virus (FINV) \\
\hline & & Oceanside virus $(\mathrm{OCV}=\mathrm{OCEV})$ \\
\hline & & Pontevès virus (PTVV) \\
\hline & & St. Abbs Head virus (SAHV) \\
\hline & & Uukuniemi virus (UUKV) \\
\hline & Yongjia uukuvirus & Yǒngjiā tick virus (YONV) \\
\hline & Zaliv Terpeniya unkuvirus & Zaliv Terpeniya virus (ZTV) \\
\hline Wenrivirus & Shrimp wenrivirus & Mourilyan virus (MoV) \\
\hline \multicolumn{3}{|l|}{ Family Tospoviridae } \\
\hline \multirow[t]{16}{*}{ Orthotospovirus } & Alstroemeria necrotic streak orthotospovirus & Alstroemeria necrotic streak virus (ANSV) \\
\hline & Alstroemeria yellow spot orthotospovirus & Alstroemeria yellow spot virus (AYSV) \\
\hline & Bean necrotic mosaic orthotospovirus & bean necrotic mosaic virus (BeNMV) \\
\hline & Calla lily chlorotic spot orthotospovirus & calla lily chlorotic spot virus (CCSV) \\
\hline & Capsicum chlorosis orthotospovirus & Capsicum chlorosis virus $(\mathrm{CaCV})$ \\
\hline & Chrysanthemum stem necrosis orthotospovirus & Chrysanthemum stem necrosis virus (CSNV) \\
\hline & Groundnut bud necrosis orthotospovirus & groundnut bud necrosis virus (GBNV) \\
\hline & Groundnut chlorotic fan spot orthotospovirus & groundnut chlorotic fan-spot virus (GCFSV) \\
\hline & Groundnut ringspot orthotospovirus & groundnut ringspot virus (GRSV) \\
\hline & Groundnut yellow spot orthotospovirus & groundnut yellow spot virus (GYSV) \\
\hline & Hippeastrum chlorotic ringspot orthotospovirus & Hippeastrum chlorotic spot virus (HCRV) \\
\hline & Impatiens necrotic spot orthotospovirus & impatiens necrotic spot virus (INSV) \\
\hline & Iris yellow spot orthotospovirus & iris yellow spot virus (IYSV) \\
\hline & Melon severe mosaic orthotospovirus & melon severe mosaic virus (MSMV) \\
\hline & Melon yellow spot orthotospovirus & melon yellow spot virus (MYSV) \\
\hline & Mulberry vein banding associated orthotospovirus & mulberry vein banding-associated virus (MVBaV) \\
\hline
\end{tabular}


Table 7 (continued)

\begin{tabular}{|c|c|c|}
\hline Genus & Species ${ }^{\text {II }}$ & Virus (abbreviation) ${ }^{\&}$ \\
\hline & Pepper chlorotic spot orthotospovirus & pepper chlorotic spot virus (PCSV) \\
\hline & Polygonum ringspot orthotospovirus & Polygonum ringspot virus (PolRSV) \\
\hline & Soybean vein necrosis orthotospovirus & soybean vein necrosis virus (SVNV) \\
\hline & Tomato chlorotic spot orthotospovirus & tomato chlorotic spot virus (TCSV) \\
\hline & Tomato spotted wilt orthotospovirus & tomato spotted wilt virus (TSWV) \\
\hline & Tomato yellow ring orthotospovirus & tomato yellow ring virus (TYRV) \\
\hline & Tomato zonate spot orthotospovirus & tomato zonate spot virus (TZSV) \\
\hline & Watermelon bud necrosis orthotospovirus & watermelon bud necrosis virus (WBNV) \\
\hline & Watermelon silver mottle orthotospovirus & watermelon silver mottle virus (WSMoV) \\
\hline & Zucchini lethal chlorosis orthotospovirus & zucchini lethal chlorosis virus (ZLCV) \\
\hline \multicolumn{3}{|c|}{ Family Wupedeviridae } \\
\hline Wumivirus & Millipede wumivirus & Wǔhàn millipede virus 2 (WhMV-2) \\
\hline
\end{tabular}

Paola; Koray Ergünay; Aura R. Garrison; Roger Hewson; Jens H. Kuhn; Ali Mirazimi; Gustavo Palacios; Anna Papa (A $\nu \nu \alpha$ П $\alpha \pi \alpha$ ) ; Jessica R. Spengler), Negarnaviricota (Eugene V. Koonin; Mart Krupovic; Jens H. Kuhn; Yuri I. Wolf), Nyamiviridae (Ralf G. Dietzgen; Dàohóng

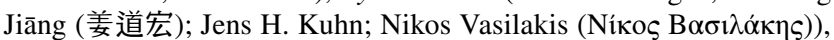
Orthomyxoviridae (Justin Bahl; Inmaculada Casas; Adolfo GarcíaSastre; Sergio H. Marshall; John W. McCauley; Gabriele Neumann; Colin R. Parrish; Daniel R. Pérez; Jonathan A. Runstadler; Martin Schwemmle), Paramyxoviridae (Anne Balkema-Buschmann; William G. Dundon; W. Paul Duprex; Andrew J. Easton; Gael Kurath; Benhur Lee; Bertus K. Rima; Lin-Fa Wang (王林发)), Peribunyaviridae (Scott Adkins; Sergey V. Alkhovsky (Альховский Сергей Владимирович); Martin Beer; Carol D. Blair; Charles H. Calisher; Michael A. Drebot; Holly R. Hughes; Amy J. Lambert; William Marciel de Souza; Marco Marklewitz; Xiǎohóng Shí (石晓宏)), Phasmaviridae (Matthew J. Ballinger; Roy A. Hall; Sandra Junglen; Stanley L. Langevin; Alex Pauvolid-Corrêa), Phenuiviridae (Thomas Briese; Rémi N. Charrel; Hideki Ebihara (海老原秀喜); Martin H. Groschup; Gustavo Palacios; Takahide Sasaya (笹谷孝英); Jin-Won Song (송 진 원)), Pneumoviridae (Paul A. Brown; Ursula J. Buchholz; Rik L. de Swart; J. Felix Drexler; W. Paul Duprex; Andrew J. Easton; Jiànróng Lǐ (李建荣); Kirsten Spann; Natalie J. Thornburg; Bernadette van den Hoogen; John V. Williams), Rhabdoviridae (Kim R. Blasdell; Rachel Breyta; Ralf G. Dietzgen; Anthony R. Fooks; Juliana Freitas-Astúa; Hideki Kondō (近 藤秀樹); Gael Kurath; David M. Stone; Robert B. Tesh; Noël Tordo;

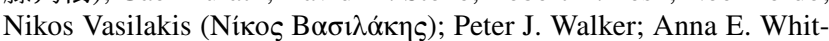
field), Sunviridae (Gael Kurath), Tenuivirus (Il-Ryong Choi; Gilda B. Jonson; Takahide Sasaya (笹谷孝英); Yukio Shirako; Tàiyún Wèi (魏 太云); Xueping Zhou (周雪平)), and Tospoviridae (Scott Adkins; Amy J. Lambert; Rayapati Naidu; Renato O. Resende; Massimo Turina; Anna E. Whitfield)

2017-2020 and 2020-2023 ICTV Chair of the Animal dsRNA and ssRNA- Viruses Subcommittee (Jens H. Kuhn); 2020-2023 ICTV Chair of the Archaeal Viruses Subcommittee (Mart Krupovic); 2020-2023 ICTV Data Secretary (Elliot J. Lefkowitz); 2017-2020 Elected Member of the ICTV Executive Committee and 2020-2023 ICTV Chair of the Plant Viruses Subcommittee (Luisa Rubino); 2017-2020 Elected Member of the ICTV Executive Committee and 2020-2023 ICTV Chair Fungal and Protist Viruses Subcommittee
(Sead Sabanadzovic); 2020-2023 ICTV Vice-President (Stuart G. Siddell); 2017-2020 ICTV Chair of the Fungal and Protist Viruses Subcommittee and 2020-2023 ICTV Chair of the Animal ssRNA+ Viruses Subcommittee (Peter Simmonds); 2017-2020 Elected Member of the ICTV Executive Committee and 2020-2023 ICTV Chair of the Animal DNA Viruses and Retroviruses Subcommittee (Arvind Varsani); 2017-2020 and 2020-2023 ICTV Proposal Secretary (Peter J. Walker); and 2017-2020 ICTV Chair of the Plant Viruses Subcommittee and the 2020-2023 ICTV President (F. Murilo Zerbini)

Chair of the 2017-2020 and 2020-2023 ICTV Bunyavirales, Filoviridae, and Negarnaviricota Study Groups (Jens H. Kuhn); Chair of the 2017-2020 and 2020-2023 ICTV Arenaviridae Study Group (Juan Carlos de la Torre); Chair of the 2020 and 2020-2023 ICTV Jingchuvirales Study Group (Nicholas Di Paola); Chair of the 2017-2020 and 2020-2023 ICTV Artoviridae and Nyamiviridae Study Groups (Ralf G. Dietzgen); Chair of the 2017-2020 and 2020-2023 ICTV Pneumoviridae Study Group (W. Paul Duprex); Chair of the 2017-2020 (Peter J. Walker) and Co-Chairs of the 2020-2023 (Juliana Freitas-Astúa and Peter J. Walker) ICTV Rhabdoviridae Study Group (Juliana FreitasAstúa; Peter J. Walker); Chair of the 2017-2020 and 2020-2023 ICTV Orthomyxoviridae Study Group (Adolfo García-Sastre); Chair of the 2020-2023 ICTV Peribunyaviridae Study Group (Holly R. Hughes); Chair of the 2017-2020 and 2020-2023 ICTV Sunviridae Study Group (Timothy H. Hyndman); Chair of the 2017-2020 and 2020-2023 ICTV Mymonaviridae Study Group (Dàohóng Jiāng (姜道宏)); Chair of the 2017-2020 and 2020-2023 ICTV Phasmaviridae Study Group (Sandra Junglen); Chair of the 2017-2020 and 2020-2023 ICTV Hantaviridae and Monjiviricetes Study Groups (Piet Maes); Chair of the 2017-2020 2020-2023 ICTV Nairoviridae and Study Group (Gustavo Palacios); Chairs of the 2017-2020 (Gustavo Palacios) and Co-Chairs (Gustavo Palacios and Takahide Sasaya) of the 2020-2023 ICTV Phenuiviridae Study Group (Gustavo Palacios and Takahide Sasaya (笹谷孝英)); and Chair of the 2017-2020 and 2020-2023 ICTV Bornaviridae Study Group (Dennis Rubbenstroth)

Funding This work was supported in part through Laulima Government Solutions, LLC prime contract with the US National Institute of Allergy and Infectious Diseases (NIAID) under Contract No. HHSN272201800013C. J.H.K. performed this work as an 
employee of Tunnell Government Services (TGS), a subcontractor of Laulima Government Solutions, LLC under Contract No. HHSN272201800013C. This work was also supported in part with federal funds from the National Cancer Institute (NCI), National Institutes of Health (NIH), under Contract No. 75N91019D00024, Task Order No. 75N91019F00130 to I.C., who was supported by the Clinical Monitoring Research Program Directorate, Frederick National Lab for Cancer Research. This work was also funded in part by Contract No. HSHQDC-15-C-00064 awarded by DHS S\&T for the management and operation of The National Biodefense Analysis and Countermeasures Center, a federally funded research and development center operated by the Battelle National Biodefense Institute (V.W.); and NIH contract HHSN272201000040I/HHSN27200004/D04 and grant R24AI120942 (N.V., R.B.T.). S.S. acknowledges partial support from the Special Research Initiative of Mississippi Agricultural and Forestry Experiment Station (MAFES), Mississippi State University, and the National Institute of Food and Agriculture, US Department of Agriculture, Hatch Project 1021494. Part of this work was supported by the Francis Crick Institute which receives its core funding from Cancer Research UK (FC001030), the UK Medical Research Council (FC001030), and the Wellcome Trust (FC001030).

\section{Declarations}

Conflict of interest The authors declare no conflicts of interest. The views and conclusions contained in this document are those of the authors and should not be interpreted as necessarily representing the official policies, either expressed or implied, of the US Department of the Army, the US Department of Defense, the US Department of Health and Human Services, the US Department of Homeland Security (DHS) Science and Technology Directorate (S\&T), or of the institutions and companies affiliated with the authors. In no event shall any of these entities have any responsibility or liability for any use, misuse, inability to use, or reliance upon the information contained herein. The US departments do not endorse any products or commercial services mentioned in this publication. The US Government retains and the publisher, by accepting the article for publication, acknowledges that the US Government retains a non-exclusive, paid up, irrevocable, world-wide license to publish or reproduce the published form of this manuscript, or allow others to do so, for US Government purposes.

Ethical approval This article does not contain any studies with human participants or animals performed by any of the authors.

\section{References}

1. Alkan C, Erisoz Kasap O, Alten B, de Lamballerie X, Charrel RN (2016) Sandfly-borne phlebovirus isolations from Turkey: new insight into the Sandfly fever Sicilian and Sandfly fever Naples species. PLoS Negl Trop Dis 10:e0004519

2. Arai S, Nguyen ST, Boldgiv B, Fukui D, Araki K, Dang CN, Ohdachi SD, Nguyen NX, Pham TD, Boldbaatar B, Satoh H, Yoshikawa Y, Morikawa S, Tanaka-Taya K, Yanagihara R, Oishi K (2013) Novel bat-borne hantavirus Vietnam. Emerg Infect Dis 19:1159-1161

3. Argenta FF, Hepojoki J, Smura T, Szirovicza L, Hammerschmitt ME, Driemeier D, Kipar A, Hetzel U (2020) Identification of reptarenaviruses, hartmaniviruses, and a novel chuvirus in captive native Brazilian boa constrictors with boid inclusion body disease. J Virol 94:e00001-20

4. Baek D, Lim S, Ju H-J, Kim H-R, Lee S-H, Moon JS (2019) The complete genome sequence of apple rootstock virus A, a novel nucleorhabdovirus identified in apple rootstocks. Arch Virol 164:2641-2644

5. Ballinger MJ, Taylor DJ (2019) Evolutionary persistence of insect bunyavirus infection despite host acquisition and expression of the viral nucleoprotein gene. Virus Evol 5:vez017

6. Bejerman N, Acevedo RM, de Breuil S, Ruiz OA, Sansberro P, Dietzgen RG, Nome C, Debat H (2020) Molecular characterization of a novel cytorhabdovirus with a unique genomic organization infecting yerba mate (Ilex paraguariensis) in Argentina. Arch Virol 165:1475-1479

7. Bennett AJ, Paskey AC, Kuhn JH, Bishop-Lilly KA, Goldberg TL (2020) Diversity, transmission, and cophylogeny of ledanteviruses (Rhabdoviridae: Ledantevirus) and nycteribiid bat flies parasitizing Angolan soft-furred fruit bats in Bundibugyo District, Uganda. Microorganisms 8:750

8. Bertazzon N, Chitarra W, Angelini E, Nerva L (2020) Two new putative plant viruses from wood metagenomics analysis of an esca diseased vineyard. Plants (Basel) 9:835

9. Bhat AI, Pamitha NS, Naveen KP, Biju CN (2020) Identification and characterization of cardamom vein clearing virus, a novel aphid-transmitted nucleorhabdovirus. Eur J Plant Pathol 156:1053-1062

10. Bishop DHL, Calisher CH, Casals J, Chumakov MP, Gaidamovich SY, Hannoun C, Lvov DK, Marshall ID, Oker-Blom N, Pettersson RF, Porterfield JS, Russell PK, Shope RE, Westaway EG (1980) Bunyaviridae. Intervirology 14:125-143

11. Black L (1940) Strains of potato yellow-dwarf virus. Am J Bot 27:386-392

12. Blasdell KR, Davis SS, Voysey R, Bulach DM, Middleton D, Williams S, Harmsen MB, Weir RP, Crameri S, Walsh SJ, Peck GR, Tesh RB, Boyle DB, Melville LF, Walker PJ (2020) Hayes Yard virus: a novel ephemerovirus isolated from a bull with severe clinical signs of bovine ephemeral fever is most closely related to Puchong virus. Vet Res 51:58

13. Bojko J, Subramaniam K, Waltzek TB, Stentiford GD, Behringer DC (2019) Genomic and developmental characterisation of a novel bunyavirus infecting the crustacean Carcinus maenas. Sci Rep 9:12957

14. Bouquet J, Melgar M, Swei A, Delwart E, Lane RS, Chiu CY (2017) Metagenomic-based surveillance of Pacific Coast tick Dermacentor occidentalis Identifies two novel bunyaviruses and an emerging human ricksettsial pathogen. Sci Rep 7:12234

15. Cao M, Zhang S, Li M, Liu Y, Dong P, Li S, Kuang M, Li R, Zhou Y (2019) Discovery of four novel viruses associated with flower yellowing disease of green Sichuan pepper (Zanthoxylum armatum) by virome analysis. Viruses 11:696

16. Chappell JG, Tsoleridis T, Onianwa O, Drake G, Ashpole I, Dobbs P, Edema W, Kumi-Ansah F, Bennett M, Tarlinton RE, Ball JK, McClure CP (2020) Retrieval of the complete coding sequence of the UK-endemic Tatenale orthohantavirus reveals extensive strain variation and supports its classification as a novel species. Viruses 12:454

17. Chiapello M, Rodríguez-Romero J, Ayllón MA, Turina M (2020) Analysis of the virome associated to grapevine downy mildew lesions reveals new mycovirus lineages. Virus Evol 6:veaa058

18. Chiapello M, Rodríguez-Romero J, Nerva L, Forgia M, Chitarra W, Ayllón MA, Turina M (2020) Putative new plant viruses associated with Plasmopara viticola-infected grapevine samples. Ann Appl Biol 176:180-191

19. Cowley JA, McCulloch RJ, Spann KM, Cadogan LC, Walker PJ (2005) Preliminary molecular and biological characterisation of Mourilyan virus (MoV): a new bunya-related virus of penaeid prawns. In: Diseases in Asian aquaculture V Proceedings of the 5th symposium on diseases in Asian aquaculture, Gold Coast, Australia. Asian Fisheries Society, Manila, Philippines, pp 113-124 
20. Cowley JA (2021) The genomes of Mourilyan virus and Wēnzhōu shrimp virus 1 of prawns comprise 4 RNA segments. Virus Res 292:198225

21. de Lara-Pinto AZ, Santos-de-Carvalho M, de Melo FL, Ribeiro ALM, Morais-Ribeiro B, Dezengrini Slhessarenko R (2017) Novel viruses in salivary glands of mosquitoes from sylvatic Cerrado Midwestern Brazil. PLoS ONE 12:e0187429

22. de Oliveira Filho EF, Moreira-Soto A, Fischer C, Rasche A, Sander AL, Avey-Arroyo J, Arroyo-Murillo F, Corrales-Aguilar E, Drexler JF (2020) Sloths host Anhanga virus-related phleboviruses across large distances in time and space. Transbound Emerg Dis 67:11-17

23. Dhaygude K, Johansson H, Kulmuni J, Sundström L (2019) Genome organization and molecular characterization of the three Formica exsecta viruses-FeV1, FeV2 and FeV4. PeerJ 6:e6216

24. Diaz-Lara A, Navarro B, Di Serio F, Stevens K, Hwang MS, Kohl J, Vu ST, Falk BW, Golino D, Al Rwahnih M (2019) Two novel negative-sense RNA viruses infecting grapevine are members of a newly proposed genus within the family Phenuiviridae. Viruses 11:685

25. Ding X, Chen D, Du Z, Zhang J, Wu Z (2019) The complete genome sequence of a novel cytorhabdovirus identified in strawberry (Fragaria ananassa Duch.). Arch Virol 164:3127-3131

26. Doherty RL, Carley JG, Mackerras MJ, Marks EN (1963) Studies of arthropod-borne virus infections in Queensland. III. Isolation and characterization of virus strains from wild-caught mosquitoes in North Queensland. Aust J Exp Biol Med Sci 41:17-39

27. Doherty RL, Whitehead RH, Wetters EJ, Gorman BM (1968) Studies of the epidemiology of arthropod-borne viru infections at Mitchell River Mission, Cape York Peninsula, North Queensland. II. Arbovirus infections of mosquitoes, man and domestic fowls, 1963-1966. Trans R Soc Trop Med Hyg 62:430-438

28. Ergünay K, Brinkmann A, Litzba N, Günay F, Kar S, Öter K, Örsten S, Sarıkaya Y, Alten B, Nitsche A, Linton Y-M (2017) A novel rhabdovirus, related to Merida virus, in fieldcollected mosquitoes from Anatolia and Thrace. Arch Virol 162:1903-1911

29. Ergünay K, Dinçer E, Kar S, Emanet N, Yalçınkaya D, Polat Dinçer PF, Brinkmann A, Hacıoğlu S, Nitsche A, Özkul A, Linton YM (2020) Multiple orthonairoviruses including CrimeanCongo hemorrhagic fever virus, Tamdy virus and the novel Meram virus in Anatolia. Ticks Tick Borne Dis 11:101448

30. Faizah AN, Kobayashi D, Isawa H, Amoa-Bosompem M, Murota K, Higa Y, Futami K, Shimada S, Kim KS, Itokawa K, Watanabe M, Tsuda Y, Minakawa N, Miura K, Hirayama K, Sawabe K (2020) Deciphering the virome of Culex vishnui subgroup mosquitoes, the major vectors of Japanese encephalitis, in Japan. Viruses 12:264

31. Fránová J, Přibylová J, Koloniuk I (2019) Molecular and biological characterization of a new strawberry cytorhabdovirus. Viruses 11:982

32. Fránová J, Sarkisova T, Jakešová H, Koloniuk I (2019) Molecular and biological properties of two putative new cytorhabdoviruses infecting Trifolium pratense. Plant Pathol 68:1276-1286

33. Gard G, Marshall ID, Woodroofe GM (1973) Annually recurrent epidemic polyarthritis and Ross River virus activity in a coastal area of New South Wales. II. Mosquitoes, viruses, and wildlife. Am J Trop Med Hyg 22:551-560

34. Gauci PJ, McAllister J, Mitchell IR, Boyle DB, Bulach DM, Weir RP, Melville LF, Gubala AJ (2015) Genomic characterisation of three Mapputta group viruses, a serogroup of Australian and Papua New Guinean bunyaviruses associated with human disease. PLoS ONE 10:e0116561

35. Gauci PJ, McAllister J, Mitchell IR, Weir RP, Melville LF, Gubala AJ (2016) Genomic characterization of Trubanaman and Gan Gan viruses, two bunyaviruses with potential significance to public health in Australia. Virol Rep 6:1-10

36. Gauci PJ, McAllister J, Mitchell IR, Cybinski D, St George T, Gubala AJ (2017) Genomic characterisation of Vinegar Hill virus, an Australian nairovirus Isolated in 1983 from Argas robertsi ticks collected from cattle egrets. Viruses 9:373

37. Goh CJ, Park D, Hahn Y (2020) Identification of Trichosanthes associated rhabdovirus 1 , a novel member of the genus Cytorhabdovirus of the family Rhabdoviridae, in the Trichosanthes kirilowii transcriptome. Acta Virol 64:36-43

38. Gondard M, Temmam S, Devillers E, Pinarello V, Bigot T, Chrétien D, Aprelon R, Vayssier-Taussat M, Albina E, Eloit M, Moutailler S (2020) RNA Viruses of Amblyomma variegatum and Rhipicephalus microplus and cattle susceptibility in the French Antilles. Viruses 12:144

39. Han X, Wang H, Wu N, Liu W, Cao M, Wang X (2020) Leafhopper Psammotettix alienus hosts chuviruses with different genomic structures. Virus Res 285:197992

40. Hao F, Wu M, Li G (2018) Molecular characterization and geographic distribution of a mymonavirus in the population of Botrytis cinerea. Viruses 10:432

41. Harvey E, Rose K, Eden J-S, Lawrence A, Doggett SL, Holmes EC (2019) Identification of diverse arthropod associated viruses in native Australian fleas. Virology 535:189-199

42. Harvey E, Rose K, Eden JS, Lo N, Abeyasuriya T, Shi M, Doggett SL, Holmes EC (2019) Extensive diversity of RNA viruses in Australian ticks. J Virol 93:e01358-e1418

43. Hepojoki J, Hepojoki S, Smura T, Szirovicza L, Dervas E, Prähauser B, Nufer L, Schraner EM, Vapalahti O, Kipar A, Hetzel U (2018) Characterization of Haartman Institute snake virus-1 (HISV-1) and HISV-like viruses-The representatives of genus Hartmanivirus, family Arenaviridae. PLoS Pathog 14:e1007415

44. Huang P, Zhang X, Ame KH, Shui Y, Xu Z, Serwadda A, Shen $H$ (2019) Genomic and phylogenetic characterization of a bunya-like virus from the freshwater Chinese mitten crab Eriocheir sinensis. Acta Virol 63:433-438

45. Hubálek Z, Juricová Z, Halouzka J, Pellantová J, Hudec K (1989) Arboviruses associated with birds in southern Moravia, Czechoslovakia. Acta Sci Nat Brno 23:1-50

46. Hubálek Z, Juricová Z, Halouzka J, Butenko AM, Kondrasina NG, Guscina EA, Morozova TN (1990) Isolation and characterization of Sedlec virus, a new bunyavirus from birds. Acta Virol 34:339-345

47. Ilyas M, Avelar S, Schuch UK, Brown JK (2018) First report of an emaravirus associated with witches' broom disease and eriophyid mite infestations of the blue palo verde tree in Arizona. Plant Dis 102:1863-1863

48. Jang C, Wang R, Wells J, Leon F, Farman M, Hammond J, Goodin MM (2017) Genome sequence variation in the constricta strain dramatically alters the protein interaction and localization map of Potato yellow dwarf virus. J Gen Virol 98:1526-1536

49. Käfer S, Paraskevopoulou S, Zirkel F, Wieseke N, Donath A, Petersen M, Jones TC, Liu S, Zhou X, Middendorf M, Junglen S, Misof B, Drosten C (2019) Re-assessing the diversity of negative strand RNA viruses in insects. PLoS Pathog 15:e1008224

50. Kapuscinski ML, Bergren NA, Russell BJ, Lee JS, Borland EM, Hartman DA, King DC, Hughes HR, Burkhalter KL, Kading RC, Stenglein MD (2021) Genomic characterization of 99 viruses from the bunyavirus families Nairoviridae, Peribunyaviridae, and Phenuiviridae, including 35 previously unsequenced viruses. PLoS Pathog 17:e1009315 
51. Karabatsos N (1985) International catalogue of arboviruses including certain other viruses of vertebrates, 3rd edn. American Society for Tropical Medicine and Hygiene, San Antonio

52. Kleanthous E, Olendraite I, Lukhovitskaya NI, Firth AE (2019) Discovery of three RNA viruses using ant transcriptomic datasets. Arch Virol 164:643-647

53. Koloniuk I, Fránová J, Sarkisova T, Přibylová J, Lenz O, Petrzik K, Špak J (2018) Identification and molecular characterization of a novel varicosa-like virus from red clover. Arch Virol 163:2213-2218

54. Kondo H, Chiba S, Toyoda K, Suzuki N (2013) Evidence for negative-strand RNA virus infection in fungi. Virology 435:201-209

55. Kubota K, Usugi T, Tomitaka Y, Shimomoto Y, Takeuchi S, Kadono F, Yanagisawa H, Chiaki Y, Tsuda S (2020) Perilla mosaic virus is a highly divergent emaravirus transmitted by Shevtchenkella sp. (Acari: Eriophyidae). Phytopathology 110:1352-1361

56. Kuhn JH, Wolf YI, Krupovic M, Zhang Y-Z, Maes P, Dolja VV, Koonin EV (2019) Classify viruses - the gain is worth the pain. Nature 566:318-320

57. Kuhn JH, Adkins S, Alioto D, Alkhovsky SV, Amarasinghe GK, Anthony SJ, Avšič-Županc T, Ayllón MA, Bahl J, Balkema-Buschmann A, Ballinger MJ, Bartonička T, Basler C, Bavari S, Beer M, Bente DA, Bergeron É, Bird BH, Blair C, Blasdell KR, Bradfute SB, Breyta R, Briese T, Brown PA, Buchholz UJ, Buchmeier MJ, Bukreyev A, Burt F, Buzkan $\mathrm{N}$, Calisher $\mathrm{CH}$, Cao M, Casas I, Chamberlain J, Chandran K, Charrel RN, Chen B, Chiumenti M, Choi I-R, Clegg JCS, Crozier I, da Graça JV, Dal Bó E, Dávila AMR, de la Torre JC, de Lamballerie X, de Swart RL, Di Bello PL, Di Paola N, Di Serio F, Dietzgen RG, Digiaro M, Dolja VV, Dolnik O, Drebot MA, Drexler JF, Dürrwald R, Dufkova L, Dundon WG, Duprex WP, Dye JM, Easton AJ, Ebihara H, Elbeaino T, Ergünay K, Fernandes J, Fooks AR, Formenty PBH, Forth LF, Fouchier RAM, Freitas-Astúa J, Gago-Zachert S, Gāo GF, García ML, García-Sastre A, Garrison AR, Gbakima A, Goldstein T, Gonzalez J-PJ, Griffiths A, Groschup MH, Günther S, Guterres A, Hall RA, Hammond J, Hassan M, Hepojoki J, Hepojoki S, Hetzel U, Hewson R, Hoffmann B, Hongo S, Höper D, Horie M, Hughes HR, Hyndman TH, Jambai A, Jardim R, Jiāng D, Jin Q, Jonson GB, Junglen S, Karadağ S, Keller KE, Klempa B, Klingström J, Kobinger G, Kondō H, Koonin EV, Krupovic M, Kurath G, Kuzmin IV, Laenen L, Lamb RA, Lambert AJ, Langevin SL, Lee B, Lemos ERS, Leroy EM, Li D, Lǐ J, Liang M, Liú W, Liú Y, Lukashevich IS, Maes P, Marciel de Souza W, Marklewitz M, Marshall SH, Martelli GP, Martin RR, Marzano S-YL, Massart S, McCauley JW, Mielke-Ehret N, Minafra A, Minutolo M, Mirazimi A, Mühlbach H-P, Mühlberger E, Naidu R, Natsuaki T, Navarro B, Navarro JA, Netesov SV, Neumann G, Nowotny N, Nunes MRT, Nylund A, Økland AL, Oliveira RC, Palacios G, Pallas V, Pályi B, Papa A, Parrish CR, Pauvolid-Corrêa A, Pawęska JT, Payne S, Pérez DR, Pfaff F, Radoshitzky SR, Rahman A-u, Ramos-González PL, Resende RO, Reyes CA, Rima BK, Romanowski V, Robles Luna G, Rota P, Rubbenstroth D, Runstadler JA, Ruzek D, Sabanadzovic S, Salát J, Sall AA, Salvato MS, Sarpkaya K, Sasaya T, Schwemmle M, Shabbir MZ, Shí X, Shí Z, Shirako Y, Simmonds P, Širmarová J, Sironi M, Smither S, Smura T, Song J-W, Spann KM, Spengler JR, Stenglein MD, Stone DM, Straková P, Takada A, Tesh RB, Thornburg NJ, Tomonaga K, Tordo N, Towner JS, Turina M, Tzanetakis I, Ulrich RG, Vaira AM, van den Hoogen B, Varsani A, Vasilakis N, Verbeek M, Wahl V, Walker PJ, Wang H, Wang J, Wang X, Wang L-F, Wèi T, Wells H, Whitfield AE, Williams JV, Wolf YI, Wú Z, Yang X, Yáng X, Yu X, Yutin N, Zerbini FM, Zhang T, Zhang Y-Z,
Zhou G, Zhou X (2020) 2020 taxonomic update for phylum Negarnaviricota (Riboviria: Orthornavirae), including the large orders Bunyavirales and Mononegavirales. Arch Virol 165:3023-3072

58. Kuwata R, Isawa H, Hoshino K, Tsuda Y, Yanase T, Sasaki T, Kobayashi M, Sawabe K (2011) RNA splicing in a new rhabdovirus from Culex mosquitoes. J Virol 85:6185-6196

59. Lanciotti RS, Kosoy OI, Bosco-Lauth AM, Pohl J, Stuchlik O, Reed M, Lambert AJ (2013) Isolation of a novel orthobunyavirus (Brazoran virus) with a $1.7 \mathrm{~kb} \mathrm{~S}$ segment that encodes a unique nucleocapsid protein possessing two putative functional domains. Virology 444:55-63

60. Laubscher F, Cordey S, Hartley M-A, Vieille G, Boillat-Blanco N, Samaka J, Mlaganile T, d'Acremont V, Kaiser L (2019) Nearly complete genome sequence of a novel phlebovirus-like virus detected in a human plasma sample by high-throughput sequencing. Microbiol Resour Announc 8:e00764-e819

61. Li CX, Shi M, Tian JH, Lin XD, Kang YJ, Chen LJ, Qin XC, Xu J, Holmes EC, Zhang YZ (2015) Unprecedented genomic diversity of RNA viruses in arthropods reveals the ancestry of negative-sense RNA viruses. Elife 4:e05378

62. Lima JA, Nunes Neto JP, Castro KS, Travassos da Rosa APA, Tesh R, Nunes MRT, Popov VL, Vasilakis N, Guzman H, Widen S, Silva SPD, Medeiros DBA, Cardoso JF, Martins LC, Azevedo R, Vasconcelos P, Chiang JO (2019) Characterization of Triniti virus supports its reclassification in the family Peribunyaviridae. J Gen Virol 100:137-144

63. Liu H, Wang G, Yang Z, Wang Y, Zhang Z, Li L, Waqas M, Hong N, Liu H, Wang G, Hong N, Hong J, Zhang J, Xu L, Qi L (2020) Identification and characterization of a pear chlorotic leaf spot-associated virus, a novel emaravirus associated with a severe disease of pear trees in China. Plant Dis 104:2786-2798

64. Liu YP, Kuo S-T, Chiou C-J, Terregino C, Tsai H-J (2019) Novel avian metaavulavirus isolated from birds of the family Columbidae in Taiwan. Vet Microbiol 236:108377

65. Longdon B, Murray GG, Palmer WJ, Day JP, Parker DJ, Welch JJ, Obbard DJ, Jiggins FM (2015) The evolution, diversity, and host associations of rhabdoviruses. Virus Evol 1:vev014

66. Lvov DK, Gromashevsky VL, Zakaryan VA, Skvortsova TM, Berezina LK, Gofman YP, Klimenko SM, Chubkova AL (1978) Razdan virus, a new ungrouped bunyavirus isolated from Dermacentor marginatus ticks in Armenia. Acta Virol 22:506-508

67. Ma H, Galvin TA, Glasner DR, Shaheduzzaman S, Khan AS (2014) Identification of a novel rhabdovirus in Spodoptera frugiperda cell lines. J Virol 88:6576-6585

68. Marklewitz M, Tchouassi DP, Hieke C, Heyde V, Torto B, Sang R, Junglen S (2020) Insights into the evolutionary origin of Mediterranean sandfly fever viruses. mSphere 5:e00598-e620

69. Marshall ID, Woodroofe GM, Gard GP (1980) Arboviruses of coastal south-eastern Australia. Aust J Exp Biol Med Sci 58:91-102

70. Medd NC, Fellous S, Waldron FM, Xuéreb A, Nakai M, Cross JV, Obbard DJ (2018) The virome of Drosophila suzukii, an invasive pest of soft fruit. Virus Evol 4:vev009

71. Mordecai GJ, Miller KM, Di Cicco E, Schulze AD, Kaukinen KH, Ming TJ, Li S, Tabata A, Teffer A, Patterson DA, Ferguson HW, Suttle CA (2019) Endangered wild salmon infected by newly discovered viruses. Elife 8:e47615

72. Mu F, Xie J, Cheng S, You MP, Barbetti MJ, Jia J, Wang Q, Cheng J, Fu Y, Chen T, Jiang D (2017) Virome characterization of a collection of $S$. sclerotiorum from Australia. Front Microbiol 8:2540

73. Nerva L, Turina M, Zanzotto A, Gardiman M, Gaiotti F, Gambino G, Chitarra W (2019) Isolation, molecular characterization and virome analysis of culturable wood fungal endophytes 
in esca symptomatic and asymptomatic grapevine plants. Environ Microbiol 21:2886-2904

74. Olmedo-Velarde A, Park AC, Sugano J, Uchida JY, Kawate M, Borth WB, Hu JS, Melzer MJ (2019) Characterization of Ti ringspot-associated virus, a novel emaravirus associated with an emerging ringspot disease of Cordyline fruticosa. Plant Dis 103:2345-2352

75. Öncü C, Brinkmann A, Günay F, Kar S, Öter K, Sarıkaya Y, Nitsche A, Linton Y-M, Alten B, Ergünay K (2018) West Nile virus, Anopheles flavivirus, a novel flavivirus as well as Meridalike rhabdovirus Turkey in field-collected mosquitoes from Thrace and Anatolia. Infect Genet Evol 57:36-45

76. Onyuok SO, Hu B, Li B, Fan Y, Kering K, Ochola GO, Zheng X-S, Obanda V, Ommeh S, Yang X-L, Agwanda B, Shi Z-L (2019) Molecular detection and genetic characterization of novel RNA viruses in wild and synanthropic rodents and shrews in Kenya. Front Microbiol 10:2696

77. Papadopoulos O, Koptopoulos G (1980) Crimean-Congo hemorrhagic fever (CCHF) in Greece: isolation of the virus from Rhipicephalus bursa ticks and a preliminary serological survey. In: Vesenjak-Hirjan J (ed) Arboviruses in the Mediterranean countries. Gustav Fischer Verlag, Stuttgart, pp 117-121

78. Peracchio C, Forgia M, Chiapello M, Vallino M, Turina M, Ciuffo M (2020) A complex virome including two distinct emaraviruses associated with virus-like symptoms in Camellia japonica. Virus Res 286:197964

79. Pettersson JH-O, Shi M, Bohlin J, Eldholm V, Brynildsrud OB, Paulsen KM, Andreassen A, Holmes EC (2017) Characterizing the virome of Ixodes ricinus ticks from northern Europe. Sci Rep 7:10870

80. Pettersson JH-O, Shi M, Eden J-S, Holmes EC, Hesson JC (2019) Meta-transcriptomic comparison of the RNA viromes of the mosquito vectors Culex pipiens and Culex torrentium in Northern Europe. Viruses 11:1033

81. Pounder KC, Begon M, Sironen T, Henttonen H, Watts PC, Voutilainen L, Vapalahti O, Klempa B, Fooks AR, McElhinney LM (2013) Novel hantavirus in wildlife, United Kingdom. Emerg Infect Dis 19:673-675

82. Reeves WK, Miller MM, Gruner WE (2018) Two Rhabdoviridae: Dillard's Draw virus, a putative new virus, and Merida virus from Culex tarsalis (Diptera: Culicidae) in New Mexico, USA. Acta Virol 62:326-329

83. Rodhain F, Maduloleblond G, Hannoun C, Tesh RB (1985) Le virus Corfou : un nouveau Phlebovirus isolé de phlébotomes en Grèce. Ann Inst Pasteur Virol 136E:161-166

84. Ruiz-Padilla A, Rodríguez-Romero J, Gómez-Cid I, Pacifico D, Ayllón MA (2021) Novel mycoviruses discovered in the mycovirome of a necrotrophic fungus. MBio 12:e03705-e03720

85. Sabbadin F, Glover R, Stafford R, Rozado-Aguirre Z, Boonham N, Adams I, Mumford R, Edwards R (2017) Transcriptome sequencing identifies novel persistent viruses in herbicide resistant wild-grasses. Sci Rep 7:41987

86. Sadeghi M, Altan E, Deng X, Barker CM, Fang Y, Coffey LL, Delwart E (2018) Virome of $>12$ thousand Culex mosquitoes from throughout California. Virology 523:74-88

87. Sameroff S, Tokarz R, Charles RA, Jain K, Oleynik A, Che X, Georges K, Carrington CV, Lipkin WI, Oura C (2019) Viral diversity of tick species parasitizing cattle and dogs in Trinidad and Tobago. Sci Rep 9:10421

88. Schoonvaere K, De Smet L, Smagghe G, Vierstraete A, Braeckman BP, de Graaf DC (2016) Unbiased RNA shotgun metagenomics in social and solitary wild bees detects associations with eukaryote parasites and new viruses. PLoS ONE 11:e0168456

89. Shi C, Beller L, Deboutte W, Yinda KC, Delang L, Vega-Rúa A, Failloux AB, Matthijnssens J (2019) Stable distinct core eukaryotic viromes in different mosquito species from Guadeloupe, using single mosquito viral metagenomics. Microbiome 7:121
90. Shi J, Shen S, Wu H, Zhang Y, Deng F (2021) Metagenomic profiling of viruses associated with Rhipicephalus microplus ticks in Yunnan Province, China. Virol Sin

91. Shi M, Lin X-D, Tian J-H, Chen L-J, Chen X, Li CX, Qin X-C, Li J, Cao J-P, Eden J-S, Buchmann J, Wang W, Xu J, Holmes EC, Zhang Y-Z (2016) Redefining the invertebrate RNA virosphere. Nature 540:539-543

92. Shi M, Lin X-D, Chen X, Tian J-H, Chen L-J, Li K, Wang W, Eden J-S, Shen J-J, Liu L, Holmes EC, Zhang Y-Z (2018) The evolutionary history of vertebrate RNA viruses. Nature 556:197-202

93. Siddell SG, Walker PJ, Lefkowitz EJ, Mushegian AR, Adams MJ, Dutilh BE, Gorbalenya AE, Bz H, Harrison RL, Junglen S, Knowles NJ, Kropinski AM, Krupovic M, Kuhn JH, Nibert M, Rubino L, Sabanadzovic S, Sanfaçon H, Simmonds P, Varsani A, Zerbini FM, Davison AJ (2019) Additional changes to taxonomy ratified in a special vote by the International Committee on Taxonomy of Viruses (October 2018). Arch Virol 164:943-946

94. Siqueira Maia LM, de Lara Pinto AZ, Santos de Carvalho M, de Melo FL, Morais Ribeiro B, Dezengrini Slhessarenko R (2019) Novel viruses in mosquitoes from Brazilian Pantanal. Viruses 11:957

95. Sõmera M, Kvarnheden A, Desbiez C, Blystad DR, Sooväli P, Kundu JK, Gantsovski M, Nygren J, Lecoq H, Verdin E, Spetz C, Tamisier L, Truve E, Massart S (2020) Sixty years after the first description: genome sequence and biological characterization of European wheat striate mosaic virus infecting cereal crops. Phytopathology 110:68-79

96. Spence L, Anderson CR, Aitken TH, Downs WG (1964) Triniti virus, a new agent isolated from Trinidadian mosquitoes. Am J Trop Med Hyg 13:114-117

97. St George TD (2012) Research on milk fever, bluetongue, Akabane, ephemeral fever and other arboviruses at CSIRO Long Pocket Laboratories, Brisbane, Australia. Ph.D. Thesis, University of Queensland, Brisbane, Australia

98. Starr EP, Nuccio EE, Pett-Ridge J, Banfield JF, Firestone MK (2019) Metatranscriptomic reconstruction reveals RNA viruses with the potential to shape carbon cycling in soil. Proc Natl Acad Sci U S A 116:25900-25908

99. Tokarz R, Williams SH, Sameroff S, Sanchez Leon M, Jain K, Lipkin WI (2014) Virome analysis of Amblyomma americanum, Dermacentor variabilis, and Ixodes scapularis ticks reveals novel highly divergent vertebrate and invertebrate viruses. J Virol $88: 11480-11492$

100. Tokarz R, Sameroff S, Tagliafierro T, Jain K, Williams SH, Cucura DM, Rochlin I, Monzon J, Carpi G, Tufts D, Diuk-Wasser M, Brinkerhoff J, Lipkin WI (2018) Identification of novel viruses in Amblyomma americanum, Dermacentor variabilis, and Ixodes scapularis ticks. mSphere 3:e00614-e00617

101. Vanmechelen B, Laenen L, Vergote V, Maes P (2017) Grotenhout virus, a novel nairovirus found in Ixodes ricinus in Belgium. Genome Announc 5:e00288-e317

102. Viljakainen L, Borshagovski AM, Saarenpää S, Kaitala A, Jurvansuu J (2020) Identification and characterisation of common glow-worm RNA viruses. Virus Genes 56:236-248

103. von Bargen S, Al Kubrusli R, Gaskin T, Fürl S, Hüttner F, Blystad D-R, Karlin DG, Jalkanen R, Büttner C (2020) Characterisation of a novel emaravirus identified in mosaic-diseased Eurasian aspen (Populus tremula). Ann Appl Biol 176:210-222

104. Walker PJ, Tesh RB, Guzman H, Popov VL, Travassos da Rosa APA, Reyna M, Nunes MRT, de Souza WM, Contreras-Gutierrez MA, Patroca S, Vela J, Salvato V, Bueno R, Widen SG, Wood TG, Vasilakis N (2019) Characterization of three novel viruses from the families Nyamiviridae, Orthomyxoviridae, and Peribunyaviridae, isolated from dead birds collected during West Nile virus surveillance in Harris County Texas. Viruses 11:927 
105. Wang Y-q, Song Y, Cao M-j, Cheng Q, Wu J-x, Hu T (2020) Identification of a novel emaravirus infecting lilac through nextgeneration sequencing. J Integr Agricult 19:2064-2071

106. Wang Y, Zhai L, Wen S, Yang Z, Wang G, Hong N (2020) Molecular characterization of a novel emaravrius infecting Actinidia spp in China. Virus Res 275:197736

107. Weir R (2002) Classification and identification of viruses isolated from mosquitoes in the Northern Territory, 1982-1992, using a range of techniques. PhD Thesis, University of Sydney, Sydney, Australia

108. Williams SH, Levy A, Yates RA, Somaweera N, Neville PJ, Nicholson J, Lindsay MDA, Mackenzie JS, Jain K, Imrie A, Smith DW, Lipkin WI (2020) The diversity and distribution of viruses associated with Culex annulirostris mosquitoes from the Kimberley Region of Western Australia. Viruses 12:717

109. Wolf YI, Kazlauskas D, Iranzo J, Lucía-Sanz A, Kuhn JH, Krupovic M, Dolja VV, Koonin EV (2018) Origins and evolution of the global RNA virome. MBio 9:e02329-e2418

110. Wright AA, Cross AR, Harper SJ (2020) A bushel of viruses: Identification of seventeen novel putative viruses by RNA-seq in six apple trees. PLoS ONE 15:e0227669

111. Xu L, Wu J, Jiang T, Qin S, Xia L, Li X, He B, Tu C (2018) Molecular detection and sequence characterization of diverse rhabdoviruses in bats, China. Virus Res 244:208-212

112. Yang C, Zhang S, Han T, Fu J, Di Serio F, Cao M (2019) Identification and characterization of a novel emaravirus associated with jujube (Ziziphus jujuba Mill) yellow mottle disease. Front Microbiol 10:1417
113. Yashina LN, Kartashov MY, Wang W, Li K, Zdanovskaya NI, Ivanov LI, Zhang Y-Z (2019) Co-circulation of distinct shrew-borne hantaviruses in the far east of Russia. Virus Res 272:197717

114. Zhang S, Yang L, Ma L, Tian X, Li R, Zhou C, Cao M (2020) Virome of Camellia japonica: discovery of and molecular characterization of new viruses of different taxa in camellias. Front Microbiol 11:945

115. Zhou J, Cao K, Zhang Z, Wang L, Li S (2020) Identification and characterization of a novel rhabdovirus infecting peach in China. Virus Res 280:197905

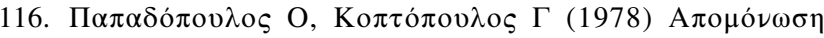

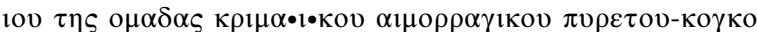

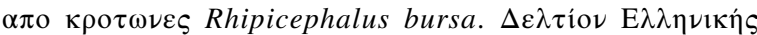

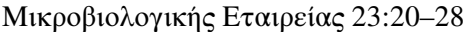

117. Альховский СВ, Львов ДК, Щелканов МЮ, Щетинин АМ, Краснослободцев КГ, Дерябин ПГ, Самохвалов ЕИ, Ботиков АГ, Закарян ВА (2013) Молекулярногенетическая характеристика вирусов Бханджа (BHAV) и Раздан (RAZV) (Bunyaviridae, Phlebovirus), изолированных от иксодовых клещей Rhipicephalus bursa Canestrini \& Fanzago, 1878, и Dermacentor marginatus Sulzer, 1776, в Закавказье. Вопр вирусол $58: 14-19$

Publisher's Note Springer Nature remains neutral with regard to jurisdictional claims in published maps and institutional affiliations.

\section{Authors and Affiliations}

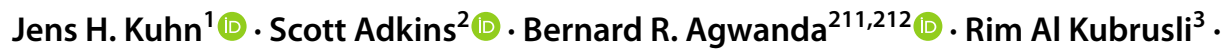

Sergey V. Alkhovsky (Альховский Сергей Владимирович) ${ }^{4}$ (D) Gaya K. Amarasinghe ${ }^{5}$ (1) Tatjana Avšič-Županc $^{6}$ (1)

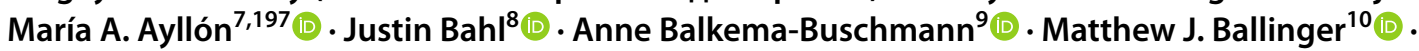

Christopher F. Basler ${ }^{11}$ (D) Sina Bavari ${ }^{12}$ (D) $\cdot$ Martin Beer $^{13}$ (D) Nicolas Bejerman ${ }^{14}$ (D) Andrew J. Bennett ${ }^{15}$.

Dennis A. Bente ${ }^{16}$. Éric Bergeron ${ }^{17}$ (I) $\cdot$ Brian H. Bird ${ }^{18}$ (I) Carol D. Blair ${ }^{19}$ (I) Kim R. Blasdell ${ }^{20}$ (D)

Dag-Ragnar Blystad ${ }^{21}$ (D) Jamie Bojko 22,198 (D) Wayne B. Borth ${ }^{23} \cdot$ Steven Bradfute ${ }^{24}$ (D) $\cdot$ Rachel Breyta $^{25,199}$ (1) .

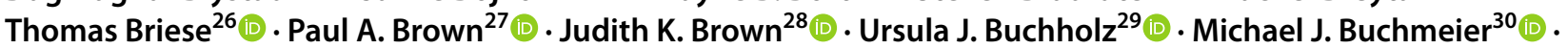

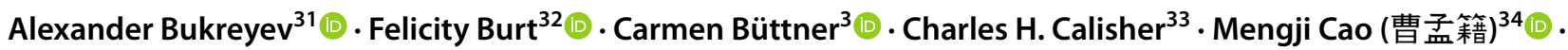

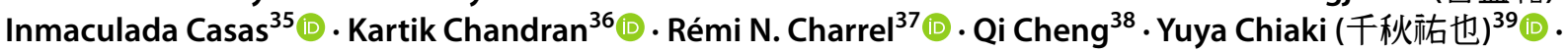
Marco Chiapello ${ }^{40}$ (II) II-Ryong Choi ${ }^{41} \cdot$ Marina Ciuffo $^{40}$ (D) J. Christopher S. Clegg ${ }^{42} \cdot$ Ian Crozier $^{43}$ (D) Elena Dal Bó ${ }^{44}$.

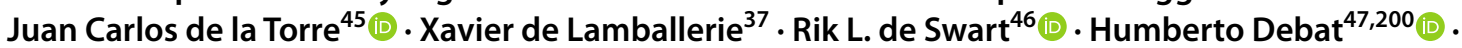
Nolwenn M. Dheilly ${ }^{48}$ (i) Emiliano Di Cicco ${ }^{49} \cdot$ Nicholas Di Paola $^{50}$ - Francesco Di Serio ${ }^{51}$ (1) $\cdot$ Ralf G. Dietzgen ${ }^{52}$. Michele Digiaro ${ }^{53} \cdot$ Olga Dolnik $^{54}$. Michael A. Drebot ${ }^{55}$. J. Felix Drexler ${ }^{56}$. William G. Dundon ${ }^{57}$ (1)

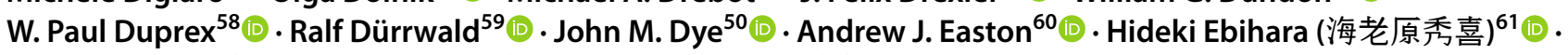
Toufic Elbeaino ${ }^{62}$ - Koray Ergünay ${ }^{63}$ - Hugh W. Ferguson ${ }^{213}$. Anthony R. Fooks ${ }^{64}$ - Marco Forgia ${ }^{65}$. Pierre B. H. Formenty ${ }^{66}$. Jana Fránová ${ }^{67}\left(\mathbb{D}\right.$. Juliana Freitas-Astúa ${ }^{68}(\mathbb{D} \text {. Jingjing Fu (付晶晶) })^{69}$. Stephanie Fürl ${ }^{70}$. Selma Gago-Zachert ${ }^{71}$ (1) - George Fú Gāo (高福) ${ }^{214} \cdot$ María Laura García ${ }^{72}$ (1) $\cdot$ Adolfo García-Sastre $^{73}$ (1) . Aura R. Garrison ${ }^{50}$. Thomas Gaskin ${ }^{74,3}$. Jean-Paul J. Gonzalez ${ }^{75,201}$ - Anthony Griffiths ${ }^{76}$.

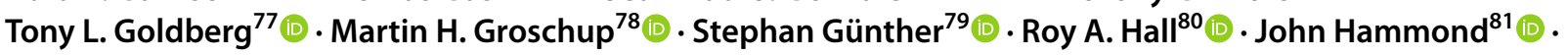
Tong Han (韩肜) $)^{69}$. Jussi Hepojoki ${ }^{82,202}$ - Roger Hewson ${ }^{83}$. Jiang Hong (洪健 $)^{84}$. Ni Hong $(\text { 洪霓 })^{85}$ (1) .

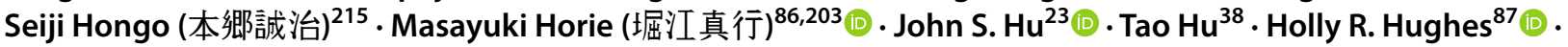

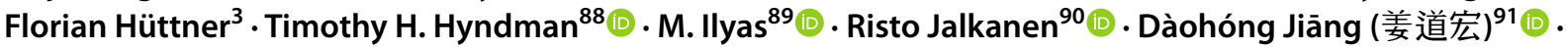
Gilda B. Jonson ${ }^{92}$. Sandra Junglen ${ }^{93,204}$. Fujio Kadono (上遠野富士夫) ${ }^{94}$. Karia H. Kaukinen ${ }^{95}$.

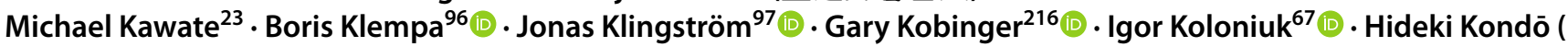

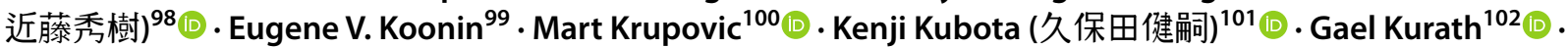
Lies Laenen ${ }^{103,205}$ (D) Amy J. Lambert ${ }^{87}$ (D) Stanley L. Langevin ${ }^{104} \cdot$ Benhur Lee $^{105}$ (D) Elliot J. Lefkowitz ${ }^{106}$ (D) 
Eric M. Leroy ${ }^{107}$ - S Shaorong Li ( 李邵蓉) ${ }^{108}$ (D) Longhui Li (李龙辉) $)^{85} \cdot$ Jiànróng Lǐ (李建荣) ${ }^{109} \cdot$ Huazhen Liu (刘华 珍 $^{85} \cdot$ Igor S. Lukashevich ${ }^{110}$ (1) - Piet Maes ${ }^{103}$ (1) - William Marciel de Souza ${ }^{111}$ (1) Marco Marklewitz ${ }^{93,206}$ (1)

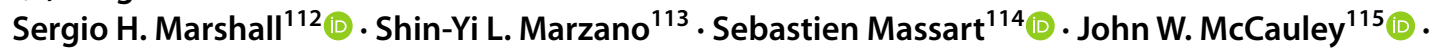
Michael Melzer ${ }^{116}$ (D) Nicole Mielke-Ehret ${ }^{117} \cdot$ Kristina M. Miller $^{95} \cdot$ Tobi J. Ming $^{118}$ (D) Ali Mirazimi ${ }^{119}$.

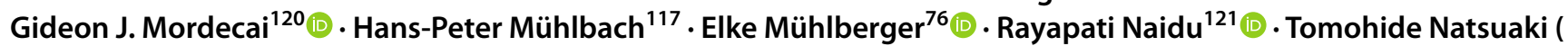
夏秋知英) $)^{122}$. . José A. Navarro ${ }^{123}$. Sergey V. Netesov (Нетёсов Сергей Викторович) ${ }^{124}$ (D)

Gabriele Neumann ${ }^{125}$ (1) Norbert Nowotny ${ }^{126,207}$ (1) Márcio R. T. Nunes ${ }^{217}$ (1) Alejandro Olmedo-Velarde ${ }^{23}$ (1) .

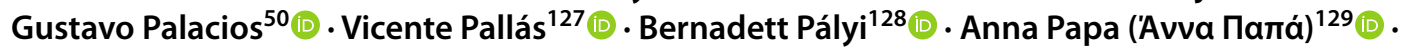

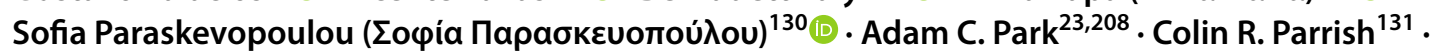
David A. Patterson ${ }^{132}$. Alex Pauvolid-Corrêa ${ }^{133,209}$ (I) Janusz T. Pawęska ${ }^{134}$ (1) Susan Payne ${ }^{135}$ (1) Carlotta Peracchio ${ }^{40}$ - Daniel R. Pérez ${ }^{136}$ - Thomas S. Postler ${ }^{137}$.

Sheli R. Radoshitzky ${ }^{139}$ ( Renato O. Resende ${ }^{140}$ (D) Carina A. Reyes ${ }^{141} \cdot$ Bertus K. Rima $^{142}$ (I) Gabriel Robles Luna ${ }^{141}$.

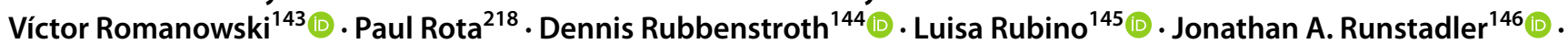

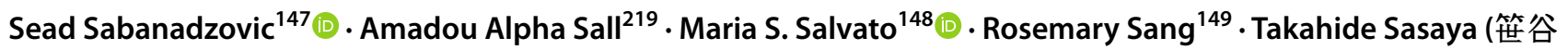

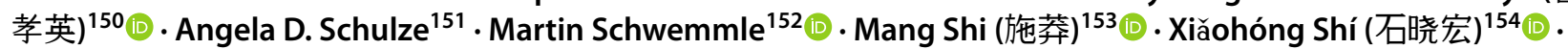
Zhènglì Shí (石正丽) $)^{155}$. Yoshifumi Shimomoto (下元祥史) $)^{156} \cdot$ Yukio Shirako ${ }^{157} \cdot$ Stuart G. Siddell ${ }^{158}$ 迥 . Peter Simmonds ${ }^{159}$. Manuela Sironi ${ }^{160}$.

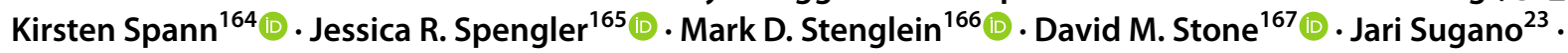
Curtis A. Suttle ${ }^{168}$ ( Amy Tabata ${ }^{95}$. Ayato Takada (高田礼人) $)^{169}$. Shigeharu Takeuchi (竹内繁治) $)^{170}$. David P. Tchouassi ${ }^{149}$. Amy Teffer ${ }^{171}$. Robert B. Tesh ${ }^{172} \cdot$ Natalie J. Thornburg ${ }^{173} \cdot$ Yasuhiro Tomitaka (富高保

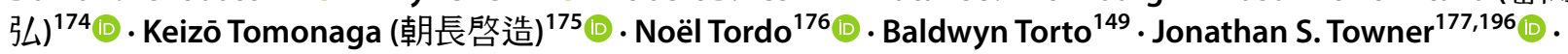
Shinya Tsuda (津田新哉) $)^{94}$. Changchun Tu (涂长春) ${ }^{178}$ ( ) Massimo Turina ${ }^{179}$ ・ Ioannis E. Tzanetakis ${ }^{180}$ (1) Janice Uchida ${ }^{23}$ - Tomio Usugi (宇杉富雄) ${ }^{101}$. Anna Maria Vaira ${ }^{40}$ - Marta Vallino ${ }^{40}$ (1)

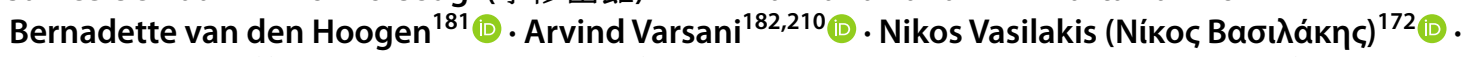

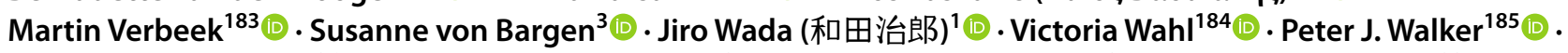
Lin-Fa Wang (王林发) $)^{186}$. Guoping Wang (王国平) ${ }^{85}$. Yanxiang Wang (王雁翔) ${ }^{85}$. Yaqin Wang (王亚琴 $)^{38}$. Muhammad Waqas $^{187} \cdot$ Tàiyún Wèi (魏太云) $)^{188} \cdot$ Shaohua Wen (温少华 $)^{85} \cdot$ Anna E. Whitfield ${ }^{189}$ (D) John V. Williams ${ }^{190}$. Yuri I. Wolf ${ }^{99}$. Jiangxiang Wu (吴建祥) $^{38}$ - Lei Xu (徐雷) $)^{138}$. Hironobu Yanagisawa $($ 栁澤広

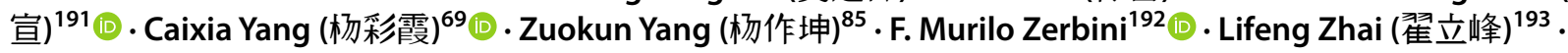
Yong-Zhen Zhang (张永振) $)^{220,221}$. Song Zhang (张松) ${ }^{34}$. Jinguo Zhang (张靖国) $)^{194}$. Zhe Zhang $(\text { 张哲 })^{85}$. Xueping Zhou (周雪平) ${ }^{195}$ (D)

Jens H. Kuhn

kuhnjens@mail.nih.gov

Scott Adkins

scott.adkins@usda.gov

Bernard R. Agwanda

bagwanda@museums.or.ke; benrisky@gmail.com

Rim Al Kubrusli

kubruslr@hu-berlin.de

Sergey V. Alkhovsky (Альховский Сергей Владимирович) salkh@ya.ru

Gaya K. Amarasinghe

GAmarasinghe@path.wustl.edu

Tatjana Avšič-Županc

Tatjana.Avsic@mf.uni-lj.si

María A. Ayllón

mariaangeles.ayllon@upm.es

Justin Bahl

Justin.Bahl@uga.edu
Anne Balkema-Buschmann

anne.buschmann@fli.de

Matthew J. Ballinger

ballinger@biology.msstate.edu

Christopher F. Basler

cbasler@gsu.edu

Sina Bavari

sinabavari@comcast.net

Martin Beer

Martin.Beer@fli.de

Nicolas Bejerman

bejerman.nicolas@inta.gob.ar

Andrew J. Bennett

andrew.j.bennett64.ctr@mail.mil

Dennis A. Bente

dabente@utmb.edu

Éric Bergeron

exj8@edc.gov 
Brian H. Bird

bhbird@ucdavis.edu

Carol D. Blair

Carol.Blair@colostate.edu

Kim R. Blasdell

kim.blasdell@csiro.au

Dag-Ragnar Blystad

dag-ragnar.blystad@nibio.no

Jamie Bojko

J.Bojko@tees.ac.uk

Wayne B. Borth

borth@hawaii.edu

Steven Bradfute

sbradfute@salud.unm.edu

Rachel Breyta

rbjmax@uw.edu

Thomas Briese

tb2047@cumc.columbia.edu

Paul A. Brown

paul.brown@anses.fr

Judith K. Brown

jbrown@ag.arizona.edu

Ursula J. Buchholz

ubuchholz@niaid.nih.gov

Michael J. Buchmeier

m.buchmeier@uci.edu

Alexander Bukreyev

alexander.bukreyev@utmb.edu

Felicity Burt

burtf@ufs.ac.za

Carmen Büttner

carmen.buettner@agrar.hu-berlin.de

Charles H. Calisher

calisher@cybersafe.net

Mengji Cao (曹孟籍)

caomengji@cric.cn

Inmaculada Casas

icasas@isciii.es

Kartik Chandran

kartik.chandran@einsteinmed.org

Rémi N. Charrel

remi.charrel@univ-amu.fr

Qi Cheng

2765227021@qq.com

Yuya Chiaki (千秋祐也)

chiakiy151@affrc.go.jp

Marco Chiapello

marco.chiapello@ipsp.cnr.it; chiapello.m@gmail.com

Il-Ryong Choi

ichoi51@hotmail.com

Marina Ciuffo

marina.ciuffo@ipsp.cnr.it
J. Christopher S. Clegg

cleggjcs@yahoo.fr

Ian Crozier

ian.crozier@nih.gov

Elena Dal Bó

elenadalbocastanion@gmail.com

Juan Carlos de la Torre

juanct@ @cripps.edu

Xavier de Lamballerie

xavier.de-lamballerie@univ-amu.fr

Rik L. de Swart

r.deswart@erasmusmc.nl

Humberto Debat

debat.humberto@inta.gob.ar

Nolwenn M. Dheilly

nolwenn.dheilly@anses.fr

Emiliano Di Cicco

edicicco@psf.ca

Nicholas Di Paola

nicholas.dipaola.ctr@mail.mil

Francesco Di Serio

francesco.diserio@ipsp.cnr.it

Ralf G. Dietzgen

r.dietzgen@uq.edu.au

Michele Digiaro

digiaro@iamb.it

Olga Dolnik

Dolnik@staff.uni-marburg.de

Michael A. Drebot

mike.drebot@canada.ca

J. Felix Drexler

felix.drexler@charite.de

William G. Dundon

W.Dundon@iaea.org

W. Paul Duprex

pduprex@pitt.edu

Ralf Dürrwald

duerrwaldr@rki.de

John M. Dye

john.m.dye1.civ@mail.mil

Andrew J. Easton

A.J.Easton@warwick.ac.uk

Hideki Ebihara (海老原秀喜)

Ebihara.Hideki@mayo.edu

Toufic Elbeaino

elbeaino@iamb.it

Koray Ergünay

ekoray@hacettepe.edu.tr

Hugh W. Ferguson

hf.fishpathology@gmail.com

Anthony R. Fooks

Tony.Fooks@apha.gov.uk 
Marco Forgia

marco.forgia@ipsp.cnr.it

Pierre B. H. Formenty

formentyp@who.int

Jana Fránová

jana@umbr.cas.cz

Juliana Freitas-Astúa

juliana.astua@embrapa.br

Jingjing $\mathrm{Fu}$ (付晶晶)

fujingjing6595@qq.com

Stephanie Fürl

stephie_fuerl@gmx.de

Selma Gago-Zachert

selma.gago-zachert@bct.uni-halle.de

George Fú Gāo (高福)

gaof@im.ac.cn

María Laura García

garcia_m@biol.unlp.edu.ar

Adolfo García-Sastre

Adolfo.Garcia-Sastre@mssm.edu

Aura R. Garrison

aura.r.garrison.civ@mail.mil

Thomas Gaskin

Thomas.Gaskin@1elf.Brandenburg.de

Jean-Paul J. Gonzalez

Jean.Paul.Gonzalez@georgetown.edu;

jpgonzalez2808@gmail.com

Anthony Griffiths

ahgriff@bu.edu

Tony L. Goldberg

tony.goldberg@wisc.edu

Martin H. Groschup

Martin.Groschup@fli.de

Stephan Günther

guenther@bni.uni-hamburg.de

Roy A. Hall

roy.hall@uq.edu.au

John Hammond

John.Hammond@usda.gov

Tong Han (韩肜)

437828698@qq.com

Jussi Hepojoki

jussi.hepojoki@helsinki.fi; jussi.hepojoki@uzh.ch

Roger Hewson

roger.hewson1@1shtm.ac.uk

Jiang Hong (洪健)

jhong@zju.edu.cn

Ni Hong (洪霓)

whni@mail.hzau.edu.cn

Seiji Hongo (本郷誠治)

shongou@med.id.yamagata-u.ac.jp

Masayuki Horie (堀江 行)

mhorie@vet.osakafu-u.ac.jp
John S. Hu

johnhu@ hawaii.edu

Tao Hu

taohu1989@zju.edu.cn

Holly R. Hughes

1tr8@cdc.gov

Florian Hüttner

baumflo@hotmail.com

Timothy H. Hyndman

T.Hyndman@murdoch.edu.au

M. Ilyas

milyassarwar@gmail.com; milyas2@ncsu.edu

Risto Jalkanen

ristjal@gmail.com

Dàohóng Jiāng (姜道宏)

daohongjiang@mail.hzau.edu.cn

Gilda B. Jonson

G.Jonson@irri.org; jonson_gilda@yahoo.com

Sandra Junglen

sandra.junglen@charite.de

Fujio Kadono (上遠野富士夫)

acaritick@yahoo.co.jp

Karia H. Kaukinen

Karia.Kaukinen@dfo-mpo.gc.ca

Michael Kawate

mkawate@hawaii.edu

Boris Klempa

boris.klempa@savba.sk

Jonas Klingström

jonas.klingstrom@ki.se

Gary Kobinger

gpkobinger@gmail.com

Igor Koloniuk

koloniuk@umbr.cas.cz

Hideki Kondō (近藤秀樹)

hkondo@rib.okayama-u.ac.jp

Eugene V. Koonin

koonin@ncbi.nlm.nih.gov

Mart Krupovic

mart.krupovic@pasteur.fr

Kenji Kubota (久保田健嗣)

kubotak@affrc.go.jp

Gael Kurath

gkurath@usgs.gov

Lies Laenen

lies.laenen@uzleuven.be

Amy J. Lambert

ahk7@cdc.gov

Stanley L. Langevin

slangevi@uw.edu

Benhur Lee

benhur.lee@mssm.edu 
Elliot J. Lefkowitz

elliotl@uab.edu

Eric M. Leroy

eric.leroy@ird.fr

Shaorong Li ( 李邵蓉)

Shaorong.Li@dfo-mpo.gc.ca

Longhui Li (李龙辉)

871163211@qq.com

Jiànróng Lǐ (李建荣)

li.926@osu.edu

Huazhen Liu (刘华珍)

1369140609@qq.com

Igor S. Lukashevich

isluka01@louisville.edu

Piet Maes

piet.maes@kuleuven.be

William Marciel de Souza

wmarciel@hotmail.com

Marco Marklewitz

marklewitz@gmx.de; marklewitzm@who.int; marco.marklewitz@charite.de

Sergio H. Marshall

sergio.marshall@pucv.cl

Shin-Yi L. Marzano

shinyi.marzano@usda.gov

Sebastien Massart

sebastien.massart@uliege.be

John W. McCauley

john.mccauley@crick.ac.uk

Michael Melzer

melzer@hawaii.edu

Nicole Mielke-Ehret

nicole_mielke@hotmail.com

Kristina M. Miller

kmillersaunders@gmail.com

Tobi J. Ming

Tobi.Ming@dfo-mpo.gc.ca

Ali Mirazimi

Ali.Mirazimi@ki.se

Gideon J. Mordecai

gidmord@gmail.com

Hans-Peter Mühlbach

hpmuehlbach@gmx.net;

muehlbach@botanik.uni-hamburg.de

Elke Mühlberger

muehlber@bu.edu

Rayapati Naidu

naidu.rayapati@wsu.edu

Tomohide Natsuaki (夏秋知英)

natsuaki@cc.utsunomiya-u.ac.jp

José A. Navarro

janavarr@ibmcp.upv.es
Sergey V. Netesov (Нетёсов Сергей Викторович)

netesov.s@nsu.ru

Gabriele Neumann

gabriele.neumann@wisc.edu

Norbert Nowotny

Norbert.Nowotny@vetmeduni.ac.at

Márcio R. T. Nunes

marcionunesbrasil@yahoo.com.br

Alejandro Olmedo-Velarde

aolmedov@hawaii.edu

Gustavo Palacios

gustavo.f.palacios.civ@mail.mil

Vicente Pallás

vpallas@ibmcp.upv.es

Bernadett Pályi

palyi.bernadett@nnk.gov.hu

Anna Papa ('A $\nu \nu \alpha \Pi \alpha \pi \alpha ́)$

annap.med@gmail.com

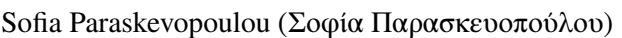

sofia.paraskevopoulou@ charite.de; sofiapara@ hotmail.com

Adam C. Park

aycpark@hawaii.edu; Adam.Y.Park@ hawaii.gov

Colin R. Parrish

crp3@cornell.edu

David A. Patterson

David.Patterson@dfo-mpo.gc.ca

Alex Pauvolid-Corrêa

pauvolid@gmail.com

Janusz T. Pawęska

januszp@nicd.ac.za

Susan Payne

SPayne@cvm.tamu.edu

Carlotta Peracchio

carlotta10029@gmail.com

Daniel R. Pérez

dperez1@uga.edu

Thomas S. Postler

tp2405@cumc.columbia.edu

Liying Qi (元立荣)

qiliying88@163.com

Sheli R. Radoshitzky

SRadoshitzky@genevausa.org

Renato O. Resende

rresende@unb.br

Carina A. Reyes

carirey2306@gmail.com

Bertus K. Rima

b.rima@qub.ac.uk

Gabriel Robles Luna

garobles@gmail.com

Víctor Romanowski

victor@biol.unlp.edu.ar; vromanowski@gmail.com 
Paul Rota

par1@CDC.GOV

Dennis Rubbenstroth

Dennis.Rubbenstroth@ fli.de

Luisa Rubino

luisa.rubino@ipsp.cnr.it

Jonathan A. Runstadler

Jonathan.Runstadler@tufts.edu

Sead Sabanadzovic

SSabanadzovic@entomology.msstate.edu

Amadou Alpha Sall

Amadou.SALL@pasteur.sn

Maria S. Salvato

MSalvato@ihv.umaryland.edu

Rosemary Sang

rsang@icipe.org

Takahide Sasaya (笹谷孝英)

tsasaya@affrc.go.jp

Angela D. Schulze

Angela.Schulze@dfo-mpo.gc.ca

Martin Schwemmle

martin.schwemmle@uniklinik-freiburg.de

Mang Shi (施莽)

shim23@mail.sysu.edu.cn

Xiǎohóng Shí (石晓宏)

Xiaohong.Shi@glasgow.ac.uk

Zhènglì Shí (石正丽)

zlshi@wh.iov.cn

Yoshifumi Shimomoto (下元祥史)

yoshifumi_shimomoto@ken2.pref.kochi.lg.jp

Yukio Shirako

yshirako@mac.com

Stuart G. Siddell

stuart.siddell@bristol.ac.uk

Peter Simmonds

peter.simmonds@ndm.ox.ac.uk

Manuela Sironi

manuela.sironi@bp.lnf.it

Guy Smagghe

Guy.Smagghe@UGent.be

Sophie Smither

sjsmither@mail.dstl.gov.uk

Jin-Won Song (송 진원)

jwsong@ korea.ac.kr

Kirsten Spann

Kirsten.Spann@qut.edu.au

Jessica R. Spengler

JSpengler@cdc.gov

Mark D. Stenglein

Mark.Stenglein@colostate.edu

David M. Stone

david.stone@cefas.co.uk
Jari Sugano

suganoj@ctahr.hawaii.edu

Curtis A. Suttle

suttle@science.ubc.ca

Amy Tabata

Amy.Tabata@dfo-mpo.gc.ca

Ayato Takada (高田礼人)

atakada@czc.hokudai.ac.jp

Shigeharu Takeuchi (竹内繁治)

s-takeuchi@jppa.or.jp

David P. Tchouassi

dtchouassi@icipe.org

Amy Teffer

akteffer@gmail.com

Robert B. Tesh

rbtesh22@gmail.com

Natalie J. Thornburg

nax3@cdc.gov

Yasuhiro Tomitaka (富高保弘)

yasut@affrc.go.jp

Keizō Tomonaga (朝長啓造)

tomonaga.keizo.5r@kyoto-u.ac.jp; tomonaga@infront.kyoto-u.ac.jp

Noël Tordo

ntordo@pasteur.fr

Baldwyn Torto

btorto@icipe.org

Jonathan S. Towner

jit8@cdc.gov

Shinya Tsuda (津田新哉)

stsuda@ hosei.ac.jp

Changchun Tu (涂长春)

changchun_tu@hotmail.com

Massimo Turina

massimo.turina@ipsp.cnr.it

Ioannis E. Tzanetakis

itzaneta@uark.edu

Janice Uchida

juchida@hawaii.edu

Tomio Usugi (宇杉富雄)

rg288887@kc5.so-net.ne.jp

Anna Maria Vaira

annamaria.vaira@ipsp.cnr.it

Marta Vallino

marta.vallino@ipsp.cnr.it

Bernadette van den Hoogen

b.vandenhoogen@erasmusmc.nl

Arvind Varsani

arvind.varsani@asu.edu

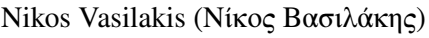

nivasila@utmb.edu

Martin Verbeek

martin.verbeek@wur.nl 
Susanne von Bargen

susanne.von.bargen@ agrar.hu-berlin.de

Jiro Wada (和田治郎)

wadaj@niaid.nih.gov

Victoria Wahl

victoria.wahl@st.dhs.gov

Peter J. Walker

peter.walker@uq.edu.au

Lin-Fa Wang (王林发)

linfa.wang@duke-nus.edu.sg

Guoping Wang (王国平)

gpwang@mail.hzau.edu.cn

Yanxiang Wang (王雁翔)

whni@mail.hzau.edu.cn

Yaqin Wang (王亚琴)

yaqinwang@zju.edu.cn

Muhammad Waqas

mwaqas223@outlook.com

Tàiyún Wèi (魏太云)

weitaiyun@fafu.edu.cn

Shaohua Wen (温少华)

33653989@qq.com

Anna E. Whitfield

awhitfi@ncsu.edu

John V. Williams

jvw@chp.edu

Yuri I. Wolf

wolf@ ncbi.nlm.nih.gov

Jiangxiang Wu (吴建祥)

wujx@zju.edu.cn

Lei Xu (徐雷)

xulei_1209@163.com

Hironobu Yanagisawa (栁澤広宣)

hironobu_yanagisa090@maff.go.jp

Caixia Yang (杨彩霞)

xueyang27@126.com

Zuokun Yang (杨作坤)

408341001@qq.com

F. Murilo Zerbini

zerbini@ufv.br

Lifeng Zhai (翟立峰)

254524946@qq.com

Yong-Zhen Zhang (张永振)

zhangyongzhen@icdc.cn; zhangyongzhen@ shphc.org.cn

Song Zhang (张松)

qq371260@email.swu.edu.cn

Jinguo Zhang (张靖国)

705868726@qq.com

Zhe Zhang (张哲)

2368188603@qq.com

Xueping Zhou (周雪平)

zzhou@zju.edu.cn
1 Integrated Research Facility at Fort Detrick, National Institute of Allergy and Infectious Diseases, National Institutes of Health, Frederick, MD, USA

2 United States Department of Agriculture, Agricultural Research Service, US Horticultural Research Laboratory, Fort Pierce, FL, USA

3 Division Phytomedicine, Faculty of Life Sciences, Humboldt-Universität zu Berlin, Berlin, Germany

4 D.I. Ivanovsky Institute of Virology of N.F. Gamaleya National Center on Epidemiology and Microbiology of Ministry of Health of Russian Federation, Moscow, Russia

5 Department of Pathology and Immunology, Washington University School of Medicine, St. Louis, MO, USA

6 Faculty of Medicine, University of Ljubljana, Ljubljana, Slovenia

7 Centro de Biotecnología y Genómica de Plantas, Universidad Politécnica de Madrid-Instituto Nacional de Investigación y Tecnología Agraria y Alimentaria, Campus de Montegancedo, Pozuelo de Alarcón, Madrid, Spain

8 Center for Ecology of Infectious Diseases, Department of Infectious Diseases, Department of Epidemiology and Biostatistics, Insitute of Bioinformatics, University of Georgia, Athens, GA, USA

9 Institute of Novel and Emerging Infectious Diseases, Friedrich-Loeffler-Institut, Federal Research Institute for Animal Health, Greifswald-Insel Riems, Germany

10 Department of Biological Sciences, Mississippi State University, Mississippi State, MS, USA

11 Center for Microbial Pathogenesis, Institute for Biomedical Sciences, Georgia State University, Atlanta, GA, USA

12 Edge BioInnovation Consulting and Mgt, Frederick, MD, USA

13 Institute of Diagnostic Virology, Friedrich-Loeffler-Institut, Greifswald-Insel Riems, Germany

14 UFyMA, INTA-CONICET, Cordoba, Argentina

15 Genomics and Bioinformatics Department, Biological Defense Research Directorate, Naval Medical Research Center-Frederick, Fort Detrick, Frederick, MD, USA

16 University of Texas Medical Branch, Galveston, TX, USA

17 Viral Special Pathogens Branch, Division of High-Consequence Pathogens and Pathology, Centers for Disease Control and Prevention, Atlanta, GA, USA

18 School of Veterinary Medicine, One Health Institute, University of California, Davis, Davis, CA, USA

19 Department of Microbiology, Immunology and Pathology, Colorado State University, Fort Collins, CO, USA

20 Commonwealth Scientific and Industrial Research Organisation (CSIRO), Australian Centre for Disease Preparedness, Geelong, VIC, Australia

21 NIBIO-Norwegian Institute of Bioeconomy Research, Oslo, Norway

22 School of Health and Life Sciences, Teesside University, Middlesbrough TS1 3BX, UK

23 University of Hawaii, Honolulu, HI, USA 
24 University of New Mexico Health Sciences Center, Albuquerque, NM, USA

25 University of Washington, Seattle, WA, USA

26 Center for Infection and Immunity, and Department of Epidemiology, Mailman School of Public Health, Columbia University, New York, NY, USA

27 Laboratory of Ploufragan-Plouzané-Niort, French Agency for Food, Environmental and Occupational Heath Safety ANSES, Ploufragan, France

28 School of Plant Sciences, University of Arizona, Tucson, AZ, USA

29 RNA Viruses Section, Laboratory of Infectious Diseases, National Institute of Allergy and Infectious Diseases, National Institutes of Health, Bethesda, MD, USA

30 Department of Molecular Biology and Biochemistry, University of California, Irvine, Irvine, CA, USA

31 Galveston National Laboratory, The University of Texas Medical Branch at Galveston, Galveston, TX, USA

32 Division of Virology, National Health Laboratory Service and Division of Virology, University of the Free State, Bloemfontein, Republic of South Africa

33 Colorado State University, Fort Collins, CO, USA

34 National Citrus Engineering and Technology Research Center, Citrus Research Institute, Southwest University, Beibei, Chongqing, People's Republic of China

35 Respiratory Virus and Influenza Unit, National Microbiology Center, Instituto de Salud Carlos III, Madrid, Spain

36 Department of Microbiology and Immunology, Albert Einstein College of Medicine, Bronx, NY, USA

37 Unité des Virus Emergents (Aix-Marseille Univ, IRD 190, Inserm 1207, IHU Méditerranée Infection), Marseille, France

38 State Key Laboratory of Rice Biology, Institute of Biotechnology, Zhejiang University, Hangzhou, People's Republic of China

39 Grape and Persimmon Research Station, Institute of Fruit tree and Tea Science, NARO, Higashihiroshima, Hiroshima, Japan

40 Institute for Sustainable Plant Protection, National Research Council of Italy (CNR), Strada delle Cacce 73, 10135 Turin, Italy

41 Plant Breeding Genetics and Biotechnology Division and International Rice Research Institute, Los Baños, Philippines

42 Les Mandinaux, Le Grand Madieu, France

43 Clinical Monitoring Research Program Directorate, Frederick National Laboratory for Cancer Research, Frederick, MD, USA

44 CIDEFI, Facultad de Ciencias Agrarias y Forestales, Universidad de La Plata, La Plata, Argentina

45 Department of Immunology and Microbiology IMM-6, The Scripps Research Institute, La Jolla, CA, USA

46 Department Viroscience, Erasmus MC, University Medical Centre Rotterdam, Rotterdam, The Netherlands
47 Centro de Investigaciones Agropecuarias, Instituto Nacional de Tecnología Agropecuaria (IPAVE-CIAP-INTA), Córdoba, Argentina

48 UMR 1161 Virology ANSES/INRAE/ENVA, ANSES Animal Health Laboratory, 94704 Maisons-Alfort, France

49 Pacific Salmon Foundation, Vancouver, BC, Canada

50 United States Army Medical Research Institute of Infectious Diseases, Fort Detrick, Frederick, MD, USA

51 Istituto per la Protezione Sostenibile delle Piante, Consiglio Nazionale delle Ricerche, Bari, Italy

52 Queensland Alliance for Agriculture and Food Innovation, The University of Queensland, St. Lucia, QLD, Australia

53 CIHEAM, Istituto Agronomico Mediterraneo di Bari, Valenzano, Italy

54 Institute of Virology, Philipps University Marburg, Marburg, Germany

55 Zoonotic Diseases and Special Pathogens, National Microbiology Laboratory, Public Health Agency of Canada, Winnipeg, MB, Canada

56 Institute of Virology, Charité-Universitätsmedizin Berlin, Corporate Member of Freie Universität Berlin, Humboldt Universität Berlin, Berlin, Germany

57 Animal Production and Health Laboratory, Joint FAO/IAEA Division of Nuclear Techniques in Food and Agriculture, Department of Nuclear Sciences and Applications, International Atomic Energy Agency, Vienna, Austria

58 School of Medicine, University of Pittsburgh, Pittsburgh, PA, USA

59 Robert Koch Institut, Berlin, Germany

60 School of Life Sciences, University of Warwick, Coventry, UK

61 Department of Molecular Medicine, Mayo Clinic, Rochester, MN, USA

62 Istituto Agronomico Mediterraneo di Bari, Valenzano, Italy

63 Virology Unit, Department of Medical Microbiology, Hacettepe University Faculty of Medicine, Ankara, Turkey

64 Animal and Plant Health Agency, Weybridge, Surrey, UK

65 Institute for sustainable plant protection, CNR, Turin, Italy

66 World Health Organization, Geneva, Switzerland

67 Plant Virology Department, Institute of Plant Molecular Biology, Biology Centre CAS, Ceske Budejovice, Czech Republic

68 Embrapa Cassava and Fruits, Cruz das Almas, Bahia, Brazil

69 College of Life Science and Engineering, Shenyang University, Shenyang, Liaoning, People's Republic of China

70 Albrecht Daniel Thaer-Institute for Crop and Animal Sciences, Division Phytomedicine, Humboldt-Universität zu Berlin, Berlin, Germany

71 Institute of Biochemistry and Biotechnology, Martin Luther University Halle-Wittenberg, Halle/Saale, Germany

72 nstituto de Biotecnología y Biología Molecular, Facultad de Ciencias Exactas, I, CONICET UNLP, La Plata, Argentina 
73 Icahn School of Medicine at Mount Sinai, New York, NY, USA

74 Landwirtschaft und Flurneuordnung, Landesamt für ländliche Entwicklung, Frankfurt (Oder), Germany

75 Department of Microbiology and Immunology, Division of Biomedical Graduate Research Organization, School of Medicine, Georgetown University, Washington, DC 20057, USA

76 Department of Microbiology and National Emerging Infectious Diseases Laboratories, Boston University School of Medicine, Boston, MA, USA

77 Department of Pathobiological Sciences, School of Veterinary Medicine, University of Wisconsin-Madison, Madison, WI, USA

78 Institute of Novel and Emerging Infectious Diseases, Friedric h-Loeffler-Institut, Greifswald-Insel Riems, Germany

79 WHO Collaborating Centre for Arboviruses and Hemorrhagic Fever Reference and Research, Department of Virology, Bernhard-Nocht Institute for Tropical Medicine, Hamburg, Germany

80 Australian Infectious Diseases Research Centre, School of Chemistry and Molecular Biosciences, The University of Queensland, Brisbane, Australia

81 Floral and Nursery Plants Research Unit, United States Department of Agriculture, Agricultural Research Service, USNA, Beltsville, MD, USA

82 Department of Virology, University of Helsinki, Medicum, Helsinki, Finland

83 London School of Hygeine and Tropical Medicine, London, UK

84 Analysis Center of Agrobiology and Environmental Sciences, Zhejiang University, Hangzhou, People's Republic of China

85 Key Lab of Plant Pathology of Hubei Province, College of Plant Science and Technology, Huazhong Agricultural University, Wuhan, People's Republic of China

86 Hakubi Center for Advanced Research, Kyoto University, Kyoto, Japan

87 Centers for Disease Control and Prevention, Fort Collins, $\mathrm{CO}, \mathrm{USA}$

88 School of Veterinary Medicine, Murdoch University, Murdoch, WA, Australia

89 Entomology and Plant Pathology, North Carolina State University, Raleigh, NC, USA

90 Silva Lapponica, Rovaniemi, Finland

91 State Key Laboratory of Agricultural Microbiology, Huazhong Agricultural University, Wuhan, Hubei Province, People's Republic of China

92 Rice Breeding Innovations Platform, International Rice Research Institute, Los Baños, Laguna, Philippines

93 Institute of Virology, Charité-Universitätsmedizin Berlin, Corporate Member of Free University Berlin, Humboldt-University Berlin, and Berlin Institute of Health, Berlin, Germany
94 Department of Clinical Plant Science, Faculty of Bioscience and Applied Chemistry, Hosei University, Koganei, Tokyo, Japan

95 Pacific Biological Station, Fisheries and Oceans Canada, Nanaimo, BC, Canada

96 Institute of Virology, Biomedical Research Center, Slovak Academy of Sciences, Bratislava, Slovakia

97 Center for Infectious Medicine, Department of Medicine Huddinge, Karolinska Institutet, Karolinska University Hospital, Stockholm, Sweden

98 Institute of Plant Science and Resources, Okayama University, Kurashiki, Japan

99 National Center for Biotechnology Information, National Library of Medicine, National Institutes of Health, Bethesda, MD, USA

100 Archaeal Virology Unit, Institut Pasteur, Paris, France

101 Central Region Agricultural Research Center, NARO, Tsukuba, Ibaraki, Japan

102 US Geological Survey Western Fisheries Research Center, Seattle, WA, USA

103 KU Leuven, Rega Institute, Zoonotic Infectious Diseases unit, Leuven, Belgium

104 Department of Microbiology, University of Washington, Washington, USA

105 Department of Microbiology, Icahn School of Medicine at Mount Sinai, New York, NY, USA

106 The University of Alabama at Birmingham, Birmingham, AL, USA

107 MIVEGEC (IRD-CNRS-Montpellier university) Unit, French National Research Institute for Sustainable Development (IRD), Montpellier, France

108 Fisheries and Oceans Canada, Pacific Biological Station, 3190 Hammond Bay Road, Nanaimo, BC V9T 6N7, Canada

109 Department of Veterinary Biosciences, College of Veterinary Medicine, The Ohio State University, Columbus, OH, USA

110 Department of Pharmacology and Toxicology, School of Medicine, and the Center for Predictive Medicine for Biodefense and Emerging Infectious Diseases, University of Louisville, Louisville, KY, USA

111 Virology Research Center, University of São Paulo, Ribeirão Preto, Brazil

112 Pontificia Universidad Católica de Valparaíso, Campus Curauma, Valparaíso, Chile

113 United States Department of Agriculture, Agricultural Research Service, Washington, USA

114 Gembloux Agro-Bio Tech, TERRA, Plant Pathology Laboratory, Liège University, Liege, Belgium

115 Worldwide Influenza Centre, Francis Crick Institute, London, UK

116 Plant and Environmental Protection Sciences, University of Hawai'i at Mānoa, Honolulu, HI, USA

117 Biocentre Klein Flottbek, University of Hamburg, Hamburg, Germany 
118 Molecular Genetics, Pacific Biological Station, Department of Fisheries and Oceans, Nanaimo, Canada

119 Folkhalsomyndigheten, Stockholm, Sweden

120 Department of Medicine, Univeristy of British Columbia, Vancouver, Canada

121 Department of Plant Pathology, Irrigated Agricultural Research and Extension Center, Washington State University, Prosser, WA, USA

122 School of Agriculture, Utsunomiya University, Utsunomiya, Tochigi, Japan

123 Instituto de Biología Molecular y Celular de Plantas, Universitat Politècnica de València-Consejo Superior de Investigaciones Científicas, Valencia, Spain

124 Novosibirsk State University, Novosibirsk, Novosibirsk Oblast, Russia

125 Influenza Research Institute, Department of Pathobiological Sciences, University of Wisconsin-Madison, Madison, WI, USA

126 Institute of Virology, University of Veterinary Medicine Vienna, Vienna, Austria

127 Instituto de Biología Molecular y Celular de Plantas (IBMCP), , Consejo Superior de Investigaciones Cientificas-Universidad Politécnica de Valencia, Valencia, Spain

128 National Biosafety Laboratory, National Public Health Center, Budapest, Hungary

129 National Reference Centre for Arboviruses and Haemorrhagic Fever Viruses, Department of Microbiology, Medical School, Aristotle University of Thessaloniki, Thessaloniki, Greece

130 Institute of Virology, Charité-Universitätsmedizin Berlin, corporate member of Freie Universität Berlin, Humboldt-Universität zu Berlin, and Berlin Institute of Health, Berlin, Germany

131 Baker Institute for Animal Health, College of Veterinary Medicine, Cornell University, Ithaca, NY, USA

132 Fisheries and Oceans Canada, Resource and Environmental Management, Simon Fraser University, Burnaby, BC, Canada

133 Department of Veterinary Integrated Biosciences and Department of Entomology, Texas A\&M University, College Station, USA

134 Center for Emerging Zoonotic and Parasitic Diseases, National Institute for Communicable Diseases of the National Health Laboratory Service, Sandringham-Johannesburg, Gauteng, South Africa

135 Department of Veterinary Pathobiology, College of Veterinary Medicine and Biomedical Sciences, Texas A\&M University, College Station, TX, USA

136 Department of Population Health, College of Veterinary Medicine, University of Georgia, Athens, GA, USA

137 Department of Microbiology and Immunology, Vagelos College of Physicians and Surgeons, Columbia University Irving Medical Center, New York, NY 10032, USA

138 Jiangxi Academy of Agricultural Sciences, Nanchang, Jiangxi, People's Republic of China
139 The Geneva Foundation, Tacoma, WA, USA

140 Departamento de Biologia Celular, Universidade de Brasília, Brasília, Brazil

141 Instituto de Biotecnología y Biología Molecular, CCT-La Plata, CONICET-UNLP, La Plata, Buenos Aires, Argentina

142 Centre for Experimental Medicine, School of Medicine, Dentistry and Biomedical Sciences, The Queen's University of Belfast, Belfast, Northern Ireland, UK

143 Instituto de Biotecnología y Biología Molecular, Centro Cientifico Technológico-La Plata, Consejo Nacional de Investigaciones Científico Tecnológico-Universidad Nacional de La Plata, La Plata, Argentina

144 Institute of Diagnostic Virology, Friedrich-Loeffler-Institut, Greifswald-Insel Riems, Germany

145 Consiglio Nazionale delle Ricerche, Istituto per la Protezione Sostenibile delle Piante, Bari, Italy

146 Department of Infectious Disease and Global Health, Tufts University Cummings School of Veterinary Medicine, 200 Westboro Road, North Grafton, MA 01536, USA

147 Department of Biochemistry, Molecular Biology, Entomology and Plant Pathology, Mississippi State University, Mississippi State, MS, USA

148 Institute of Human Virology, University of Maryland School of Medicine, Baltimore, MA, USA

149 International Centre of Insect Physiology and Ecology, Nairobi, Kenya

150 Institute for Plant Protection, National Agriculture and Food Research Organization, Tsukuba, Japan

151 Molecular Genetics Lab, Pacific Biological Station, Fisheries and Oceans Canada, Nanaimo, BC, Canada

152 Faculty of Medicine, University Medical Center-University Freiburg, Freiburg, Germany

153 Sun Yat-sen University, Shenzhen, People's Republic of China

154 MRC-University of Glasgow Centre for Virus Research, Glasgow, Scotland, UK

155 CAS Key Laboratory of Special Pathogens, Wuhan Institute of Virology, Center for Biosafety Mega-Science, Chinese Academy of Sciences, Wuhan, Hubei, People's Republic of China

156 Kochi Agricultural Research Center, Nankoku, Kochi, Japan

157 Asian Center for Bioresources and Environmental Sciences, University of Tokyo, Tokyo, Japan

158 School of Cellular and Molecular Medicine, University of Bristol, Bristol, UK

159 Nuffield Department of Medicine, University of Oxford, Oxford, UK

160 Bioinformatics Unit, Scientific Institute IRCCS "E. Medea", Bosisio Parini, Italy

161 Faculty of Bioscience Engineering, Department of Plants and Crops, Ghent University, Ghent, Belgium

162 CBR Division, DSTL, Porton Down, Salisbury, Wiltshire, UK 
163 Department of Microbiology, College of Medicine, Korea University, Seoul, Republic of Korea

164 School of Biomedical Sciences, Faculty of Health, Queensland University of Technology, Brisbane, QLD, Australia

165 Viral Special Pathogens Branch, Division of High-Consequence Pathogens and Pathology, Centers for Disease Control and Prevention, Atlanta, USA

166 Department of Microbiology, Immunology, and Pathology, College of Veterinary Medicine and Biomedical Sciences, Colorado State University, Fort Collins, CO, USA

167 Centre for Environment, Fisheries and Aquaculture Science, Weymouth, Dorset, UK

168 Departments of Earth, Ocean and Atmospheric Sciences, Microbiology and Immunology, and Botany, and the Institute for Oceans and Fisheries, University of British Columbia, Vancouver, Canada

169 Division of Global Epidemiology, Research Center for Zoonosis Control, Hokkaido University, Sapporo, Japan

170 Japan Plant Protection Association Kochi Experiment Station, Konan, Kochi, Japan

171 Department of Forest Sciences, University of British Columbia, Vancouver, Canada

172 Department of Pathology, The University of Texas Medical Branch, Galveston, TX, USA

173 Centers for Disease Control and Prevention, Atlanta, GA, USA

174 Kyushu Okinawa Agricultural Research Center, NARO, Koshi, Kumamoto, Japan

175 Institute for Frontier Life and Medical Sciences (inFront), , Kyoto University, Kyoto, Japan

176 Unité des Stratégies Antivirales, WHO Collaborative Centre for Viral Haemorrhagic Fevers and Arboviruses, OIE Reference Laboratory for RVFV \& CCHFV, Institut Pasteur, Paris, France

177 Viral Special Pathogens Branch, Division of High-Consequence Pathogens Pathology, National Center for Emerging and Zoonotic Infectious Diseases, Centers for Disease Control and Prevention, Atlanta, GA, USA

178 Changchun Veterinary Research Institute, Chinese Academy of Agricultural Sciences, Changchun, Jilin Province, People's Republic of China

179 National Institute of Optics, National Research Council of Italy (INO-CNR), Via Branze 45, 25123Brescia, Italy

180 Department of Entomology and Plant Pathology, Division of Agriculture, University of Arkansas System,, Fayetteville, AR 72701, USA

181 Department of Viroscience, Erasmus MC, University Medical Centre Rotterdam, Rotterdam, The Netherlands

182 The Biodesign Center for Fundamental and Applied Microbiomics, Center for Evolution and Medicine School of Life Sciences, Arizona State University, Tempe, AZ, USA

183 Wageningen University and Research, Biointeractions and Plant Health, Wageningen, The Netherlands
184 National Biodefense Analysis and Countermeasures Center, Fort Detrick, Frederick, MD, USA

185 School of Chemistry and Molecular Biosciences, University of Queensland, St. Lucia, QLD, Australia

186 Programme in Emerging Infectious Diseases, Duke-NUS Medical School, Singapore, Singapore

187 Key Laboratory of Crop Disease Monitoring and Safety Control in Hubei Province, College of Plant Science and Technology, Huazhong Agricultural University, Wuhan, Hubei, People's Republic of China

188 Fujian Province Key Laboratory of Plant Virology, Institute of Plant Virology, Fujian Agriculture and Forestry University, Fuzhou, Fujian, People's Republic of China

189 Department of Entomology and Plant Pathology, North Carolina State University, Raleigh, NC, USA

190 School of Medicine, University of Pittsburgh, Pittsburgh, PA, USA

191 Narita Branch, Yokohama Plant Protection Station, Narita, Chiba, Japan

192 Departamento de Fitopatologia, Instituto de Biotecnologia Aplicada à Agropecuária, Universidade Federal de Viçosa, Viçosa, Minas Gerais, Brazil

193 Key Laboratory of Horticultural Plant Biology, Ministry of Education, Wuhan 430070, Hubei , People's Republic of China

194 National Sand Pear Germplasm Repository in Wuchang, Research Institute of Fruit and Tea, Hubei Academy of Agricultural Science, Wuhan, Hubei, People's Republic of China

195 State Key Laboratory for Biology of Plant Diseases and Insect Pests, Institute of Plant Protection, Chinese Academy of Agricultural Sciences, Beijing, People's Republic of China

196 Institut Pasteur de Guinée, Conakry, Guinea

197 Departamento de Biotecnología-Biología Vegetal, Escuela Técnica Superior de Ingeniería Agronómica, Alimentaria y de Biosistemas, Universidad Politécnica de Madrid, Madrid, Spain

198 National Horizons Centre, Teesside University, Darlington DL1 1HG, UK

199 US Geological Survey, Western Fisheries Research Center, Seattle, WA, USA

200 Unidad de Fitopatología y Modelización Agrícola, Consejo Nacional de Investigaciones Científicas y Técnicas (UFYMA-CONICET), Córdoba, Argentina

201 Centaurus Biotechnologies, CTP, Manassas, VA, USA

202 Institute of Veterinary Pathology, Vetsuisse Faculty, University of Zurich, Zurich, Switzerland

203 Division of Veterinary Sciences, Graduate School of Life and Environmental Sciences, Osaka Prefecture University, Izumisano, Japan

204 German Centre for Infection Research, Berlin, Germany

205 Department of Laboratory Medicine, University Hospitals Leuven, Leuven, Belgium 
206 German Center for Infection Research (DZIF), Berlin, Germany

207 College of Medicine, Mohammed Bin Rashid University of Medicine and Health Sciences, Dubai, United Arab Emirates

208 Hawaii Department of Agriculture, Honolulu, HI, USA

209 Laboratory of Respiratory Viruses and Measles, Fiocruz, Rio de Janeiro, Brazil

210 Structural Biology Research Unit, Department of Clinical Laboratory Sciences, University of Cape Town, Observatory, Cape Town, South Africa

211 Zoology Department, National Museums of Kenya, Nairobi, Kenya

212 Jomo Kenyatta University of Agriculture \& Technology, Nairobi, Kenya

213 School of Veterinary Medicine, St. George's University, True Blue, Grenada

214 National Institute for Viral Disease Control and Prevention, Chinese Center for Disease Control and Prevention, Beijing, People's Republic of China
215 Department of Infectious Diseases, Yamagata University Faculty of Medicine, Yamagata, Japan

216 Department of Microbiology, Immunology and Infectious Diseases, Université Laval, Quebec City, Canada

217 Evandro Chagas Institute, Ministry of Health, Pará, Brazil

218 National Center for Immunization and Respiratory Diseases, Centers for Disease Control and Prevention, Atlanta, GA, USA

219 Institut Pasteur de Dakar, Dakar, Senegal

220 National Institute for Communicable Disease Control and Prevention, Chinese Center for Disease Control and Prevention, Changping, Beijing, People's Republic of China

221 Shanghai Public Health Clinical Center \& Institutes of Biomedical Sciences, Fudan University, Shanghai, People's Republic of China 